\title{
Development and Gender Inequality
}

\author{
Dissertation zur Erlangung des \\ wirtschaftswissenschaftlichen Doktorgrades der \\ Wirtschaftswissenschaftlichen Fakultät der Universität \\ Göttingen
}

Vorgelegt von: Francesca Lamanna

Aus: Washington DC, USA

October, 2011 
Erstgutachter: Prof.Stephan Klasen Ph.D.

Zweitgutachterin: Jun.Prof. Carola Grün

Tag der mündlichen Prüfung: Goettingen, 1. Juli, 2010 


\title{
Acknowledgements
}

\author{
Alla mia famiglia:
}

Dedicato alla mia bellissima familia di origine, alla mia mamma Titta e al mio papa Franco per la loro pazienza e per avermi resa una donna sicura di se ed indipendente, $e$ alla mia nuova strepitosa famiglia, al mio paziente marito, Daniele, che mi ha accompagnata in questa difficile avventura ed ai miei bimbi che hanno sacrificato giochini, giochetti e bagnetti per farmi lavorare.

\section{To my supervisor:}

A particular thank you goes to Professor Klasen for his continue support over the years. I still remember the first day I walked into your office and you asked me: 'Why do you want to do a PhD? Where do you see yourself in 5 years?" Seven years have gone by (a little longer than expected.....) and here I am doing what I always wanted to do.

It would have never been possible without his brilliant leadership! 



\section{Table of Contents}

List of Figures vii

List of Tables ix

Introduction 1

Chapter 1. The Impact of Gender Inequality in Education and Employment on Economic Growth in Developing Countries: Updates and Extensions 5

Abstract 5

1.1. Introduction 5

1.2. Gender Inequality and Economic Performance: Theory and Evidence 8

1.3. Education, Employment, and Economic Performance 13

1.4. Data and Estimation procedure 18

1.5. Results 23

1.6. Conclusions and Caveats 34

Appendix Chapter 1 37

Chapter 2. Gender bias in child mortality: Empirical evidence from India 43

Abstract 43

2.1. Introduction 43

2.2. Theoretical Model 45

2.3. Literature review 46

2.4. Methodology 49

2.5. The Data 50

2.6. The Empirical Model 59

2.7. Results 61

2.8. Conclusion 64

Chapter 3. Gender inequality in Health Care Utilization in India between 1986 and 1996: Is there any Progress? 67 Abstract 67

3.1. Introduction 67

3.2. Methods 69

3.3. Sources of Data and Measurement of Variables 70 
3.4. Patterns of Gender inequality in Health Care Utilization 71

3.5. Econometric Analysis 75

3.6. Conclusion 79

Appendix Chapter 3 80

Chapter 4. Intra-household Gender Disparities in Children's Medical Care before Death in India 83

Abstract 83

4.1. Introduction 83

4.2. Source of data and Measurement of Variables 86

4.3. Methodology 87

4.4. Results 88

4.5. Conclusion 101

References 104 


\section{List of Figures}

Figure 1.1 Real Regional per capita annual growth rate 1960-2000 15

Figure 1.2 Real Regional per capita annual growth rate per decade 15

Figure 2.1 Mortality estimates for rural and urban areas in India 51

Figure 2.2 Proportion of boys and girls under age five surviving in India 53

Figure 2.3 Proportion of boys and girls under age five surviving in Uttar Pradesh 53

Figure 3.1 Difference between actual and need based probability of getting medical help for girls and boys 76

Figure 3.2 The difference between actual and need based out-and in-patient health expenditure for girls and boys 77

Figure 4.1 Percentage of children died in hospital by sex, age, and location 91

Figure 4.2 Percentage of children died in hospital by sex, age, and income quintile 91

Figure 4.3 Probability of dying at different places as a function of age of the deceased child 95

Figure 4.4 Probability of dying at different places as a function of number of female siblings 96

Figure 4.5 Probability of dying at different places as a function of age of the deceased child (interaction between age and gender included) 98

Figure 4.6 Probability of dying at different places as a function of number of female siblings (interaction between number of female siblings and gender included) 



\section{List of Tables}

Table 1.1 Variables names, definition and data source _ـ 14

Table 1.2 Descriptive statistic for Cross-Section Analysis __ 23

Table 1.3 Gender Inequality in Education and Economic Growth __ 25

Table 1.4 Gender inequality and growth differences between Regions __ 27

Table 1.5 Gender inequality and Economic growth __ 31

Table 1.6 Gender Inequality in Education and Employment and Growth impact (EAP-

MENA) _ 32

Table 1.7 Gender Inequality in Education and Employment and Growth impact (EAP-SA)

Table 1.8 List of Countries for our analysis by region __ 37

Table 1.9 Annual per capita income and other non-economic Indicators by Region, 19601990 38

Table 1.10 Education Indicators by Region, 1960-1999___ 39

Table 1.11 Labor market Indicators by Region, 1960-2000 ___ 41

Table 2.1 Infant and child mortality by background and demographic characteristics _ 52

Table 2.2 Descriptive Statistics (mean and standard deviation, based on the sample of ever married women that have at least one child under age 5)__ 57

Table 2.3 Proportional Hazard model___ 60

Table 3.1 Percentage of children treated for sickness reported during the last 15 days before the survey __ 72

Table 3.2 Non-medical out-patient health expenses (in Rupees.) for boys and girls _ 73

Table 3.3 Non-medical in-patient health expenses (in Rs.) for boys and girls __ 73

Table 3.4 Patterns of access to health care and sex ratio in 1986 \& 1996 by state __ 74

Table 3.5 Getting medical care given illness (Marginal coefficients of a probit model) 78

Table 3.6 Descriptive Statistics of the Variables Used in the Analysis__ 80

Table 3.7 Distribution of children's actual and need-predicted utilization of health care services by sex and year _ 81

Table 4.1 Descriptive statistics __ 87 
Table 4.2 Place of death for different age group children by location, income, and gender 90

Table 4.3 Determinants of place of death: Multinomial logistic regression results 93

Table 4.4 Determinants of place of death with interaction variables: Multinomial logistic regression results 97

Table 4.5 Robustness test 101 


\section{Introduction}

"Poverty, under nutrition, mortality, low rate of alphabetism,... are problems that concern men and women and different classes. But the systematically inferior position of women inside and outside the household in many society points to the necessity of treating gender as a force on its own in development analysis." (Sen, 1990b)

The four essays collected in this volume aim is to shed some light on specific aspect in which women are discriminated against (employment, education and access to health care) in developing countries and on the impact that gender inequalities have on development.

"A great deal of evidence from around the world indicates that gender inequalities undermine the effectiveness of development policies - in fundamental ways. Yet gender issues are often absent from policy dialogue and policymaking. Does poverty cause larger gender disparities, or does gender inequality lead to poverty? And the evidence suggests that the relationship goes both ways. Reducing poverty will go some way towards reducing harmful gender disparities. But neither gender disparities nor poverty can be eliminated without addressing gender issues directly. Recognizing that poverty and gender inequality are intertwined can help us formulate more effective development strategies." (World Bank, 2001)

This volume is divided in four chapters, which examine different life's spheres in which women could be discriminated against in developing countries. ${ }^{1}$ Chapter one is a co-authored chapter with Professor Stephan Klasen, Chapter three and four are coauthored chapters with Professor Stephan Klasen and Abay Asfaw.

The first chapter investigates the impact of gender bias in education and employment on economic growth in developing countries. There is a sizable literature that analyses the impact of gender inequality in education on economic growth. A number of theoretical and empirical contributions have found a negative link between gender

\footnotetext{
${ }^{1}$ It is important to mention that previous versions of the articles included in this volume were published as co-authored papers in Journals or as working Papers. I would like to take the opportunity to thank the German Research Council (DFG) and the World Bank for financing my PhD research. A first version of the essay presented in chapter one of this volume was commissioned as background paper for a 2004 World Bank Publication; Gender and Development in the Middle East and North Africa. Women in the Public Sphere. The research presented in Chapter two, three and four was conducted as part of a larger research project financed by the DFG on Gender Bias in mortality in South Asia.
} 
inequality and economic growth (e.g. Oded Galor and David Weil, 1996; Nils-Petter Lagerlöf, 2003; Dollar and Gatti, 1999; Klasen, 2002). This literature suggests that, largely due to the impact of female education on fertility and the creation of human capital of the next generation, a lower gender gap will spur economic development. The effects on growth found are quite large for the regions where gender inequality is sizable, such as South Asia or the Middle East and North Africa (MENA). In fact, Klasen (2002) estimated that 0.9 percentage points of the 1.8 percentage point annual per capita growth difference between the countries in MENA and those in East Asia and the Pacific can be attributed to higher initial gender inequality in education there as well as a slower closing of the gap vis-à-vis East Asia and the Pacific. This chapter, using cross-country data for ninety-three countries in the period 1960-2000, expands the results of these previous studies on education gaps on growth and extends the analysis to employment gaps using panel data. The results show that the combined 'costs' of education and employment gaps in Middle East and North Africa and South Asia amount respectively to 0.9-1.7 and 0.11.6 percentage point differences in growth (depending on the preferred specification) where gender gaps in employment appear to have a larger and increasing effect on economic growth than gender gaps in education.

The second chapter investigates the microeconomic determinants of child mortality in India using a very large and representative dataset. Studies from demographers, physicians, epidemiologists, and other disciplines have shown that women have inherent biological and behavioural advantages of living longer than men at all ages in the same socio-economic environment (Hart, 1988; UNDP, 1995; Waldron, 1995; World Health Organization, 1998; Gjonca, et al., 1999; Kalben, 2002). This fact is known since 1750 when mortality rates were computed from the first Swedish national census (Kalben, 2002). It has also become clear that an improvement in social, cultural, and economic conditions enhances this biological advantage of women (WHO, 1998). Gjonca, et al. (1999:1-2) show that 'infant and childhood mortality is higher for boys than for girls, and these higher death rates for males continue throughout their entire life span'. However, this biological advantage of women could not be realised in South Asian countries. Various researchers, using different demographic techniques, have shown that between 60 and 100 million women are missing in Asia and North Africa (Sen, 1992; Coale, 1991; Klasen, 1994). While the magnitude varies from one study to another (depending on the data and the standard sex ratio reference level used), the excess mortality of women in South Asia is no longer contentious. It is also only in this part of 
the world that the life expectancy of women at birth is lower or equal to men, despite the biological advantage of women as a group to live longer than men. The nonresponsiveness of this discrimination to the improvement in the economic status of households (Hill and Upchurch, 1995; Kurz and Johnson-Welch, 1997) also makes the issue of 'excess female mortality' a serious concern in this region. It is generally hypothesised that this higher than expected female mortality in South Asian countries reflects social, cultural, familial, behavioural, and other discriminatory behaviour of households, communities, and sometimes governments against girls and women. Therefore, there is a crucial need to investigate factors and mechanisms that jeopardise the biological advantage of women to live longer than men and consequently produced millions of 'missing women' and unbalanced sex ratio in this part of the world.

In the literature authors investigate immediate determinants of discrimination and the effects on girls' nutrition status and mortality (gender biased allocation of resources, i.e. food, health care). In the past nutritional imbalances were considered as one of the basic reasons for excess female deaths especially among young children. In the literature it is argued that girls receive less food than boys, or food of relatively poor quality. However, recent findings reveal that there is no significant gender discrimination in nutrition among 0-5 year old children (Kurz and Lohnson-Welch, 1977; Das Gupta, 1987; Hazarika, 2000). Mothers' education is another factor that might affect the extent of sex differentials in mortality especially among children. Studies conducted in Bangladesh (Bhuiya, 1991) and India (Bourne and Walker, 1991) reveal that the predicted gender disparities in mortality is very low for female children of literate mothers compared to female children of illiterate mothers. The denial of equal access to health care is also considered as one of the most important factors that may explain the higher than expected women mortality in South Asian countries. Singh, et al. (1962), Aziz (1977), Chen, et al. (1981) and Kurz and Johnson-Belch (1997), report gender discrimination in getting medical care and immunization in Punjab, Bangladesh, Pakistan, and other developing countries. However, most of the studies which have tried to investigate the impact of health on gender bias in mortality focus on young children and on specific types of health care services such as immunization, visiting health care providers, and the like (Chaudhury, 1988; Chen, et al., 1981; Rajeshwari, 1996; Sood and Nagla, 1994; Dasgupta, 1987), while the concept of health care goes far beyond a mere visit of a health care provider. Moreover, most of the studies relied on one time period data and on descriptive statistics, which limit the depth of their analysis. This essay constitutes a first attempt in 
this direction. The study shows that not only children have very high mortality rates in India especially if coming from poor household, have illiterate mothers and live in northern states, but the hazard ratio of dying is throughout higher for girls than boys. The estimations show that girls born in northern states, having illiterate mothers have $60 \%$ more chances to die in their first five years in India than boys.

The aim of the last two chapters of my dissertation is to fill the gap in the literature and provide a more comprehensive and nationally representative analysis investigating intra-household discrimination in access to health care in India.

More specifically the essay in Chapter three shows that the increased return on investment on women in India in the past decades is reflected in the decline in health care utilization disparities between girls and boys. India experienced a large and significant improvement in health care utilization between girls and boys in the period 1986-1996. The results emphasize that significant improvement were observed in the probability of getting medical help during illness in this period and also that the amount of health care expenditures between boys and girls during the period under observation increased. These promising results have important policy implications and needs to be addressed in a timely manner. Evidence of gender inequality in heath care utilization is still wide spread in India and varies across states; only a sharp and homogenous increase in the return on investment for girls across the country will produce the expected results in the next decades.

The essay in Chapter four argues that intra-household gender-discrimination in receipt of medical attention can be one of the most important factors explaining the unbalanced sex ratio in the country. The $52^{\text {nd }}$ Indian National Sample Survey, which collected detailed verbal autopsies, is used in this analysis to show that girls are 1.7 times less likely to die in hospital than their brothers. The estimated coefficient of different interaction variables also reveal that the probability of infant and young girls with alive female siblings to die in the hospital is extremely low. The estimations confirm that girls are highly discriminated against in access to hospital treatment.

These four essays show that gender inequalities exact high human costs and high costs to development-and because the factors that cause gender inequalities to persist are difficult for individuals alone to change-there is a strong case for public action to promote gender equality. 


\title{
Chapter 1.The Impact of Gender Inequality in Education and Employment on Economic Growth in Developing Countries: Updates and Extensions ${ }^{2}$
}

\begin{abstract}
Using cross-country and panel regressions, we investigate to what extent gender gaps in education and employment reduce economic growth. Using most recent data and investigating a long time period (1960-2000), we update the results of previous studies on education gaps on growth and extend the analysis to employment gaps using panel data. The combined 'costs' of education and employment gaps in Middle East and North Africa and South Asia amount respectively to 0.9-1.7 and 0.1-1.6 percentage point differences in growth compared to East Asia. Gender gaps in employment appear to have an increasing effect on economic growth differences between regions, with the Middle East and North Africa and South Asia suffering from slower growth in female employment
\end{abstract}

\subsection{Introduction}

There are many reasons to be concerned about existing gender inequalities in important well-being related dimensions such as education, health, employment, or pay. From a welfare as well as an equity perspective, such gender inequalities are problematic as they lower well-being and are a form of injustice in most conceptions of equity of justice. $^{3}$ While such a view would argue for reducing gender inequalities in these dimensions of well-being on intrinsic grounds, recently a literature has developed that has investigated the instrumental effects of gender inequality on other important development outcomes with a particular focus on economic growth. Without denying the importance of reducing gender inequality on intrinsic grounds, this paper is a contribution to that latter literature.

\footnotetext{
${ }^{2}$ A previous version of this paper co-authored with Stephan Klasen was published in the Feminist Economics in 2009.

${ }^{3}$ See Klasen and Wink (2003) and Klasen $(2002,2007)$ for a discussion of these issues.
} 
A significant focus of that literature has been to examine the impact of gender inequality in education on economic growth. A number of theoretical contributions have suggested a negative link between gender inequality and economic growth (e.g. Oded Galor and David Weil 1996; Nils-Petter Lagerlöf 2003). This literature shows that, largely due to the impact of female education on fertility and the creation of human capital of the next generation, a lower gender gap will spur economic development. The next section will briefly summarize the main findings from that literature.

In parallel, an empirical literature has also examined these effects. While some earlier studies had suggested that gender inequality in education might actually increase economic growth (Robert Barro and Jong-Wha Lee 1994; Barro and Xavier Sala-I-Martin 1995), more recent work has shown that the opposite appears to be the case (Anne Hill and Elizabeth King 1995; David Dollar and Roberta Gatti 1999; Kristin Forbes 2000; Stephen Knowles, Paula Lorgelly and Dorian Owen 2002; Stephan Klasen 2002; Steven Yamarik and Sucharita Ghosh 2003; Dina Abu-Ghaida and Klasen 2004). These studies not only differed from previous analyses in their findings of the impact of gender inequality on economic growth, but also were able to explain why earlier studies had found the opposite effect and why more careful econometric techniques yielded the new finding that gender inequality in education reduces economic growth. ${ }^{4}$

These macro studies are also consistent with findings using micro data showing that girls have a higher marginal return to education, and even more so, if the impact of female education on fertility and education of the next generation is included (Hill and King 1995; World Bank 2001; King, Klasen, and Maria Porter 2008).

The effects found are quite large for the regions where gender inequality is sizable, such as South Asia or the Middle East and North Africa (MENA). In fact, Klasen (2002) estimated that 0.9 percentage points of the 1.8 percentage point annual per capita growth difference between the countries in MENA and those in East Asia and the Pacific can be

\footnotetext{
${ }^{4}$ Among the problems in the findings by Barro and co-authors identified by these studies were the absence of regional dummy variables, particularly for Latin America and East Asia. In the former, low initial gender gaps were accompanied by low growth, while in the latter relatively high initial gender gaps were accompanied by high subsequent growth. In the absence of regional dummy variables, a causal link is made between these associations. It is quite likely, however, that the growth experiences of these regions were also influenced by other region-specific factors that are largely unrelated to gender gaps. The fact that these regional dummies are (at least jointly) significant and that then the negative effect of female education reverses itself once regional (or country fixed) effects are considered supports this view. Further problems with these studies are the use of initial period education variables, the high collinearity between male and female education, and the endogeneity of these variables. For a discussion of these issues, see Dollar and Gatti (1999), Lorgelly and Owen (1999), Forbes (2000) and Klasen (2002),
} 
attributed to higher initial gender inequality in education there as well as a slower closing of the gap vis-à-vis East Asia and the Pacific. ${ }^{5}$

While these results are instructive, they are based on information on education and economic performance until 1990. Recently, new data on education achievement and economic performance have become available that now stretch to 2000 so that one purpose of the paper is to update the findings of the impact of gender inequality on economic growth. We will do this by using an updated and extended data set and the same econometric specification that was used in Klasen (2002). For some regions (including the MENA region), an update is particularly germane as the gender gaps in education have been closing more rapidly recently so that one would expect smaller but still remarkable costs for the existing gender gap in education.

A subject that has not been investigated in great detail is the impact of gender inequality in employment and pay on economic growth. The relatively small theoretical literature on the subject yields conflicting results (e.g. Robert Blecker and Stephanie Seguino 2002; Berta Esteve-Volart 2004; Tiago de Cavalcanti and Jose Tavares 2007). While there is some empirical literature suggesting that high earnings gaps, combined with high female labour force participation rates, helped spur export-oriented economic growth in some Asian countries (e.g. Stephanie Seguino 2000a, b; Matthias Busse and Christian Spielmann 2006), there has not been a thorough empirical investigation of the role of gender gaps in employment on economic growth and the few studies existing have to be treated with caution due to problems of endogeneity, unobserved heterogeneity and poor data quality and availability.

These issues can best be treated in a panel framework, where one considers the impact of initial female labour force participation on subsequent economic growth, and thus can at least partly address issues of endogeneity and unobserved heterogeneneity. With forty years of data, such an analysis is now possible and therefore a second aim of the paper is to investigate the impact of gender gaps in labour force participation on economic growth in such a panel framework.

\footnotetext{
${ }^{5}$ The reported figures in Klasen (2002) are actually slightly different, as Israel, Sudan, and Turkey were all included in the Middle East Region. For this report, they were allocated to other regions (Israel to OECD, Turkey to Eastern Europe, Central Asia and Sudan to Sub Saharan Africa) and therefore the analysis in Klasen (2002) was redone to reflect this. The figures reported above are based on that analysis.
} 


\subsection{Gender Inequality and Economic Performance: Theory and Evidence}

There have been a number of theoretical and empirical studies finding that gender inequality in education and employment reduce economic growth. ${ }^{6}$ The main arguments from the literature, which are discussed in detail in Klasen (1999, 2002, 2006) are briefly summarized below.

Regarding gender inequality in education, the theoretical literature suggests as a first argument that such gender inequality reduces the average amount of human capital in a society and thus harms economic performance. It does so as by artificially restricting the pool of talent from which to draw for education and thereby excluding highly qualified girls (and taking less qualified boys instead, e.g. Dollar and Gatti, 1999). Moreover, if there are declining marginal returns to education, restricting the education of girls to lower levels while taking the education of boys to higher levels means that the marginal return to educating girls is higher than that of boys and thus would boost overall economic performance (World Bank 2001; Knowles et al. 2002).

A second argument relates to externalities of female education. Promoting female education is known to reduce fertility levels, reduce child mortality levels, and promote the education of the next generation. Each factor in turn has a positive impact on economic growth. Thus gender gaps in education reduce the benefits to society of high female education (e.g. Galor and Weil 1996; Lagerlöf 1999; World Bank 2001; King, Klasen, and Porter 2008).

A third argument relates to international competitiveness. Many East Asian countries have been able to be competitive on world markets through the use of femaleintensive export-oriented manufacturing industries, a strategy that is now finding followers in South Asia and individual countries across the developing world (Klasen, 2006). In order for such competitive export industries to emerge and grow, women need to be educated and there must no barrier to their employment in such sectors. Gender inequality in education and employment would reduce the ability of countries to capitalize on these opportunities (Seguino 2000a, b; World Bank 2001; Busse and Spielmann 2006). ${ }^{7}$

\footnotetext{
${ }^{6}$ See, for example, Abu-Ghaida and Klasen (2004), Klasen (2006), Jennifer Stotsky (2006) and Mark Blackden et al (2007), for a review.

${ }^{7}$ There is also some empirical support for the claim by Seguino (2000a, b) that higher gender wage gaps were a further pre-condition of these export-oriented strategies. There is a related debate as to whether growth has reduced these gender wage gaps, which appears to be the case in many, but not all countries. For
} 
Regarding gender gaps in employment, there are a number of closely related arguments. First, there is a similar argument that it imposes a distortion on the economy as do gender gaps in education. It artificially reduces the pool of talent from which employers can draw upon, thereby reducing the average ability of the workforce (e.g. Esteve-Volart 2004). Such distortions would not only affect dependent employed, but similar arguments could be made for self-employed in agricultural and non-agricultural sectors where unequal access to critical inputs, technologies, and resources would reduce the average productivity of these ventures thereby reducing economic growth (see Mark Blackden et al 2007). As self-employment (including in agriculture) is included in our empirical assessment, these arguments might have some empirical relevance in accounting for the results.

A second also closely related argument suggests that gender inequality in employment can reduce economic growth via demographic effects. A model by Cavalcanti and Tavares (2007) suggest that gender inequality in employment would be associated with higher fertility levels which in turn reduce economic growth.

Thirdly, the results by Blecker and Seguino (2002) imply that gender gaps in employment access would also reduce economic growth as it would deprive countries to use (relatively cheap) female labour as a competitive advantage in an export-oriented growth strategy.

A fourth argument relates to the importance of female employment and earnings for their bargaining power within families. There is a sizable literature that demonstrates that female employment and earnings increase their bargaining power in the home (e.g. Amartya Sen 1990; Thomas Duncan 1997; Lawrence Haddad, John Hoddinott, and Harold Alderman 1997; World Bank 2001; Stephan Klasen and Claudia Wink 2003; King, Klasen, and Porter 2008). This not only benefits the women concerned, but their greater bargaining power can have a range of growth-enhancing effects. These could include higher savings as women and men differ in their savings behaviour (e.g. Stephanie Seguino and Maria Sagrario Floro 2003), more productive investments and use and repayment of credit (see Janet Stosky 2006), and higher investments in the health and education of their children, thus promoting human capital of the next generation and therefore economic growth (e.g. Thomas 1997; World Bank 2001).

a discussion, see Seguino (2000a, b), Klasen (2002), Busse and Spielmann (2006) and Stotsky, (2006), among others. 
A fifth argument relates to governance. There is a growing but still rather speculative and suggestive literature that has collated evidence that workers, on average, appear to be less prone to corruption and nepotism than men (World Bank 2001; Anand Swamy, Omar Azfar, Stephen Knack and Young Lee 2001). If these findings prove to be robust, greater female employment might be beneficial for economic performance in this sense as well. ${ }^{8}$

There is a related theoretical literature that examines the impact of gender discrimination in pay on economic performance. Here the theoretical literature is quite divided. On the one hand, studies by Galor and Weil (1996) and Calvalcanti and Tavares (2007) suggest that large gender pay gaps will reduce economic growth. Such gender pay gaps reduce female employment, increase fertility, and lower economic growth through these participation and demographic effects. In contrast, Blecker and Seguino (2002) highlight a different mechanism, leading to contrasting results. They suggest that high gender pay gaps and associated low female wages increase the competitiveness of exportoriented industrializing economies and thus boost the growth performance of these countries. The most important difference of this study, in contrast to the models considered above, is that it is focusing more on short-term demand-induced growth effects, while the other models are long-term growth models where growth is driven by supply constraints. Clearly both effects can be relevant, depending on the time horizon considered, an issue that is also discussed briefly below.

It is important to point out that it is theoretically not easy to separate the effects between gender gaps in education, employment, and pay. In fact, in most of the models considered above, gender gaps in one dimension tend to lead to gender gaps in other dimensions, with the causality running in both directions. ${ }^{9}$ For example, gender gaps in education might automatically lead to gender gaps in employment, particularly in the formal sector, where employers will prefer educated workers and thus will not consider applications of uneducated women. Conversely, if there are large barriers to female employment or gender gaps in pay, rational parents (and girls) might decide that education of girls is not as lucrative which might therefore lead to lower demands for female

\footnotetext{
${ }^{8}$ See a related discussion in King, Klasen, and Porter (2008) about the growth and welfare effects of women as policy-makers. The 'causes' of these differences in behavior may well be related to different socialization of girls and boys, a subject that leads beyond the scope of this paper.

${ }^{9}$ The one exception is again the short-term model of Blecker and Seguino where large gender gaps in pay, combined with small gender gaps in education and employment, deliver the growth-enhancing effects.
} 
education and resulting gender gaps in education. ${ }^{10}$ Thus gender gaps in education and employment are closely related to each other. ${ }^{11}$

They are not measuring the same thing, however, and thus are important to investigate separately. For one, it might be the case that the two issues are largely driven by institutional factors that govern education and employment access and do not therefore greatly depend on each other. For example, one might think of an education policy that strives to achieve universal education and thus reduces gender gaps, while there continue to be significant barriers to employment for females in the labour market. This might be particularly relevant to the situation in the Middle East and North Africa but most recently also for South Asia. Moreover, the externalities of female education and female employment are not all the same. For example, female education is likely to lead to lower fertility and child mortality of the off-spring, while the effect of female employment on these items is likely to be much smaller and more indirect (working mainly through greater female bargaining power; and there may be also be opposite effects including that the absence of women in the home might in some cases negatively impact on the quality of child care). Conversely, the governance externality applies solely to female employment, not to female education.

On the empirical evidence, there is a considerable literature now documenting that gender gaps in education reduce economic growth. King and Hill (1993) as well as Knowles et al. (2002) use a Solow-growth framework and find that gender gaps in education significantly reduce the level of GDP. Dollar and Gatti (1999), Forbes (2000), Yamarik and Ghosh (2003), Appiah and McMahon (2002) and Klasen (2002) investigate the impact of gender gaps on economic growth and all find that gender gaps in education have a negative impact on subsequent economic growth. They also find that the earlier results by Barro and Lee (1994) that female education might negatively impact economic growth do not stand up to closer econometric scrutiny.

There are much fewer empirical studies on the impact of gender gaps in employment and pay on economic growth, largely related to data and econometric issues discussed above. Klasen (1999) found that increases in female employment were associated with higher growth in a cross-country context. It included growth in female employment as a variable explaining economic growth and found a positive effect. This

\footnotetext{
${ }^{10}$ On these issues, see discussions in King and Hill (1993), Alderman et al. (1995, 1996), and World Bank (2001)

${ }^{11}$ Also, it is not obvious which factor is the prime cause of gender gaps that one should then include in a reduced form estimation.
} 
might have accounted for another 0.3 percentage points in the growth difference between the MENA region and East Asia and the Pacific (EAP). But these findings have to be treated with caution as they may suffer from reverse causality. In particular, it might be the case that high growth draws women into the labor force (rather than increasing female participation promoting economic growth). There are no easy ways to correct for this econometrically as there are unlikely to be valid instruments that can be used. Also, there are questions about the international comparability of data on labor force participation rates. To the extent that the problems of comparability affect levels of labor force participation, but not trends over time, these problems might be avoided in a fixed effects panel setting as the one we are undertaking here.

At the sub-national level, Berta Esteve-Volart has found significant negative effects of gender gaps in employment and managerial positions on economic growth of India's states using panel data and controlling for endogeneity using instrumental variables (Esteve-Volart, 2004).

There are some papers by Seguino (2000a, b) that support the contention that the combination of low gender gaps in education and employment with large gender gaps in pay (and resulting low female wages) were a contributing factor to the growth experience of export-oriented middle income countries. Supporting this empirical claim is a paper by Busse and Spielman (2006) which finds for a sample of 23 developing countries that a combination of low gender gaps in education and employment and large gender gaps in pay helped promote exports. Unfortunately, there are no comprehensive, standardized and comparable data on gender pay gaps across many countries so that these analyses have been based on relatively small and rather specific samples of countries.

Also empirically, there are some questions about separation of the effects of gender gaps in education and employment. In regressions that only consider the effect of gender gaps in education, they might implicitly also measure the impact of gender gaps in employment, particularly if the two are highly correlated. Such high correlation might also make it difficult to separately identify the effects when both are included in a regression (due to the multicollinearity problem). ${ }^{12}$ Also, it will be difficult to assess

\footnotetext{
${ }^{12}$ It turns out that in our total sample, gender gaps in education and employment are not very closely correlated so that it should be possibly to separately identify the effects. This overall low correlation is largely driven by a negative correlation between gender gaps in education and employment in Sub Saharan Africa and, to a lesser extent, South Asia, while in the other regions, the correlation is positive and usually large and significant. This negative correlation in Sub Saharan Africa is related to high female employment in agriculture despite low levels of female education; in this case, low education is not a barrier to high
} 
which of the two is the causal driver of the other, given the close and plausible theoretical and empirical linkage.

In sum, there is considerable theoretical support for the notion that gender gaps in education and employment are likely to reduce economic performance (while the literature on the effect of gender pas in pay is more divided). The empirical results also point to negative effects of gender gaps in education, but there is little reliable cross-country evidence on gender gaps in employment. In the following section we will discuss gender gaps in education and employment by developing region before estimating the impact of these gaps on economic performance there.

\subsection{Education, Employment, and Economic Performance}

In this section we will present data on growth, education, and employment of the different world regions with particular focus on the Middle East and North Africa Region (MENA), ${ }^{13}$ Sub Saharan Africa, and South Asia, the areas with particularly high gender gaps in education and/or employment. The data sources and definitions are shown in Table 1.1.

As shown in Figure 1.1, the fastest-growing region in the past forty years according to our data set has been the region of East Asia and the Pacific. The real per capita annual growth rate between 1960 and 2000 in this region was 4.05\%. On the contrary, the region that registered least growth is the Sub-Saharan Africa region (0.57\%). Latin American and Caribbean countries (LAC) did not experience high growth rates either: they grew 1.53\% annually. Middle East and OECD countries' growth rates are in-between at 2.24\% and $2.66 \%$ annual growth per capita, respectively. To better analyze the pattern of the per capita growth rate we will decompose it in decades for the past forty years (1960s-1970s1980s and 1990s) and consider the different world's regions growth rates in the different decades.

female employment as is the case elsewhere (in the formal sector in Africa, see Klasen 2006; Blackden et al. 2007)

${ }^{13}$ See Annexes for the list of countries per region for which we have data availability. 
Table 1.1 Variables names, definition and data source

\begin{tabular}{|c|c|c|}
\hline Variable & Definition & Data source \\
\hline G & $\begin{array}{l}\text { Per capita annual compound growth } \\
\text { rate in Purchasing power parity (PPP) }\end{array}$ & Penn World Table (6.1) \\
\hline INV & Average investment rates & Penn World Table (6.1) \\
\hline POPGRO & Population growth rate & Penn World Table (6.1) \\
\hline OPEN & $\begin{array}{l}\text { Average of exports plus imports as a } \\
\text { share of GDP }\end{array}$ & $\begin{array}{l}\text { World Development } \\
\text { Indicators (WDI, 2002) }\end{array}$ \\
\hline LFG & Labor Force growth rate & WDI, 2002 \\
\hline FERT & Level of fertility & WDI, 2003 \\
\hline M5 & Under five mortality rate & WDI, 2004 \\
\hline Life & Life expectancy measured in years & WDI, 2005 \\
\hline ED & $\begin{array}{l}\text { Number of year of schooling for the } \\
\text { male population( }\left(15^{+} \text {and } 25^{+}\right)\end{array}$ & Barro and Lee (2000) \\
\hline AED & $\begin{array}{l}\text { Number of year of schooling for the } \\
\text { population }\end{array}$ & Barro and Lee (2000) \\
\hline GED & $\begin{array}{l}\text { Absolute growth in male years of } \\
\text { schooling }\end{array}$ & Barro and Lee (2000) \\
\hline GAED & $\begin{array}{l}\text { Absolute growth in total years of } \\
\text { schooling }\end{array}$ & Barro and Lee (2000) \\
\hline RED & Female-Male ratio of schooling & Barro and Lee (2000) \\
\hline RGED & $\begin{array}{l}\text { Female-male ratio of the growth in the } \\
\text { years of schooling }\end{array}$ & Barro and Lee (2000) \\
\hline MACT & Male economic activity rate (15-64) & ILO Laborsta (2003) \\
\hline FACT & Female economic activity rate (15-64) & ILO Laborsta (2003) \\
\hline RACT & $\begin{array}{l}\text { Female-Male Ratio of Activity Rates } \\
(15-64)\end{array}$ & ILO Laborsta (2003) \\
\hline TACT & Total economic activity rate (15-64) & ILO Laborsta (2003) \\
\hline FLFT & $\begin{array}{l}\text { Female share of the total labor force } \\
(15-64)\end{array}$ & ILO Laborsta (2003) \\
\hline
\end{tabular}

Notes:

Note that the sample of countries included is restricted due to data availability, see Annex for detailed listing. Figures refer to unweighted averages and not all countries in each region are included due to data availability. World region: SA (South Asia), SSA (Sub-Saharan Africa), ECA (Eastern Europe), EAP (East Asia and Pacific), LAC (Latin America and Caribbean, MENA (Middle East and North Africa), OECD (Industrialized countries members of OECD). 
Figure 1.1 Real Regional per capita annual growth rate 1960-2000

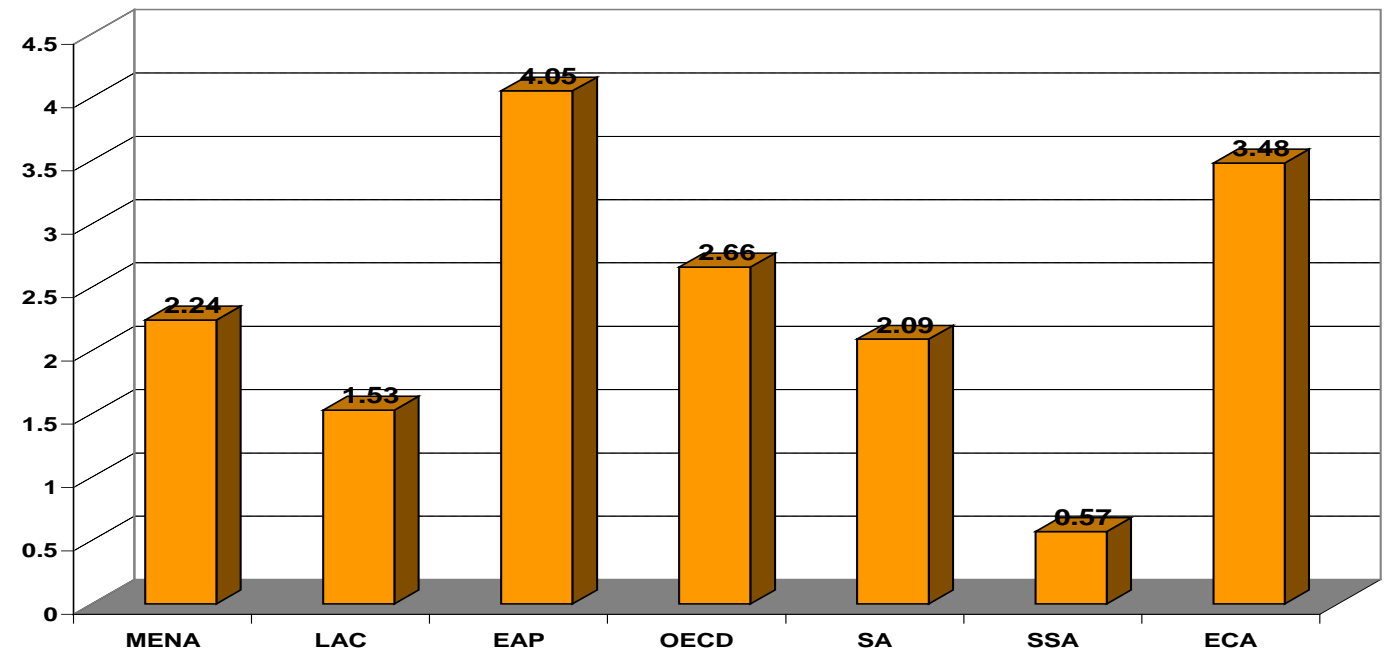

Source: Penn World Table 6.1.

Considering the growth rate per decade in Figure 1.2 allows us to take into account the growth rates of Eastern Europe (ECA), because after 1990 the data available for this region increases significantly. During the nineties those countries were in transition and their rate of per capita growth was very low (0.26\%). But also in Sub-Saharan Africa, the annual per capita growth rate decreased in the last 4 decades and actually shows negative growth in the 1990s (-0.21).

Figure 1.2 Real Regional per capita annual growth rate per decade

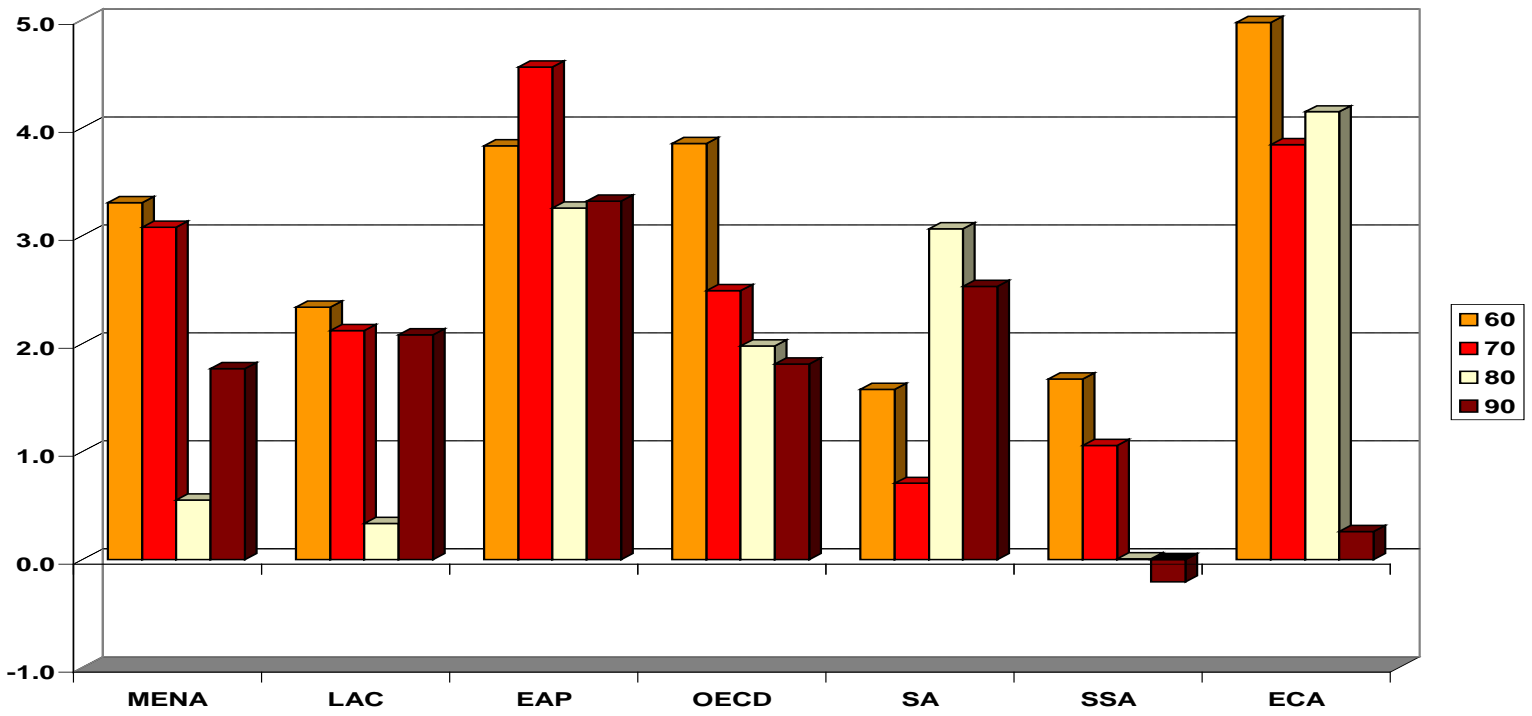

Source: Penn World Table 6.1. 
In other world regions the per capita growth rate was generally higher in the 1960s and 1970s and then it decreased in the 1980s and 1990s with the exception of the South Asia region (SA) where the annual growth rate grew quickly in 1980s and was maintained almost at the same level in the 1990s. This result was largely driven by India and Sri Lanka. But their neighbors (EAP countries) still remain the countries that experience largely higher annual per capita growth rate in each decade. The region of Middle East and North Africa (MENA) together with Latin America seems to be successfully recovering from very low growth in the 1980s. One should point out that the data for the Middle East and North Africa included in the analysis do not consider many of the oil-exporting Arab states including Saudi Arabia, Kuwait, UAE, Oman, and Libya for which no income data over time. ${ }^{14}$ Nevertheless, the growth experience there is to a considerable extent influenced by the direct and indirect impact of oil prices on oil-producing (and neighboring) countries. ${ }^{15}$

Non-economic indicators of well-being show a similar pattern, although some differences emerge (Appendix Table 1.9). The three indicators shown, under five mortality, fertility, and life expectancy all show larger improvements than the income measures. But the pace of improvements is similar to the growth indicator, with East Asia and Pacific showing the fastest improvements on most indicators, while Sub Saharan Africa showing the slowest. Here the MENA region compares very favorably with rapid improvements in life expectancy and under five mortality, and large reductions in fertility, particularly in the past 20 years while in South Asia the improvement was generally smaller.

Turning to the indicators of concern here, gender inequality in education and employment, in the appendix Tables 1.10 and 1.11 show the development in the regions between 1960 and 2000 by decade. The tables show that in all the regions, the education level of the adult population has increased considerably since 1960. Male and female adults have between 1.8 and 4.4 more years of education in 2000 than in 1960, with Sub Saharan Africa showing the slowest progress and East Asia and the MENA region the fastest. Regarding gender inequality, the data show considerable gender inequality in education in 1960 in most regions. The worst affected were South Asia, Sub Saharan Africa, and the MENA region, where female adults had about half or less the education

\footnotetext{
${ }^{14}$ Also note that following the World Bank country classification system, Turkey is considered to belong to the Eastern Europe and Central Asia and Israel to OECD.

${ }^{15}$ Iran is the only major oil producer included in the sample, but Egypt, Algeria, and Yemen also depend, directly or indirectly (via migration and remittances) on oil-production.
} 
level than their male peers. In all regions, this gap has been reduced, but the gap remains sizable in some. In South Asia, female adults still only have about $60 \%$ of the educational achievement of males, and the gap has closed quite slowly in Sub Saharan Africa. The gaps have been closing faster in East Asia and Pacific and also in the MENA region where female adults (15 and older) now have about $73 \%$ of the education of males.

Appendix Table 1.11 examines data on labor force participation rates by gender, the female share of the labor force, and the rates of formal sector employment. The data show that inequality in labor force participation is also considerable, although the gaps have been narrowing. From these data a consistent pattern emerges. In particular, East Asia and the Pacific as well as Latin America show rapidly declining gender gaps in labor force participation and formal sector employment; Sub Saharan Africa show declines in female labor force participation and employment, but from a high level; ${ }^{16}$ and the MENA region has the lowest female labor force participation rate and formal sector participation of women throughout the period. As in other regions, in MENA the gaps in employment have also narrowed in recent decades, but by less than most other regions. ${ }^{17}$ In South Asia the gender gap in employment in the past four decades was only marginally reduced.

From our theoretical discussion, we would expect that excluding women from the pool of talent is particularly damaging formal sector employment which may depend predominantly on having the best talent. Thus using the gender gap in formal sector employment might be most appropriate. On the other hand, these data are available from the ILO for a much smaller pool of countries and it appears that measurement error and international comparability is particularly problematic using these data. Therefore for the empirical analysis that follows, we will use the gender gaps in total employment only.

Even if formal sector employment data are not readily available and comparable, one might still want to use overall employment rather than labor force participation data as the presumed theoretical effects are related to employment rather than participation. The difference between the two is, of course, unemployment rates. While we do not have reliable employment data at the national level, the KILM data of the ILO (ILO, 2007) suggest that, first, unemployment rates are below $10 \%$ in all regions except the MENA

\footnotetext{
${ }^{16}$ Sub Saharan Africa's high female labor participation rate is largely confined to the agricultural sector which still employs the majority of workers in most Sub Saharan African countries. The international comparability of labor force participation data in own-account agriculture is particularly problematic. In formal sector employment, female employment rates are much lower and the gender gap is significant; but these data are, as discussed, missing for many countries and show consistency and comparability problems.

${ }^{17}$ The combination of rapidly shrinking gender gaps in education yet large and persistent gender gaps in employment in the MENA region constitutes a major puzzle. See World Bank (2004) for a careful discussion.
} 
region (where they are believed to hover around 12-14\%), and that, second, the differences in male and female unemployment rates are quite low (usually less than 1 percentage point) so that labor force participation data appear to be reasonable proxies for employment levels by sex. ${ }^{18}$

In general, however, the quality and comparability also of the ILO labor force data is open to question. These constitute estimates based sometimes on very patchy primary data. The comparability problems are likely to be larger in level differences across countries than in trends over time. Despite these problems, we are forced to rely on the available ILO labor force data as the only available cross-country panel data for our analysis. Inherent measurement error in all the labor force estimates leads to the wellknown downward bias of coefficients in regression analyses. Thus any effect that we find is likely to understate the true extent of the effect. Unfortunately, it is very difficult to econometrically control for measurement error. We know little about its structure, nor are there good instruments to address it. We hope that our panel analyses will at least partly reduce this problem to the extent that measurement error and comparability problems are lower across time than they are across space and can therefore be partly controlled for by using country-specific effects.

\subsection{Data and Estimation procedure}

Since the early 1990s a good deal of empirical growth research using cross-country data was inspired by new growth theories and the availability of better data. In our estimation strategy, we make use of cross-country and panel growth regressions as have been pioneered by Barro (1991) and used in a large literature since. Our particular estimation strategy for the cross-section analysis follows Klasen (2002); in the panel analysis we will extend the analysis. As our focus is on long-run economic growth, the most basic specification will use purely cross-country data where the period 1960-2000 will be treated as a single observation for each country. In order to partly control for possible endogeneity issues and unobserved heterogeneity, we will also consider panel regressions that treat each decade as one observation. Those panel regressions will also

\footnotetext{
${ }^{18}$ Unemployment rates for females in Latin America and in the Middle East and North Africa are several points higher than for males. Thus in these regions, the gender gap in employment is actually slightly larger than in labor force participation. But as this gender gap in unemployment rates is rather stable over time, it would be absorbed by the country-specific effects in our panel estimation. We also tried to use sectoral employment data that is available for some countries since the 1980s to adjust our labor force participation data to focus on non-agricultural employment. But there were so many data gaps and measurement error and comparability was so severe that these data turned out to be unusable.
} 
allow us to properly study the impact of gender inequalities in employment on economic growth.

We include a number of regressors that were found to effect economic growth in the literature, including population growth, labor force growth, openness (exports plus imports as a share of GDP), the investment rate, human capital, and regional dummy variables to capture region-specific effects, which are invariably not captured in such cross-country regressions and can include common geographic, institutional, policy, trade, or conflict experiences within regions. ${ }^{19}$

In order to avoid some of the methodological problems of earlier studies on gender inequality and economic growth, we do not include in our equations male and female education level separately. Instead, we generate four different education variables, one for the initial level of education in 1960, one for the gender gap in the level of education in the 1960, one for the growth in the level of education in the period 1960-2000 and one for the growth rate of the female-male education level ratio for the period 1960-2000. For the level of education, we could use the average education, the male or the female education level. Each would make different assumptions about the possibilities to affect the gender gap. Using the male educational level as a proxy for average education provides an upperbound estimate of the effect of gender inequality in education on growth as it implicitly assumes that one could improve the gender gap in education by sending more girls to school without having to take out boys (as the male education levels is held constant this way). ${ }^{20}$ In the alternative specification, when we use average education and the gender gap in average education in our equations we assume that any increase in female education means an equal sized reduction in male education and thus constitutes a lower-bound estimate of the effect of gender inequality on economic growth.

It may well be the case that gender inequality in education has a direct impact on economic growth; but gender inequality may also affect economic growth through effects it has on investment rates, population growth, and labor force growth (see previous discussion). The interest is in capturing both the direct and indirect effects of gender inequality on economic growth. Following Klasen (2002) we will estimate a set of

\footnotetext{
${ }^{19}$ We have also undertaken some further robustness checks using more variables used in standard growth regression analysis. The results are available on request. While the use of regional dummy variables is invariably a measure of our ignorance, in many cross-country regressions they turn out to be significant pointing to region-specific left-out variables that are hard to capture in standard cross-country regressions. ${ }^{20}$ Knowles et al. (2002) suggest that this is the most suitable specification for analyzbing gender gaps in education. This specification was also used in Klasen (2002).
} 
regressions to capture these two effects. Using the variables defined in Table 1.1 the equations estimated in the cross-country analysis are the following: ${ }^{21}$

$$
\begin{aligned}
& g=\alpha+\beta_{1} I N V+\beta_{2} P O P G R O+\beta_{3} L F G+\beta_{4} E D 60+\beta_{5} G E D+\beta_{6} R E D 60+ \\
& \beta_{7} R G E D+\beta_{8} X+C \\
& I N V=\alpha+\beta_{9} P O P G R O+\beta_{10} L F G+\beta_{11} E D 60+\beta_{12} G E D+\beta_{13} R E D 60+ \\
& \beta_{14} R G E D+\beta_{15} X+C \\
& P O P G R O=\alpha+\beta_{16} \text { OPEN + } \beta_{17} E D 60+\beta_{18} G E D+\beta_{19} R E D 60+ \\
& \beta_{20} R G E D+\beta_{21} X+C \\
& L F G=\alpha+\beta_{22} \text { OPEN + } \beta_{23} E D 60+\beta_{24} G E D+\beta_{25} R E D 60+\beta_{26} R G E D+ \\
& \beta_{27} X+C \\
& (1.4)
\end{aligned}
$$$$
g=\alpha+\beta_{28} \text { OPEN }+\beta_{29} E D+\beta_{30} G E D+\beta_{31} R E D 60+\beta_{32} R G E D+
$$$$
\beta_{33} X+\epsilon
$$

$g=\alpha+\beta_{34} I N V+\beta_{35} P O P G R O+\beta_{36}$
$\beta_{39} R E D 60+\beta_{40} R G E D+\beta_{41} X+\epsilon$

$$
g=\alpha+\beta_{42} A E D+\beta_{43} G A E D+\beta_{44} R E D 60+\beta_{45} R G E D+\beta_{46} X+\epsilon
$$

The first equation measures the direct impact of education and the gender bias in education on economic growth, as it controls for investment, population and labor force growth. In all regressions we do control for regional variation. ${ }^{22}$

The data used in this paper come from different data sources. Table 1.1 provides information on data sources and a description of the computation of the main variables of interest.

Education and gender bias in education could, however, influence population growth, investment and labor force growth in the future. Therefore there is a need to consider the indirect impact of education and gender inequalities on economic growth via these variables (equation 2-4). The total effect of gender inequality in education on growth is

\footnotetext{
${ }^{21}$ Note: equation 3 and 4 contain an additional explanatory variable with respect to Klasen (2002); openness.

${ }^{22}$ We use dummy variables for all regions, where the region left out is East Asia and Pacific.
} 
determined by the path analysis, in which we simply sum the direct effect and indirect effects of gender inequalities in education on growth (see Klasen, 2002).

The fifth equation is the so called "reduced form” regression. In this equation, investment, population and labor force growth variables are omitted. We expect the coefficients on education of this regression to measure the total effect of gender bias in education directly. The results should then be comparable to the sum of direct and indirect effects calculated using the path analysis.

Equations 6-7 consider the total number of years of schooling as a measure for the average human capital generating a lower bound estimate of these effects.

The model is then re-estimated using panel data where dependent and explanatory variables refer to the following decades; 1960-69, 1970-79, 1980-89, 1990-2000. Using panel data would allow us to control for endogeneity of the education and employment variables by using initial values of each decade, and address unobserved heterogeneity and/or measurement error using country-specific effects. ${ }^{23}$ This way we feel we are able to generate more robust estimates, particularly regarding the employment variables where endogeneity and measurement error are likely to be particularly problematic.

We will use several variables to investigate the impact of gender inequalities in employment on growth across the world. In a first specification we will add to our equation female share of the labor force. This specification holds the total labor force fixed and just adjusts the female share of labor force assuming that higher female employment could only come about through increased total employment. While this might be the best specification, it does not allow for possible influences of male labor force participation on economic growth, which might bias the results. ${ }^{24}$ We use a similar technique to that employed in the cross-country growth regression model for the education variables with employment. We generate upper and lower bound estimates. We use male activity rates together with female-male ratio as upper bound estimates (the assumption is that the female-male ratio could be increased without reducing male activity rates, basically more jobs in total) and the total activity rate together with the female-male ratio as lower bound (the assumption is that any additional female job would lead to fewer male jobs). As with

\footnotetext{
${ }^{23}$ In the panel we use the total years of schooling of the population over 25 . We do so because in the panel analysis we only have a ten-year window in which human capital (and gender differences) can have an effect and thus we want to focus our attention on the human capital of the labor force (rather than also including the 15-24 year old, only some of whom are in the labor force). In robustness checks, we also include the years of education of adults 15 or older to particularly capture the effects of young educated women who make up a significant share of female employment in many developing countries.

${ }^{24}$ On the other hand, empirically male labor force participation rates do not differ much across space and over time so that the growth effects observed are probably due to increased female employment.
} 
the education estimates, we believe that the true effects are closer to the former than the latter specification. It turns out that the best panel specification is to use fixed effects to control for unobserved heterogeneity ${ }^{25}$.

Compared to Klasen (2002), the country sample is smaller due firstly to changes in data availability from Penn World Tables, secondly to the elimination of apparently inconsistent data for education in two countries and thirdly to the lack of data for many transition countries before $1990 .^{26}$

In addition to the dependent and explanatory variables of our cross-country model we do report child mortality (under 5 years of life) in 1960 (M560) and in 2000 (M500), the fertility rate (FERT) and the gross domestic product per capita (GDP) in 1960 and in 2000 for each region. This includes a number of variables typically used in cross-country growth models. We already commented above on trends and regional differences in GDP growth, education, labor force, and non-income indicators of well-being by decade.

One point of note is the variable RGED which measures the female-male ratio of growth in education in the period 1960-2000. This variable clearly reflects the different progress made in reducing the gender gap in education in a region. While the ratio is far above 1 in East Asia and the Pacific, suggesting that females expanded their education faster than males, the reverse is the case especially in South Asia (0.77) but also in MENA region (0.87). The figures for SSA shows that female expanded their education about as fast as men. Table 1.2 also includes data on other regressors including the investment rate, population growth, labor force growth. Here well-known differences emerge. The region of East Asia and the Pacific is notable for its high investment rates, its high level of openness, and its moderate population growth. The reverse is the case for Sub Saharan Africa. The MENA region shows very high levels of population growth, but also sizable investment rates and levels of openness. While South Asia shows relatively high rates of population growth and low level of openness and investment. ${ }^{27}$

\footnotetext{
${ }^{25}$ We have run the regressions for random effect but specification tests (Hausman tests) suggested that the fixed effect specification is superior.

26 The previous version of the Penn Table (5.6) provided data for the following additional countries: Djibouti, Malta, Oman, Puerto Rico, Saudi, Somalia, Surinam, Iraq, Liberia, Myanmar, Reunion, Sudan, Swaziland, and Yugoslavia. For the last 9 countries Barro-Lee data on education were available. In addition to that the data for Eastern Europe countries were not limited to the 1990s. Penn 6.1 provides data for the entire sample set only for two Eastern Europe countries (Romania and Cyprus). Barro-Lee education data are suspicious for Austria and Bolivia, as they suggest stagnating or declining educational attainment despite substantial increases in enrolments. Hence we dropped these two countries from our analysis.

${ }^{27}$ It is quite difficult to adequately measure trade openness and the variable we use, export plus imports as a share of GDP, are not free from problems as these ratios are systematically lower in larger economies despite
} 
Table 1.2 Descriptive statistic for Cross-Section Analysis

\begin{tabular}{lcccccccc}
\hline & TOTAL & MENA & LAC & EAP & OECD & SA & SSA & ECA \\
\hline \hline G & 1.78 & 2.24 & 1.53 & 4.05 & 2.66 & 2.09 & 0.57 & 3.48 \\
INV & 15.48 & 13.18 & 13.96 & 20.53 & 23.92 & 11.21 & 10.45 & 17.31 \\
OPEN & 72.98 & 71.41 & 79.37 & 87.82 & 57.26 & 38.6 & 74.76 & 81.91 \\
M560 & 166.65 & 233.75 & 135.5 & 139.56 & 37.45 & 228 & 273.08 & 80.78 \\
M500 & 64.35 & 45.13 & 32 & 31.77 & 6.62 & 80.65 & 147.42 & 16.38 \\
POPGRO & 1.89 & 2.75 & 1.79 & 2.01 & 0.73 & 2.2 & 2.5 & 0.91 \\
FERT60 & 5.31 & 7.12 & 6.12 & 5.69 & 2.88 & 6.3 & 6.49 & 3.24 \\
FERT00 & 3.15 & 3.32 & 2.7 & 2.27 & 1.67 & 3.45 & 5.09 & 1.47 \\
GDP60 & 3377 & 1971 & 3299 & 1813 & 8473 & 930 & 1478 & 2233 \\
GDP00 & 8693 & 4462 & 6897 & 12033 & 23153 & 2186 & 2375 & 7910 \\
LFG & 2.02 & 2.95 & 2.35 & 2.69 & 0.86 & 2.33 & 2.46 & 1 \\
RED60 & 0.7 & 0.39 & 0.91 & 0.59 & 0.93 & 0.29 & 0.47 & 0.73 \\
RGED & 1.03 & 0.87 & 1.09 & 1.24 & 1.02 & 0.77 & 0.97 & 1.05 \\
EDF60 & 3.41 & 0.65 & 3.26 & 2.74 & 6.56 & 0.89 & 1.19 & 5.24 \\
GEDF & 0.07 & 0.11 & 0.07 & 0.1 & 0.07 & 0.06 & 0.05 & 0.09 \\
Source: WDI $2002, P e n n$ & World Table 6.1, Barro \& Lee $(2000)$. All refers to variables means.
\end{tabular}

\subsection{Results}

Table 1.3 shows the basic set of regressions using the methods of Klasen (2002) but with the new data that now stretch from 1960-2000. We start by considering the basic regression in column 1. Before turning to the education variables, we briefly comment on the other regressors. Compared to Klasen (2002), we observe a considerably better fit of the regression results, which might partially be due to the slightly smaller (and more homogeneous) sample. Also, all the direct and reduced form regressions pass the omitted variable test. ${ }^{28}$ The substantive results confirm many of the findings from the empirical growth literature. First, we see a strong conditional convergence effect, there is a sizable positive impact of investment on economic growth, a large negative impact of population growth, while we also observe a large positive impact of labour force growth. These findings confirm that the timing of the demographic transition can have a powerful impact on economic growth (David Bloom and Jeffrey Williamson 1998). The size of the effect is considerably larger now than it was in Klasen (2002). When population growth is falling due to lower fertility, but labour force growth is still high due to past high fertility, countries are receiving a 'demographic gift' of a low dependency burden (Bloom and

identical trade policies; other proxies have different problems. For a discussion, see Jeffrey Frankel and David Roemer (1999) and Dani Rodrik and FranciscoRodriguez (2000)

${ }^{28}$ The population growth regression does not pass the Reset test, suggesting that omitted variables and/or non-linearities in these regressions might be a problem. This does not affect out main (including the size of the direct, indirect and total effects) results and could only have a possible (and likely minor) influence on the relative importance of these two indirect effects. 
Williamson 1998) that allows higher savings, a higher ratio of workers to population, and higher investment demand. Given that fertility in the MENA and South Asia region is falling rapidly, one would expect the region to enter this phase of the 'demographic gift' in coming decades. To what extent they will be able to capitalize on this opportunity will depend largely on the ability to generate employment for the large numbers of young people entering the labour force in coming decades.

Of the regional dummy variables, only those for Sub Saharan Africa and Latin America have a (marginally) significant negative coefficient. The size of the coefficients are much smaller than in Klasen (2002), suggesting that the model is better able to explain the growth differences between regions than was possible in Klasen (2002).

Turning to the education variables, the initial male education and the growth of male education have the expected positive signs, although only the education growth variable is significant. The initial female-male ratio of education has the expected positive sign but it is not significant (differently from Klasen, 2002 where it was marginally significant). In contrast, the female-male ratio of growth in adult years of schooling is significant and larger in magnitude than found in Klasen (2002). As these coefficients express the direct effect of gender inequality on economic growth, it appears that the direct effect of initial gender inequality on economic growth is relatively small while the impact of the gender inequality in the growth of education has a sizable direct impact on growth. ${ }^{29}$

Columns 2-4 estimate the indirect impact of gender inequality in education on economic growth through the effects they have on investment, population growth, and labour force growth. The investment regression shows that the initial female male ratio of education has a significant positive effect on growth, while the impact of gender inequality in the growth of education is also positive but not significant. In the population growth and labour force growth regressions, the impact of gender inequality in education is in the right direction, though not significant. ${ }^{30}$

\footnotetext{
${ }^{29}$ But here, endogeneity might be a problem which will be partially addressed in the panel regressions.

${ }^{30}$ While there is a large and conclusive literature that shows that female education reduces fertility (e.g. see Schultz 1997; Klasen, 1999; and World Bank 2001 for a survey), the link between female education and population growth rates is less strong as population growth is also affected by the age structure of the population. In a population with a large share of women in child-bearing age, even a low total fertility rate for each of them can generate considerable population growth compared to a population where the share of women is lower. Therefore it is not surprising that the link here is weaker than if one used the total fertility rate as the dependent variable. When we include labor force growth in the population equation to proxy for the effect of the age structure, the effects of the initial female-male ratio of schooling and the ratio of the growth become significant, as expected.
} 
Table 1.3 Gender Inequality in Education and Economic Growth

\begin{tabular}{|c|c|c|c|c|c|c|c|}
\hline $\begin{array}{l}\text { Dependent } \\
\text { variable }\end{array}$ & Growth (1) & $\begin{array}{l}\text { INV } \\
(2) \\
\end{array}$ & POPGRO (3) & $\begin{array}{c}\text { LFG } \\
\text { (4) } \\
\end{array}$ & Growth (5) & $\begin{array}{c}\text { Growth } \\
(6)+ \\
\end{array}$ & $\begin{array}{c}\text { Growth } \\
(7)+ \\
\end{array}$ \\
\hline \multirow[t]{2}{*}{ LOGGDP60 } & $-2.27 * * *$ & -3.51 & -0.18 & -0.21 & $-2.47 * * *$ & $-2.29 * * *$ & $-2.52 * * *$ \\
\hline & 0.5 & 3.1 & 0.34 & 0.36 & 0.63 & 0.52 & 0.65 \\
\hline \multirow[t]{2}{*}{ POPGRO } & $-2.80 * * *$ & 0.91 & & & & $-2.79 * * *$ & \\
\hline & 0.53 & 2.25 & & & & 0.53 & \\
\hline \multirow[t]{2}{*}{ LFG } & $2.33^{* * *}$ & 0.04 & & & & $2.32 * * *$ & \\
\hline & 0.47 & 2.1 & & & & 0.47 & \\
\hline \multirow[t]{2}{*}{ OPEN } & -0.001 & $0.041^{* *}$ & -0.003 & -0.002 & $0.005^{*}$ & -0.0005 & $0.006^{*}$ \\
\hline & 0.003 & 0.02 & 0.002 & 0.002 & 0.004 & 0.003 & 0.004 \\
\hline \multirow[t]{2}{*}{ INV } & $0.06^{* * *}$ & & & & & $0.06^{* * *}$ & \\
\hline & 0.02 & & & & & 0.02 & \\
\hline \multirow[t]{2}{*}{ RED60 } & 0.68 & $5.84 * *$ & -0.4 & -0.17 & $1.75^{* *}$ & 0.76 & $1.72^{* *}$ \\
\hline & 0.85 & 3.08 & 0.32 & 0.33 & 0.89 & 0.89 & 0.91 \\
\hline \multirow[t]{2}{*}{ ED60 } & 0.01 & $0.92^{* *}$ & -0.02 & 0.01 & $0.16^{* *}$ & 0 & $0.13^{*}$ \\
\hline & 0.07 & 0.44 & 0.05 & 0.06 & 0.09 & 0.08 & 0.1 \\
\hline \multirow[t]{2}{*}{ GED } & $10.42^{* * *}$ & 35.42 & -1.01 & 0.85 & $17.33^{* * *}$ & $10.59 * * *$ & $18.31^{* * *}$ \\
\hline & 4.35 & 28.95 & 1.94 & 2.14 & 4.46 & 4.78 & 4.86 \\
\hline \multirow[t]{2}{*}{ RGED } & $0.70 * * *$ & 2.07 & 0.001 & 0.05 & $0.95^{* * *}$ & $0.47 * *$ & $0.62 * *$ \\
\hline & 0.29 & 2.19 & 0.25 & 0.25 & 0.37 & 0.25 & 0.34 \\
\hline \multirow[t]{2}{*}{ SA } & -0.07 & -3.58 & -0.17 & $-0.46^{* *}$ & $-0.90 *$ & -0.02 & $-0.85^{*}$ \\
\hline & 0.59 & 3.07 & 0.24 & 0.24 & 0.64 & 0.61 & 0.65 \\
\hline \multirow[t]{2}{*}{ SSA } & $-0.83^{*}$ & $-6.92 * * *$ & $0.40 * *$ & -0.06 & $-2.49 * * *$ & $-0.81 *$ & $-2.47 * * *$ \\
\hline & 0.57 & 2.76 & 0.22 & 0.22 & 0.7 & 0.58 & 0.71 \\
\hline \multirow[t]{2}{*}{ ECA } & -0.1 & 3.57 & $-0.91^{* *}$ & $-1.32 * * *$ & -0.46 & -0.1 & -0.46 \\
\hline & 0.63 & 2.8 & 0.41 & 0.54 & 0.87 & 0.63 & 0.88 \\
\hline \multirow[t]{2}{*}{ LAC } & $-0.87^{*}$ & $-4.87 * *$ & 0.08 & -0.17 & $-1.79 * * *$ & $-0.87 *$ & $-1.81 * * *$ \\
\hline & 0.56 & 2.73 & 0.28 & 0.27 & 0.74 & 0.56 & 0.74 \\
\hline \multirow[t]{2}{*}{ MENA } & -0.17 & -3.77 & $0.72 * *$ & 0.48 & $-1.26^{* *}$ & -0.12 & $-1.24^{* *}$ \\
\hline & 0.53 & 3.77 & 0.42 & 0.41 & 0.66 & 0.52 & 0.65 \\
\hline \multirow[t]{2}{*}{ OECD } & 0.47 & $4.81 *$ & $-1.07 * * *$ & $-1.64^{* * *}$ & -0.12 & 0.55 & 0.01 \\
\hline & 0.6 & 3.04 & 0.37 & 0.38 & 0.83 & 0.6 & 0.82 \\
\hline \multirow[t]{2}{*}{ CONSTANT } & $7.35^{* * *}$ & 13.65 & $3.26 * * *$ & $3.39 * * *$ & $7.16^{* * *}$ & $7.65^{* * *}$ & $7.73^{* * *}$ \\
\hline & 1.84 & 11.8 & 1.06 & 1.11 & 2.1 & 1.85 & 2.14 \\
\hline ADJ R2 & 0.76 & 0.66 & 0.64 & 0.62 & 0.63 & 0.76 & 0.64 \\
\hline OV Test & passed & passed & Failed & Passed & passed & passed & Passed \\
\hline OBS & 93 & 93 & 93 & 93 & 93 & 93 & 93 \\
\hline
\end{tabular}

Source: Authors computation

Heteroscedasticity-adjusted standard-errors reported under the coefficients. *** Refers to 99\%; ** to 95\%; and $*$ to $90 \%$ significance level using a one-tail test. +: regression with total education instead of male education only. OV test refers to the Ramsey Reset test for omitted variables. Regions (SA, SSA, ECA, LAC, MENA and OECD) are dummies, missing dummy is East Asia and Pacific.

Column 5 shows the reduced form regression, which omits the investment, population growth, and labour force growth variables and thus gives a direct estimate of 
the total effect of gender inequality in education on economic growth. The coefficients on both the initial ratio as well as the ratio of educational growth are considerably larger than in column 1 and now both are highly significant. This suggests that gender inequality in education, both initial as well as gaps in educational growth, have a significant negative impact on growth. A comparison between column 1 and 5 shows that the initial gender gap in education has mainly an indirect impact on economic growth (it appears from column 2 to be via investment) while the female-male ratio of educational growth has mainly a direct impact.

Regressions 6 and 7 use average education and thus estimate a lower bound effect of the impact of gender inequality on economic growth. The effects are generally predictably smaller and somewhat less significant.

In Table 1.4 we calculate to what extent gender bias in education can explain growth differences between the various regions of the world. We do this for the upper and lower bound estimates. Fortunately, the difference between these two estimates is fairly small.

We also note that the sum of direct and indirect effect (regression 1-4) gives very similar results as the direct estimate from the reduced form (regression 5). As expected, the regions with the largest gender gaps in education, South Asia, Sub Saharan Africa and MENA suffer the largest losses in terms of economic growth. But there are big differences here. In contrast to Klasen (2002) where both South Asia and the MENA region were suffering similar losses of about 0.9 percentage points in annual per capita growth per year, the losses are now slightly larger for South Asia, around 1 percentage point, and very much smaller for the MENA region, at about 0.7 percentage points per year. The difference for the diverging performance lies in the faster expansion of female schooling in the MENA region which has contributed to closing the gender gap in education, while progress in South Asia was much more modest.

When examining the pathways through which gender inequality in MENA, South Asia and Sub-Saharan Africa leads to lower growth, there is a sizable direct effect which amounts to about $60 \%$ of the total difference. This direct effect refers mainly to the lowering of the quality of human capital as a result of gender inequalities in education. But this is actually somewhat smaller than found in Klasen (2002) where for MENA about $75 \%$ of the total effect was accounted for by the direct effect. The indirect effect via investment has become somewhat smaller while via demographic more important. Clearly all pathways investigated contribute to the resulting growth difference, and the magnitudes 
have shifted toward a greater importance of the demographic pathway which suggests that higher female education lowers population growth which in turn helps improve economic growth.

Table 1.4 Gender inequality and growth differences between Regions

\begin{tabular}{|c|c|c|c|c|c|c|}
\hline & \multicolumn{5}{|c|}{ Difference } & \multirow{2}{*}{$\begin{array}{c}\text { Difference } \\
\text { MENA- } \\
\text { EAP } \\
\end{array}$} \\
\hline & $\begin{array}{l}\text { Difference } \\
\text { SSA-EAP } \\
\end{array}$ & $\begin{array}{c}\text { Difference } \\
\text { SA-EAP } \\
\end{array}$ & $\begin{array}{c}\text { MENA- } \\
\text { EAP } \\
\end{array}$ & $\begin{array}{l}\text { Difference } \\
\text { SSA-EAP } \\
\end{array}$ & $\begin{array}{c}\text { Difference } \\
\text { SA-EAP } \\
\end{array}$ & \\
\hline $\begin{array}{l}\text { Total annual } \\
\text { growth difference }\end{array}$ & 3.48 & 1.96 & 1.74 & 3.48 & 1.96 & 1.74 \\
\hline Accounted for by: & \multicolumn{3}{|c|}{ Upper bound estimate } & \multicolumn{3}{|c|}{ Lower bound estimate } \\
\hline $\begin{array}{l}\text { Direct effect of gender } \\
\text { inequality in } \\
\text { education (1) } \\
\text { Of which: }\end{array}$ & $0.26^{31}$ & 0.52 & 0.38 & 0.22 & 0.45 & 0.33 \\
\hline Initial ratio (RED60) & 0.08 & 0.2 & 0.14 & 0.09 & 0.23 & 0.15 \\
\hline $\begin{array}{l}\text { Ratio of educational } \\
\text { growth (RGED) }\end{array}$ & 0.18 & 0.31 & 0.24 & 0.13 & 0.22 & 0.17 \\
\hline $\begin{array}{l}\text { Indirect effects: } \\
\text { via investment } \\
\text { via population }\end{array}$ & 0.08 & 0.17 & 0.12 & 0.07 & 0.14 & 0.07 \\
\hline $\begin{array}{l}\text { growth (3) } \\
\text { via labor force }\end{array}$ & 0.14 & 0.33 & 0.22 & 0.1 & 0.26 & 0.17 \\
\hline growth (4) & -0.02 & -0.06 & -0.04 & -0.01 & -0.04 & -0.02 \\
\hline Total Indirect Effect & 0.22 & 0.34 & 0.3 & 0.16 & 0.36 & 0.22 \\
\hline Of which: & & & & & & \\
\hline Initial ratio (RED60) & 0.13 & 0.32 & 0.22 & 0.12 & 0.29 & 0.14 \\
\hline $\begin{array}{l}\text { Ratio of educational } \\
\text { growth (RGED) }\end{array}$ & 0.07 & 0.12 & 0.09 & 0.04 & 0.07 & 0.04 \\
\hline $\begin{array}{l}\text { Total Direct and } \\
\text { Indirect effect }\end{array}$ & 0.46 & 0.95 & 0.69 & 0.38 & 0.81 & 0.55 \\
\hline $\begin{array}{l}\text { Total effect using } \\
\text { Reduced form (5) }\end{array}$ & 0.47 & 0.97 & 0.7 & 0.38 & 0.81 & 0.41 \\
\hline Of which: RED60 & 0.22 & 0.52 & 0.36 & 0.21 & 0.52 & 0.24 \\
\hline Of which: RGED & 0.25 & 0.45 & 0.35 & 0.17 & 0.29 & 0.16 \\
\hline
\end{tabular}

Source: Authors computation

Table 1.5 shows the result of panel regressions using fixed effects, which was found to be the preferred specification based on the Hausman test. Also here, the empirical findings in those regressions are consistent with the empirical and theoretical literature: we find conditional convergence, a positive effect on growth of the working age population, and a negative effect of population growth, though both are significant in only

\footnotetext{
${ }^{31}$ Sums do not add up precisely due to rounding
} 
some specifications. ${ }^{32}$ Investment rates significantly promote growth and openness has a small positive, but rarely significant impact.

The specification in regression 8 only examines the impact of gender gaps in education on economic growth. In contrast to the panel results in Klasen (2002) and the cross-section results shown here, the positive effect of a high female-male years of schooling ratio among the adult population (the female-male ratio of education of adults 25 or older) is relatively small and not statistically significant. Further investigations show that this is not driven by a slightly different composition of sample, but by the addition of the 1990s. If the 1990s are dropped, a higher females-male ratio of years of schooling has a large and significant effect (not shown here). In fact, it is due to the two regions Latin America and Sub Saharan Africa in the 1990s. If we exclude these regions for that time period, regression 9 shows that then the positive effect of higher gender equality in education is again sizable and significant. ${ }^{33}$ It appears that the moderate to poor growth performance in these two regions despite falling gender gaps in education is important enough to reduce the overall effect of educational gender gaps to insignificance. It seems plausible to assume that the poor growth performance particularly of Sub Saharan Africa was not related to the reduced gender gaps in education, but many other factors that have been analyzed in the literature (e.g. Paul Collier and Jan Willem Gunning 1999; World Bank 2006). Conversely, regression 9 suggests that in all other regions, the impact of gender gaps in education on growth remains as strong in the 1990s as before (in fact, slightly stronger).

In regression 10, we replace the education variable with the education of adults 15 or older. This is to also capture the effects of high employment rates of educated women in the young age groups of 15-24 which might have a particularly large impact on growth. It turns out that in this specification the effect of gender gaps in education on growth are only significant if we limit the analysis to OECD, East Asian, and South Asian countries. But there the effect is very large and highly significant. This appears plausible as these are the regions where young educated women have been particularly active in the labor market.

\footnotetext{
32 This may be related to the fact that the impact of population growth and labor force growth materializes with some delay and may therefore not be well-captured in the 10 year periods considered.

${ }^{33}$ It is even larger if we consider the reduced form estimate, i.e. if we leave out the investment rate, labor force growth, and population growth. In both cases, they are larger than identical panel regressions in Klasen (2002).
} 
In regressions 11 to 16 , we consider the full sample again and include various employment variables. ${ }^{34}$ We consider two different explanatory variables for the labor force participation: the female share of the total labor force (FLFT) and the ratio of female to male economic activity rates (RACT=FACT/MACT). In regression 11 the female share of the labor force (FLFT) has a positive, large significant coefficient on economic growth, i.e. countries where the (initial) female share increased from decade to decade were able to achieve higher rates of subsequent economic growth. The effect of gender-gaps in education (ORED 25+) in this specification is considerable but not significant. If we exclude Sub Saharan Africa and Latin America in the 1990s, the effect becomes much larger and highly significant. ${ }^{35}$ In regression 12 , we use the other education variable (YRED 15+) which shows a large impact of education gaps on growth, and a smaller and no longer significant impact of female shares of the labor force, again reduced to OECD, East Asia, and South Asia.

In regression 13 we use the male economic active rate (MACT) and the ratio of the female to male economic active rates (RACT) as an alternative way to capture the gender gap in employment. This female-male ratio is highly significant and positive, while the male economic active rate has a non-significant negative sign. If we add the education gap in regression 14 the coefficient on the gender gap in employment is still positive and significant but smaller, while the coefficient on the male activity rate is now positive but still insignificant. The coefficient on educational gaps is not significant. In the reduced sample (excluding Sub Saharan Africa and Latin America for the 1990s), it becomes significant also in this specification while the impact of employment gaps becomes slightly smaller but remains significant (see regression 15). Lastly, we limit our sample to OECD countries, East Asia, and South Asia and use the alternative education variable and find that then education gaps have a very large impact on growth while employment gaps have a smaller (and only marginally significant) impact on growth.

Since the coefficient on the male activity rate is small and insignificant, altering the male activity rate when one increases the female activity rate would not have a significant impact on growth. Thus, in contrast to the education regressions in Table 1.3 it is not

\footnotetext{
${ }^{34}$ We also analysed the sample where we dropped Sub Saharan Africa and Latin America in the 1990s and report on the results where appropriate.

${ }^{35}$ The regression is not shown but available on request.
} 
necessary to calculate an upper and lower bound regression as the male activity rate seems to be immaterial for growth. ${ }^{36}$

On the whole, these results suggest that gender gaps in employment have a negative impact on economic growth. For the MENA and South Asia region, where female labor force participation is still very low, this could have a significant impact on economic growth. The results also give some interesting insights into the relative importance of education and employment gaps in different time periods. In the full sample of countries, educational gender gaps are not so important, while employment gaps have a particularly large impact on economic performance. This is largely due to the experience of the 1990s where gender gaps in employment appear to be more consequential than those in education. Once Sub-Saharan Africa and Latin America in the 1990s are excluded, however, education and employment gaps have a similar impact on economic growth. If we change to an education variable that particularly includes young people, the results suggest indeed that education gaps are more important than employment gaps, at least in the OECD, East Asia, and South Asia. This suggests that pervious studies that only examined gender gaps in education were partly implicitly capturing the effects of gender gaps in employment and it is indeed useful to consider the two jointly as we have done here. It also suggests, however, that it is not easy to clearly answer the question as to the relative important of the two which appears to be quite sensitive to the sample, time period, and education variable used. This will become more apparent below.

Once again, we simulate the impact of gender inequality in education and employment based on these panel regressions. In Table 1.6 we show to what extent the difference in economic growth between East Asia and the Pacific and the MENA can be accounted for by differences in gender inequality in education and employment. Estimates based on regression 9 already show that gender gaps in education can account for a sizable portion of growth differences, but this difference in declining, due to a shrinking difference in gender gaps in education between the two regions.

Once gender gaps in employment are included, the share of growth differences explained by these combined gaps increases significantly; in fact, in the 1960s, 1970s and 1990s, the gaps can account for all of the growth differences or even more than that in

\footnotetext{
${ }^{36}$ This is confirmed by regressions (not shown here) where we replaced the male activity rate with the total activity rate and now find that the impact of the gender gap is larger while the impact of the total activity rate is now negative. These regressions are available on request.
} 
some specifications suggesting that the MENA region would have grown faster than East Asia in the absence of the gaps. The growth costs, compared to East Asia, of gender gaps in employment, are increasing over time as the gender gaps in employment are shrinking much faster in East Asia than in MENA.

Table 1.5 Gender inequality and Economic growth

\begin{tabular}{|c|c|c|c|c|c|c|c|c|c|}
\hline & 8 & 9 & 10 & 11 & 12 & 13 & 14 & 15 & 16 \\
\hline \multirow[t]{2}{*}{ LOGGDP } & $-5.54 * * *$ & $-7.82 * * *$ & $-10.37 * * *$ & $-6.08 * * *$ & $-10.81^{* * *}$ & $-6.99 * * *$ & $-6.14 * * *$ & $-8.48 * * *$ & $-11.09 * * *$ \\
\hline & 1.42 & 1.33 & 1.31 & 1.43 & 1.32 & 1.28 & 1.48 & 1.41 & 1.28 \\
\hline \multirow[t]{2}{*}{ POPGRO } & $-0.57 *$ & -0.44 & -0.22 & -0.47 & -0.23 & $-0.47^{*}$ & $-0.59 *$ & -0.45 & -0.2 \\
\hline & 0.42 & 0.35 & 0.4 & 0.4 & 0.39 & 0.37 & 0.42 & 0.37 & 0.39 \\
\hline \multirow[t]{2}{*}{$L F G$} & 0.31 & $0.46 *$ & 0.32 & 0.38 & 0.34 & $0.48 *$ & $0.45^{*}$ & $0.54 * *$ & 0.29 \\
\hline & 0.27 & 0.31 & 0.4 & 0.31 & 0.4 & 0.3 & 0.31 & 0.31 & 0.37 \\
\hline \multirow[t]{2}{*}{ FLFT } & & & & $7.86 * *$ & 4.17 & & & & \\
\hline & & & & 3.49 & 3.36 & & & & \\
\hline \multirow[t]{2}{*}{ OPEN } & 0.002 & 0.005 & 0.006 & 0 & 0.006 & 0.001 & 0.001 & 0.003 & 0.007 \\
\hline & 0.004 & 0.005 & 0.008 & 0.005 & 0.007 & 0.005 & 0.004 & 0.005 & 0.007 \\
\hline \multirow[t]{2}{*}{$I N V$} & $0.09 * * *$ & $0.10^{* * *}$ & $0.13^{* * *}$ & $0.10^{* * *}$ & $0.14^{* * *}$ & $0.12^{* * *}$ & $0.10^{* * *}$ & $0.10 * * *$ & $0.14^{* * *}$ \\
\hline & 0.03 & 0.03 & 0.02 & 0.03 & 0.02 & 0.03 & 0.03 & 0.03 & 0.02 \\
\hline \multirow[t]{2}{*}{ OED25+ } & 0 & 0.08 & & 0 & & & 0 & 0.05 & \\
\hline & 0.16 & 0.17 & & 0.16 & & & 0.16 & 0.16 & \\
\hline \multirow[t]{2}{*}{ ORED25+ } & 0.43 & $2.30 * *$ & & 1.01 & & & 1.14 & $3.09 * *$ & \\
\hline & 1.45 & 1.28 & & 1.43 & & & 1.51 & 1.41 & \\
\hline \multirow[t]{2}{*}{ YED15+ } & & & $0.31 * *$ & & $0.31 * * *$ & & & & $0.29 * * *$ \\
\hline & & & 0.13 & & 0.12 & & & & 0.12 \\
\hline \multirow[t]{2}{*}{ YRED15+ } & & & $3.33^{* *}$ & & $3.66^{* *}$ & & & & $4.42 * * *$ \\
\hline & & & 1.65 & & 1.7 & & & & 1.76 \\
\hline \multirow[t]{2}{*}{ RACT } & & & & & & $5.41 * * *$ & $3.72 * *$ & $2.97 * *$ & $1.93 *$ \\
\hline & & & & & & 1.48 & 1.51 & 1.37 & 1.49 \\
\hline \multirow[t]{2}{*}{ MACT } & & & & & & -0.7 & 3.85 & -0.91 & -6.6 \\
\hline & & & & & & 6.69 & 6.9 & 7.03 & 5.73 \\
\hline \multirow[t]{2}{*}{$1960 S$} & 0.12 & -0.65 & $-1.32 * * *$ & 0.59 & $-0.97 *$ & 0.61 & 0.4 & -0.21 & -0.49 \\
\hline & 0.57 & 0.59 & 0.51 & 0.61 & 0.59 & 0.58 & 0.7 & 0.76 & 0.74 \\
\hline \multirow[t]{2}{*}{$1970 S$} & 0.04 & -0.52 & $-1.04 * * *$ & 0.37 & $-0.80 * *$ & 0.3 & 0.28 & -0.18 & -0.47 \\
\hline & 0.38 & 0.41 & 0.38 & 0.41 & 0.44 & 0.37 & 0.46 & 0.51 & 0.54 \\
\hline \multirow[t]{2}{*}{$1980 S$} & $-0.60 * *$ & $-1.07 * * *$ & $-0.62 * * *$ & $-0.44^{*}$ & $-0.52 * *$ & -0.31 & -0.46 & $-0.86 * * *$ & -0.33 \\
\hline & 0.26 & 0.29 & 0.25 & 0.27 & 0.26 & 0.26 & 0.29 & 0.33 & 0.3 \\
\hline \multirow[t]{2}{*}{ Constant } & $20.20 * * *$ & $26.79 * * *$ & $34.93 * * *$ & $18.53^{* * *}$ & $34.58 * * *$ & $21.45^{* * *}$ & $16.04 * *$ & $27.53^{* * *}$ & $40.98^{* * *}$ \\
\hline & 4.87 & 4.78 & 4.73 & 4.89 & 4.55 & 7.8 & 8.03 & 7.51 & 6.32 \\
\hline$R 2$ & 0.32 & 0.43 & 0.6 & 0.34 & 0.61 & 0.36 & 0.34 & 0.44 & 0.62 \\
\hline OBS & 341 & 296 & 143 & 341 & 307 & 441 & 341 & 296 & 143 \\
\hline
\end{tabular}

Source: Authors computation.

Note: Heteroscedasticity-adjusted standard errors reported under the coefficient. *** Refers to 99\%; ** to $95 \%$; and * to $90 \%$ significance level using a one-tail test. In regressions 9 and 15 , the sample excludes Sub Saharan Africa and Latin America for the 1990s. In regressions 10, 12, and 16, only OECD, East Asian and South Asian countries are included. 
In most specifications, the gender gaps in employment explain a larger share of the growth differences with East Asia, suggesting that MENA is particularly held back by its low female labor force participation rates, a subject much discussed in the literature (e.g. World Bank 2004).

Table 1.6 Gender Inequality in Education and Employment and Growth impact (EAP-MENA)

\begin{tabular}{|c|c|c|c|c|}
\hline & 1960s & 1970s & 1980s & 1990s \\
\hline $\begin{array}{l}\text { Growth difference EAP-MENA } \\
\text { by decades }\end{array}$ & 0.53 & 1.48 & 2.71 & 1.55 \\
\hline \multicolumn{5}{|l|}{ Regression 9} \\
\hline Education effect (ORED) & 0.41 & 0.65 & 0.61 & 0.54 \\
\hline \multicolumn{5}{|l|}{ Regression 11} \\
\hline Education effect (ORED) & 0.18 & 0.29 & 0.27 & 0.24 \\
\hline Employment effect (FLFT) & 0.75 & 0.86 & 0.96 & 1.06 \\
\hline Total Effect & 0.93 & 1.15 & 1.23 & 1.3 \\
\hline \multicolumn{5}{|l|}{ Regression 13} \\
\hline Employment effect (RACT) & 1.15 & 1.36 & 1.62 & 1.73 \\
\hline \multicolumn{5}{|l|}{ Regression 14} \\
\hline Education effect (ORED) & 0.2 & 0.32 & 0.3 & 0.27 \\
\hline Employment effect (RACT) & 0.79 & 0.94 & 1.11 & 1.19 \\
\hline Total Effect & 0.99 & 1.26 & 1.41 & 1.45 \\
\hline \multicolumn{5}{|l|}{ Regression 15} \\
\hline Education effect (ORED) & 0.55 & 0.88 & 0.82 & 0.72 \\
\hline Employment effect (RACT) & 0.63 & 0.75 & 0.89 & 0.95 \\
\hline Total effect & 1.18 & 1.62 & 1.71 & 1.67 \\
\hline
\end{tabular}

Table 1.7 shows to what extent the growth differences between South Asia and East Asia can be explained by gender gaps in education and employment. Here the impact of larger educational gender gaps in South Asia plays a particularly large role. Depending on the specification, it can account for a growth difference between 0.2 and 1.4 percentage points. In contrast, the impact of employment effects is generally smaller, but is increasing over time. In fact, the ILO data we use showed smaller gender gaps in employment in South Asia than in East Asia in the 1960s and 1970s; if these level difference are to be believed, then South Asia's main problem has been, apart from their stubbornly high gender gaps in education, that female employment has expanded much slower than in East Asia and this is exacting a rising growth costs, compared to East Asia. 
While these calculations nicely show the particular constraints in different regions, they cannot give clear answers to the question whether gender gaps in education or employment lead to higher growth costs. This depends to a significant degree on the education variable, the time period, and the sample. But we can say with more certainty that in relative terms, MENA's problem are more on the employment front, while in South Asia they are more on the education front (though rising on the employment front).

Table 1.7 Gender Inequality in Education and Employment and Growth impact (EAP-SA)

\begin{tabular}{|c|c|c|c|c|}
\hline & 1960s & 1970s & 1980s & 1990s \\
\hline $\begin{array}{l}\text { Growth difference EAP-SA } \\
\text { by decades }\end{array}$ & 2.26 & 3.86 & $\mathbf{0 . 1 9}$ & 0.79 \\
\hline \multicolumn{5}{|l|}{ Regression 9} \\
\hline Education effect (ORED) & 0.57 & 0.5 & 0.67 & 0.73 \\
\hline \multicolumn{5}{|l|}{ Regression 10} \\
\hline Education effect (YRED) & 0.69 & 0.88 & 0.95 & 0.78 \\
\hline \multicolumn{5}{|l|}{ Regression 11} \\
\hline Education effect (ORED) & 0.25 & 0.22 & 0.29 & 0.32 \\
\hline Employment effect (FLFT) & -0.17 & 0.09 & 0.34 & 0.45 \\
\hline Total Effect & 0.08 & 0.31 & 0.63 & 0.77 \\
\hline \multicolumn{5}{|l|}{ Regression 12} \\
\hline Education effect (YRED) & 1.08 & 1.11 & 1.19 & 1 \\
\hline Employment effect (FLFT) & -0.09 & 0.05 & 0.18 & 0.24 \\
\hline Total Effect & 0.98 & 1.15 & 1.37 & 1.24 \\
\hline \multicolumn{5}{|l|}{ Regression 13} \\
\hline Employment effect (RACT) & -0.37 & -0.02 & 0.43 & 0.6 \\
\hline \multicolumn{5}{|l|}{ Regression 14} \\
\hline Education effect (ORED) & 0.28 & 0.25 & 0.33 & 0.36 \\
\hline Employment effect (RACT) & -0.26 & -0.01 & 0.29 & 0.42 \\
\hline Total effect & 0.03 & 0.24 & 0.63 & 0.78 \\
\hline \multicolumn{5}{|l|}{ Regression 15} \\
\hline Education effect (ORED) & 0.77 & 0.67 & 0.9 & 0.99 \\
\hline Employment effect (RACT) & -0.2 & -0.01 & 0.24 & 0.33 \\
\hline Total effect & 0.56 & 0.66 & 1.14 & 1.32 \\
\hline \multicolumn{5}{|l|}{ Regression 16} \\
\hline Education effect (YRED) & 1.3 & 1.34 & 1.44 & 1.21 \\
\hline Employment effect (RACT) & -0.13 & -0.01 & 0.15 & 0.22 \\
\hline Total effect & 1.17 & 1.33 & 1.59 & 1.43 \\
\hline
\end{tabular}




\subsection{Conclusions and Caveats}

The challenge of increasing the economic growth of a country is, as suggested here, to a considerable extent linked to the role played by women in the society. The costs of discrimination toward women in education and employment not only harm the women concerned, but impose a cost for the entire society.

In South Asia women are still in the twenty first century very much discriminated against in both education level and economic participation. In Middle East and North Africa the gender gap in education has been reduced from high levels, but gender gaps in employment remain pervasive. In contrast to some Asian countries, where export-oriented industries have led to a reduction of the gender gap in the labour market in the last decades, increased female education in MENA has not translated into higher labour market participation. Women in this region are encountering structural barriers37 in employment but those barriers may also be social, cultural, and ideological (World Bank 2004).

Regarding the growth costs of gender inequality, we find the following:

Firstly, gender inequality in education reduces economic growth also in the 1990s. The findings from earlier studies that used data up until 1990 are largely confirmed through this expanded analysis although the impact of gender gaps in education in the 1990s in the panel specification is sensitive to the inclusion of specific regions in the 1990s.

Secondly, gender inequality in education in the Middle East and North Africa and South Asia region continues to harm growth in that region, but by decreasing amounts. This is due to the fact that gender gaps in education have been sharply reduced there over the past two decades, with much faster progress in MENA than in South Asia. As a result, we expect gender inequality in education to play a decreasing role in harming growth prospects in MENA and South Asia. While this is true in an absolute sense, it is not always true in a relative sense. As East Asia has closed its gender gaps in education much faster than South Asia, the growth differences accounted for by differences in gender gaps between the two regions mounted in past decades.

Thirdly, the panel analysis suggests that gender inequality in employment has a sizable negative impact on economic growth. Simulations suggest that MENA's and

\footnotetext{
${ }^{37}$ Structural barriers related to the economic reconstruction, recession and limited domestic and foreign investment.
} 
South Asia growth prospects, when compared to other regions, are significantly reduced through this effect as the impact of gender inequality in employment is large and has been falling much slower than in other regions.

Thus a significant constraint to higher economic growth in those regions appears to be the substantial gender inequality persisting in education and employment. While these results are suggestive, we want to emphasize that the assessment of the impact of employment gaps is based on data that are measured with error and are often not fully comparable internationally. It is shocking that comparable labor force participation and employment data are not available for most developing countries. This is despite the fact that increasing numbers of household and labor force surveys are undertaken in these countries, but the results are not used to generate consistent and comparable data on employment, labor force participation and pay. ${ }^{38}$ This remains a major challenge for the ILO and other international organizations charged with providing such data.

Also, the usual caveats of cross-country regressions apply, including omitted variable bias, model uncertainty, endogeneity, among others. We have tried to control for some of these issues, but more work will be needed to solidify the findings. Lastly, we need to acknowledge that our results concern the impact of gender gaps in education and employment on measured national output. To the extent that higher female labor force participation comes at the expense of reduced household labor, the economic and wellbeing losses of such a reduction is not included in our assessment. The extent to which this might be a problem is clearly an area of further research.

If our results are confirmed by further studies, this points to an urgent need of increasing female education level and their participation in the labour force. While our results suggests that changing the composition of the labour force to include more females (and thus fewer males) would have a positive effect on growth, a more realistic policy recommendation would be to develop an employment-intensive growth strategy that makes particular use of females. At the least, the results suggest that current barriers to female employment are not only disadvantageous to females, but also appear to reduce economic growth in developing countries, and particularly in MENA and South Asia

One should also bear in mind the findings from a large literature suggesting that gender inequality in education and employment also have a significant negative impact on

\footnotetext{
${ }^{38}$ This is particularly lamentable as these household surveys have been used by the World Bank to generate roughly consistent and comparable and publicly available poverty statitics for developing countries. It is a shame that ILO does not have the capacity, funding, or political will to use these same data to generate internationally comparable employment data.
} 
other development goals such as reductions in fertility, child mortality, and undernutrition. Thus reducing existing gender inequality in education and employment will not only promote growth, but also further these other valuable development goals. ${ }^{39}$

\footnotetext{
${ }^{39}$ Abu-Ghaida and Klasen (2004) and King et al (2008) to estimate the magnitude of these effects.
} 


\section{Appendix Chapter 1}

Table 1.8 List of Countries for our analysis by region

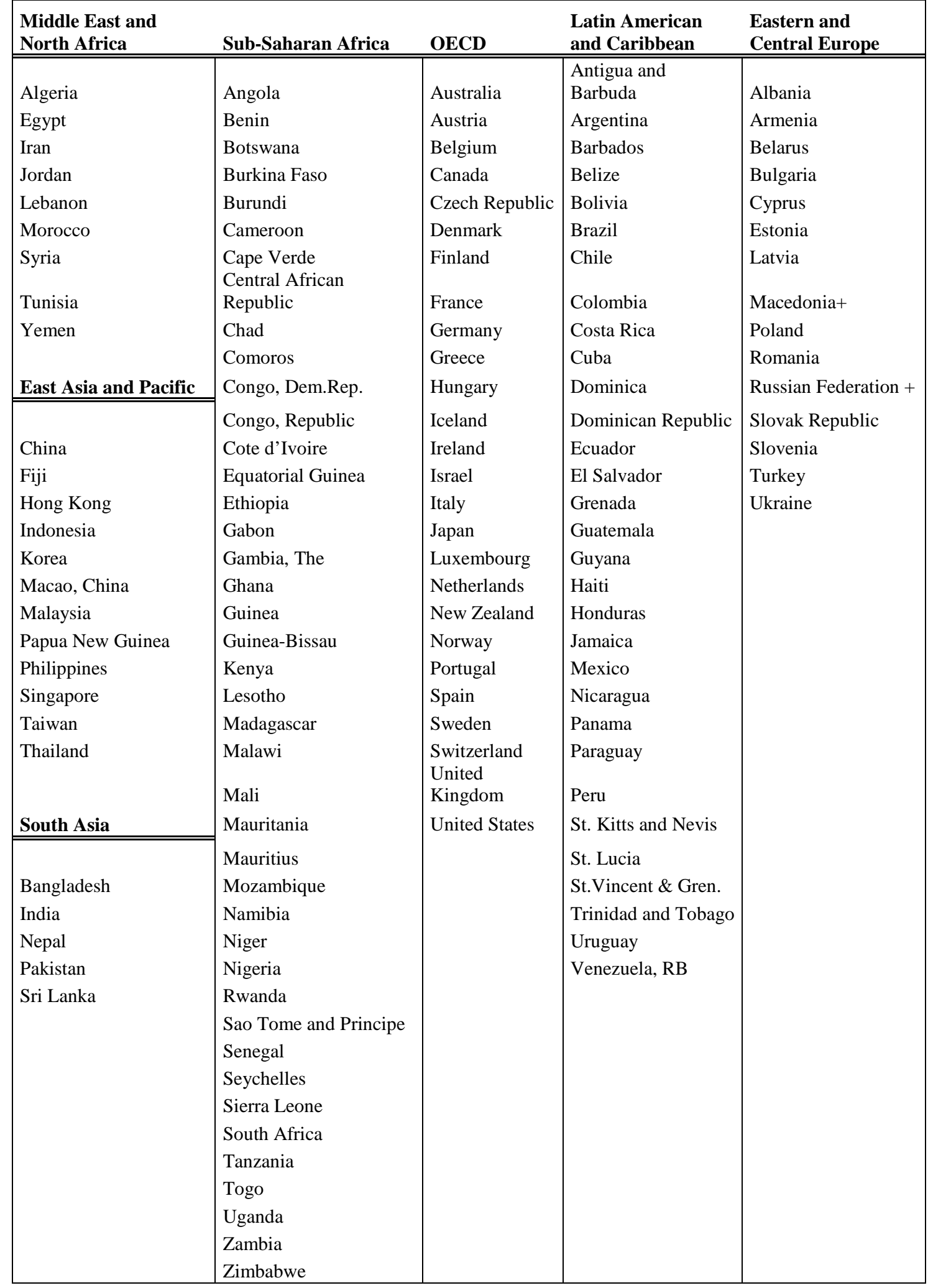

+ Data were not available for the entire period of analysis 
Table 1.9 Annual per capita income and other non-economic Indicators by Region, 1960-1990

\begin{tabular}{|c|c|c|c|c|c|}
\hline EAP & 1960 & 1970 & 1980 & 1990 & 2000 \\
\hline Under five mortality & 138.5 & 89.63 & 56.43 & 42 & 31.59 \\
\hline Total fertility & 5.62 & 4.65 & 3.39 & 2.83 & 2.31 \\
\hline Life expectancy & 52.57 & 59.87 & 64.94 & 68.76 & 71.55 \\
\hline Income per capita & 1813 & 2963 & 5117 & 8930 & 11755 \\
\hline \multicolumn{6}{|l|}{ SA } \\
\hline Under five mortality & 228 & 192 & 154.6 & 109.4 & 80.64 \\
\hline Total fertility & 6.3 & 6.02 & 5.54 & 4.31 & 3.45 \\
\hline Life expectancy & 45.32 & 50.02 & 54.7 & 59.36 & 63.8 \\
\hline Income per capita & 930 & 1099 & 1187 & 1660 & 2186 \\
\hline \multicolumn{6}{|l|}{ SSA } \\
\hline Under five mortality & 273.89 & 233.86 & 182.47 & 148.96 & 146.15 \\
\hline Total fertility & 6.49 & 6.53 & 6.49 & 5.98 & 5.13 \\
\hline Life expectancy & 40.4 & 44.3 & 48.08 & 51.18 & 49.06 \\
\hline Income per capita & 1488 & 1868 & 2087 & 2182 & 2400 \\
\hline \multicolumn{6}{|l|}{ MENA } \\
\hline Under five mortality & 233.75 & 188.13 & 137.57 & 68.88 & 45.14 \\
\hline Total fertility & 7.12 & 6.78 & 6.13 & 4.68 & 3.32 \\
\hline Life expectancy & 47.89 & 53.08 & 58.55 & 64.86 & 68.37 \\
\hline Income per capita & 1968 & 2762 & 3660 & 3499 & 4462 \\
\hline \multicolumn{6}{|l|}{ ECA } \\
\hline Under five mortality & 80.78 & 55.11 & 43.2 & 25.05 & 16.4 \\
\hline Total fertility & 3.24 & 2.78 & 2.4 & 2.14 & 1.47 \\
\hline Life expectancy & 66.15 & 68.77 & 69.59 & 70.79 & 71.59 \\
\hline Income per capita & 2233 & 3650 & 5300 & 9323 & 7346 \\
\hline \multicolumn{6}{|l|}{ LAC } \\
\hline Under five mortality & 135.58 & 109 & 70.91 & 42.65 & 30.85 \\
\hline Total fertility & 6.13 & 5.37 & 4.1 & 3.29 & 2.69 \\
\hline Life expectancy & 57.25 & 61.64 & 65.72 & 69.14 & 71.56 \\
\hline Income per capita & 3362 & 4270 & 5072 & 5471 & 7086 \\
\hline \multicolumn{6}{|l|}{ OECD } \\
\hline Under five mortality & 37.67 & 26.05 & 15.14 & 9.73 & 6.61 \\
\hline Total fertility & 2.87 & 2.46 & 1.93 & 1.79 & 1.65 \\
\hline Life expectancy & 70.19 & 71.72 & 73.8 & 75.76 & 77.73 \\
\hline Income per capita & 8386 & 12024 & 15420 & 18875 & 23173 \\
\hline
\end{tabular}

Source: Penn World Table 6.1 and WDI 2002. Please note that the data for ECA refer to only two observations before the 1990s (Cyprus and Romania). All are unweighted averages and might in some cases be affected by compositional changes. 
Table 1.10 Education Indicators by Region, 1960-1999

\begin{tabular}{|c|c|c|c|c|c|}
\hline East Asia and Pacific & 1960 & 1970 & 1980 & 1990 & 1999 \\
\hline female education 25+ (OFED25+) & 2.11 & 2.71 & 3.75 & 5.22 & 6.55 \\
\hline male education 25+ (OED25+) & 4.11 & 4.74 & 5.59 & 6.81 & 7.8 \\
\hline total education 25+ (OTED25+) & 3.13 & 3.73 & 4.68 & 6.02 & 7.18 \\
\hline ratio female-male education 25+ (ORED25+) & 0.5 & 0.56 & 0.65 & 0.75 & 0.83 \\
\hline female education $15+($ FED) & 2.74 & 3.53 & 4.46 & 5.46 & 6.7 \\
\hline male education $15+(\mathrm{ED})$ & 4.6 & 5.21 & 5.9 & 6.77 & 7.85 \\
\hline total education 15+ (TED) & 3.68 & 4.38 & 5.19 & 6.12 & 7.28 \\
\hline ratio female male education $15+$ (RED) & 0.59 & 0.67 & 0.7 & 0.76 & 0.84 \\
\hline South Asia & 1960 & 1970 & 1980 & 1990 & 1999 \\
\hline female education 25+ (OFED25+) & 0.7 & 1.24 & 1.51 & 1.9 & 2.55 \\
\hline male education 25+ (OED25+) & 1.77 & 2.37 & 3.2 & 3.83 & 4.49 \\
\hline total education 25+ (OTED25+) & 1.27 & 1.72 & 2.39 & 2.89 & 3.54 \\
\hline ratio female-male education 25+ (ORED25+) & 0.25 & 0.34 & 0.36 & 0.43 & 0.51 \\
\hline female education 15+ (FED) & 0.89 & 1.3 & 1.86 & 2.68 & 3.23 \\
\hline male education 15+ (ED) & 1.9 & 2.48 & 3.58 & 4.5 & 5.05 \\
\hline total education 15+ (TED) & 1.42 & 1.91 & 2.75 & 3.62 & 4.16 \\
\hline ratio female male education 15+ (RED) & 0.29 & 0.37 & 0.43 & 0.54 & 0.6 \\
\hline Sub-Saharan Africa & 1960 & 1970 & 1980 & 1990 & 1999 \\
\hline female education 25+ (OFED25+) & 0.92 & 0.97 & 1.37 & 1.92 & 2.63 \\
\hline male education 25+ (OED25+) & 1.67 & 1.8 & 2.54 & 3.21 & 3.92 \\
\hline total education 25+ (OTED25+) & 1.28 & 1.37 & 1.93 & 2.54 & 3.25 \\
\hline ratio female-male education 25+ (ORED25+) & 0.43 & 0.45 & 0.47 & 0.55 & 0.62 \\
\hline female education 15+ (FED) & 1.23 & 1.39 & 1.73 & 2.34 & 2.87 \\
\hline male education 15+ (ED) & 2.05 & 2.32 & 2.76 & 3.52 & 3.92 \\
\hline total education 15+ (TED) & 1.63 & 1.84 & 2.23 & 2.92 & 3.38 \\
\hline ratio female male education $15+$ (RED) & 0.48 & 0.52 & 0.6 & 0.62 & 0.7 \\
\hline Middle East and North Africa & 1960 & 1970 & 1980 & 1990 & 1999 \\
\hline female education 25+ (OFED25+) & 0.44 & 0.6 & 1.25 & 2.57 & 4.18 \\
\hline male education 25+ (OED25+) & 1.36 & 2.1 & 3.23 & 4.99 & 6.39 \\
\hline total education 25+ (OTED25+) & 0.91 & 1.34 & 2.24 & 3.78 & 5.29 \\
\hline ratio female-male education 25+ (ORED25+) & 0.32 & 0.28 & 0.39 & 0.51 & 0.65 \\
\hline female education 15+ (FED) & 0.65 & 1.17 & 1.86 & 3.17 & 4.77 \\
\hline Male education $15+(\mathrm{ED})$ & 1.76 & 2.85 & 3.58 & 5.11 & 6.52 \\
\hline Total education 15+ (TED) & 1.21 & 2.01 & 2.72 & 4.14 & 5.65 \\
\hline ratio female male education 15+ (RED) & 0.38 & 0.41 & 0.47 & 0.58 & 0.73 \\
\hline
\end{tabular}

Table 1.10 to be continued 


\section{Continuation Table 1.10}

\begin{tabular}{|c|c|c|c|c|c|}
\hline Eastern Europe and Central Asia & 1960 & 1970 & 1980 & 1990 & 1999 \\
\hline female education 25+ (OFED25+) & 3.48 & 4.12 & 5.2 & 6.62 & 7.33 \\
\hline male education $25+($ OED25+) & 5.28 & 5.66 & 6.82 & 8.02 & 8.32 \\
\hline total education 25+ (OTED25+) & 4.34 & 4.87 & 5.99 & 7.32 & 7.82 \\
\hline ratio female-male education 25+ (ORED25+) & 0.59 & 0.66 & 0.7 & 0.78 & 0.85 \\
\hline female education 15+ (FED) & 5.24 & 5.9 & 6.56 & 8.24 & 7.57 \\
\hline male education $15+(E D)$ & 6.13 & 6.71 & 7.82 & 8.92 & 8.61 \\
\hline total education $15+($ TED) & 5.66 & 6.29 & 7.18 & 8.57 & 8.09 \\
\hline ratio female male education $15+$ (RED) & 0.82 & 0.85 & 0.83 & 0.91 & 0.86 \\
\hline Latin America and Caribbean & 1960 & 1970 & 1980 & 1990 & 1999 \\
\hline female education 25+ (OFED25+) & 2.91 & 3.35 & 4.2 & 5.08 & 5.87 \\
\hline male education 25+ (OED25+) & 3.42 & 3.93 & 4.65 & 5.42 & 6 \\
\hline total education 25+ (OTED25+) & 3.16 & 3.63 & 4.42 & 5.25 & 5.94 \\
\hline ratio female-male education 25+ (ORED25+) & 0.83 & 0.83 & 0.89 & 0.93 & 0.98 \\
\hline female education 15+ (FED) & 3.3 & 3.88 & 4.81 & 5.52 & 6.08 \\
\hline male education $15+(E D)$ & 3.69 & 4.3 & 5.09 & 5.73 & 6.27 \\
\hline total education $15+($ TED) & 3.49 & 4.09 & 4.95 & 5.62 & 6.18 \\
\hline ratio female male education 15+ (RED) & 0.9 & 0.89 & 0.94 & 0.96 & 0.96 \\
\hline OECD & 1960 & 1970 & 1980 & 1990 & 1999 \\
\hline female education 25+ (OFED25+) & 6.39 & 6.91 & 7.84 & 8.4 & 9.12 \\
\hline male education 25+ (OED25+) & 6.98 & 7.62 & 8.68 & 9.3 & 9.82 \\
\hline total education 25+ (OTED25+) & 6.66 & 7.25 & 8.24 & 8.83 & 9.46 \\
\hline ratio female-male education 25+ (ORED25+) & 0.91 & 0.9 & 0.9 & 0.9 & 0.93 \\
\hline female education $15+($ FED) & 6.54 & 7.13 & 8.06 & 8.69 & 9.3 \\
\hline male education $15+(E D)$ & 7.11 & 7.7 & 8.66 & 9.27 & 9.85 \\
\hline total education 15+ (TED) & 6.81 & 7.4 & 8.35 & 8.97 & 9.57 \\
\hline ratio female male education $15+$ (RED) & 0.91 & 0.92 & 0.93 & 0.93 & 0.94 \\
\hline
\end{tabular}

Source: Barro-Lee (2000). All refer to unweighted averages. 
Table 1.11 Labor market Indicators by Region, 1960-2000

\begin{tabular}{|c|c|c|c|c|c|}
\hline East Asia and Pacific & 1960 & 1970 & 1980 & 1990 & 2000 \\
\hline male economic activity rate, 15-64 (MACT) & 90.69 & 87.82 & 86.41 & 85.71 & 84.94 \\
\hline total economic activity rate, $15-64$ (TACT) & 66.43 & 67.25 & 69.84 & 71.07 & 72.47 \\
\hline ratio female-male economic activity rate, 15-64 (RACT) & 0.45 & 0.52 & 0.61 & 0.66 & 0.7 \\
\hline female economic activity rate, 15-64 (FACT) & 41.33 & 46.25 & 52.85 & 56.47 & 59.67 \\
\hline female share of labor force, 15-64 (FLFT) & 28.52 & 32.41 & 36.13 & 38.66 & 40.31 \\
\hline female employee rate (EMPLF) & & 0.17 & 0.22 & 0.29 & 0.3 \\
\hline male employee rate (EMPLM) & & 0.39 & 0.43 & 0.46 & 0.45 \\
\hline ratio female-male employees (REMPL) & & 0.4 & 0.49 & 0.6 & 0.66 \\
\hline \multicolumn{6}{|l|}{ South Asia } \\
\hline male economic activity rate, 15-64 (MACT) & 92.5 & 90.4 & 88.6 & 87.61 & 86.22 \\
\hline total economic activity rate, $15-64$ (TACT) & 71.99 & 70.31 & 68.91 & 68.62 & 69.1 \\
\hline ratio female-male economic activity rate, 15-64 (RACT) & 0.52 & 0.53 & 0.53 & 0.55 & 0.59 \\
\hline female economic activity rate, 15-64 (FACT) & 48.61 & 47.84 & 47.22 & 47.88 & 50.87 \\
\hline female share of labor force, 15-64 (FLFT) & 30.71 & 31.28 & 31.82 & 32.9 & 35.28 \\
\hline female employee rate (EMPLF) & & 0.05 & 0.06 & 0.1 & 0.08 \\
\hline male employee rate (EMPLM) & & 0.27 & 0.3 & 0.34 & 0.27 \\
\hline ratio female-male employees (REMPL) & & 0.15 & 0.18 & 0.27 & 0.26 \\
\hline \multicolumn{6}{|l|}{ Sub Saharan Africa } \\
\hline male economic activity rate, $15-64$ (MACT) & 92.65 & 91.34 & 89.75 & 88.59 & 87.49 \\
\hline total economic activity rate, $15-64$ (TACT) & 80.81 & 79.49 & 78.13 & 77.17 & 76.57 \\
\hline ratio female-male economic activity rate, 15-64 (RACT) & 0.75 & 0.75 & 0.75 & 0.75 & 0.75 \\
\hline female economic activity rate, 15-64 (FACT) & 69.62 & 68.59 & 67.2 & 66.44 & 66.1 \\
\hline female share of labor force, 15-64 (FLFT) & 43.45 & 43.59 & 43.53 & 43.56 & 43.48 \\
\hline female employee rate (EMPLF) & & 0.12 & 0.09 & 0.09 & 0.03 \\
\hline male employee rate (EMPLM) & & 0.46 & 0.27 & 0.26 & 0.08 \\
\hline ratio female-male employees (REMPL) & & 0.2 & 0.26 & 0.28 & 0.34 \\
\hline \multicolumn{6}{|l|}{ Middle East and North Africa } \\
\hline male economic activity rate, 15-64 (MACT) & 88.84 & 85.39 & 82.03 & 81.02 & 81.21 \\
\hline total economic activity rate, $15-64$ (TACT) & 55.44 & 54.04 & 53.49 & 54.34 & 57.62 \\
\hline ratio female-male economic activity rate, 15-64 (RACT) & 0.24 & 0.27 & 0.31 & 0.34 & 0.41 \\
\hline female economic activity rate, 15-64 (FACT) & 21.56 & 23.21 & 25.54 & 27.5 & 33.7 \\
\hline Female share of labor force, 15-64 (FLFT) & 19.01 & 21.45 & 23.89 & 25.09 & 28.94 \\
\hline Female employee rate (EMPLF) & & 0.07 & 0.07 & 0.09 & 0.11 \\
\hline male employee rate (EMPLM) & & 0.56 & 0.53 & 0.56 & 0.58 \\
\hline ratio female-male employees (REMPL) & & 0.12 & 0.13 & 0.18 & 0.25 \\
\hline
\end{tabular}

Table 1.11 to be continued 


\section{Continuation Table 1.11}

\begin{tabular}{|c|c|c|c|c|c|}
\hline \multicolumn{6}{|l|}{ Eastern Europe and Central Asia } \\
\hline male economic activity rate, $15-64$ (MACT) & 88.67 & 84.83 & 83.76 & 81.47 & 80.31 \\
\hline total economic activity rate, 15-64 (TACT) & 73.22 & 73.12 & 74.97 & 73.66 & 73.65 \\
\hline ratio female-male economic activity rate, $15-64$ (RACT) & 0.67 & 0.73 & 0.79 & 0.81 & 0.84 \\
\hline female economic activity rate, 15-64 (FACT) & 59.42 & 62.18 & 66.24 & 65.85 & 66.97 \\
\hline female share of labor force, 15-64 (FLFT) & 42.49 & 43.46 & 44.74 & 45.13 & 46 \\
\hline female employee rate (EMPLF) & & 0.25 & 0.38 & 0.41 & 0.31 \\
\hline male employee rate (EMPLM) & & 0.51 & 0.62 & 0.55 & 0.44 \\
\hline ratio female-male employees (REMPL) & & 0.45 & 0.57 & 0.68 & 0.6 \\
\hline \multicolumn{6}{|l|}{ Latin America and Caribbean } \\
\hline male economic activity rate, 15-64 (MACT) & 91.64 & 88.57 & 86.34 & 85.41 & 84.63 \\
\hline total economic activity rate, 15-64 (TACT) & 59.55 & 59.45 & 61.12 & 63.43 & 65.78 \\
\hline ratio female-male economic activity rate, 15-64 (RACT) & 0.3 & 0.34 & 0.41 & 0.49 & 0.56 \\
\hline female economic activity rate, 15-64 (FACT) & 27.91 & 30.51 & 35.73 & 41.77 & 46.88 \\
\hline female share of labor force, 15-64 (FLFT) & 22.93 & 25.24 & 28.87 & 32.77 & 35.63 \\
\hline female employee rate (EMPLF) & & 0.18 & 0.21 & 0.22 & 0.24 \\
\hline male employee rate (EMPLM) & & 0.51 & 0.48 & 0.4 & 0.42 \\
\hline ratio female-male employees (REMPL) & & 0.37 & 0.45 & 0.56 & 0.56 \\
\hline \multicolumn{6}{|l|}{ OECD } \\
\hline male economic activity rate, 15-64 (MACT) & 90.28 & 86.8 & 84.66 & 81.55 & 81.12 \\
\hline total economic activity rate, $15-64$ (TACT) & 63.35 & 64.99 & 68.64 & 70.57 & 72 \\
\hline ratio female-male economic activity rate, 15-64 (RACT) & 0.41 & 0.5 & 0.62 & 0.73 & 0.77 \\
\hline female economic activity rate, 15-64 (FACT) & 37.32 & 43.16 & 52.72 & 59.36 & 62.82 \\
\hline female share of labor force, 15-64 (FLFT) & 29.45 & 33.11 & 37.96 & 41.48 & 43.06 \\
\hline female employee rate (EMPLF) & & 0.32 & 0.41 & 0.48 & 0.48 \\
\hline male employee rate (EMPLM) & & 0.65 & 0.64 & 0.62 & 0.59 \\
\hline ratio female-male employees (REMPL) & & 0.48 & 0.62 & 0.75 & 0.79 \\
\hline
\end{tabular}

Source: WISTAT 3, LABORSTA (ILO Bureau of Statistics).

Note: All refer to unweighted averages. Employees data only until 1995. The male and female employee rate refers to the numbers of dependently employed as a share of the working age population. As it 


\title{
Chapter 2. Gender bias in child mortality: Empirical evidence from India
}

\begin{abstract}
Despite the high mortality rates and the availability of a large and comprehensive microdataset, there is little research on the microeconomic determinants of gender bias in child mortality using such data in India. The aim of this paper is to fill this gap in the literature, focusing particularly on the country's gender differences in under-five child mortality. In this paper, using a very rich microdataset that comprises more than 90,000 ever-married women across 26 Indian states and a sophisticated method of estimation, the Cox proportional hazard model, the author finds that children under five face higher mortality rates if born in households that are poorer, with a large number of women, where the mother has little autonomy, the father is illiterate, the birth interval is small and the child has a twin. The author also finds that in India the sex of the child plays a significant role in determining the hazard rate. Girls under five are much more likely to die than boys, particularly if the girl has older sisters.
\end{abstract}

\subsection{Introduction}

Gender equality is a concern that is recognized as a development goal by the large number of countries worldwide who signed and ratified the United Nations Convention on the Elimination of all Forms of Discrimination Against Women (CEDAW) and the Millennium Development Goals (MDG). In most countries, however, there is evidence of gender inequality in various spheres of life (i.e., education, employment and health). This paper focuses attention on a specific aspect of discrimination against women in India, gender bias in mortality.

Amartya Sen contributed much to the theoretical and empirical analysis of gender bias in mortality in the world (1989, 1990 and 1992). He developed a method to assess the cumulative impact of gender bias in mortality by estimating the additional number of females of all ages who could be alive if there had been equal treatment of the sexes among the cohorts that are alive today. In a series of papers in the late 1980s, Sen claimed that about 100 million women were dead as a result of unequal treatment in the allocation 
of survival-related goods (concept of “missing women”). A number of other papers on the topic were written in the following decade. The absolute number of missing women computed by those authors differs from paper to paper but those numbers are always dramatically high, suggesting that gender bias in mortality is far from being a minor issue (Klasen 1999, Klasen and Wink 2002). Sen (1989, 1990 and 1992) and all other authors found that girls and women suffer from elevated mortality rate, particularly in South Asia and China.

Boys have a natural mortality disadvantage especially in childhood (Waldron 1993). Nevertheless this biological advantage of women over men in longevity can be different if there is asymmetry in basic life and death matters, including nutrition, ${ }^{40}$ health care and medical attention. Sen argues that these differences result from the influence of social action and public policy in the country.

India with its 1.1 billion people ${ }^{41}$ is a country of vast demographic diversity. Child mortality has declined in the past two decades but still remains high (76 children out of 1000 in $2006^{42}$ ). Relative survival chances for boys and girls have changed substantially (Murthi, Guio and Dreze, 1995). Girls’ mortality, however, is still greater than boys and the share of "missing women" in the country is particularly high. In India despite high mortality rates and the availability of a large and comprehensive microdataset, there has not been much research on the microeconomic determinants of child mortality using such data. Most analyses of gender bias in mortality in India have been conducted using aggregate datasets or small household surveys (at the region, district or village level). ${ }^{43}$ The main aim of this paper is to fill this gap in the gender bias in mortality literature.

Using a rich dataset for India (National Family Health Survey [NFHS] 1998-99), this paper investigates the determinants of child mortality in the first five years of life. Particular attention is given to the impact of specific explanatory variables (household composition and characteristics, mother's characteristics and prenatal care, father's and children's characteristics and especially gender) on child mortality.

\footnotetext{
${ }^{40}$ From birth, the gender of an infant testifies to its cultural needs. Evidence from villages as dispersed as Morinda in Punjab, Karnataka and Kuppam in Tamil Nadu suggests that male babies are breast-fed for longer than females. Das Gupta (1987), in her surveys of Ludhiana villages in Punjab, noted a tendency towards daughters being weaned on to a vegetarian diet and sons to a non-vegetarian one.

${ }^{41}$ Data source: World Bank 2007.

${ }^{42}$ Data source: Unicef 2008.

${ }^{43}$ Das Gupta, 1987.
} 
The paper is organized in seven sections. Section one presents the theoretical model, section two surveys the existing literature on gender bias in mortality in Asia and introduces the variables commonly used in the literature. Section 3 presents the paper's methodology and section 4 the data used. Section 5 presents the empirical model and section 6 the results. Section 7 concludes while presenting some policy options and further areas of investigation.

\subsection{Theoretical Model}

In the literature, the allocation of resources among children and more specifically the sex-specific allocation of them have been investigated using as a framework an investment model (Hill and King, 1993).

Investment in child education, nutrition and health are not made by the primary beneficiaries but by their care givers. The household's decision-making to invest in education, health care and nutrition of their children can be represented by a simple intergenerational investment model that illustrates rates of return on investment in women. In that model authors stresses the importance of market incentives to invest in women. The family will rationally decide to invest more resources in the child that will provide higher rate of return on investment.

Rate of returns may be gender-specific. When this is the case the opportunity cost of a child's time varies by gender and such cost will lead to differences in rates of investment. Sex-specific investment in children will then depend on their potential economic contributions to the household now and later.

In this paper we show that when return on girls is lower for girls than boys, women will be discriminated against. Children in most developing countries are an alternative system of social security. In this case, the so-called "return” refers to child labour services to the household and to transfer of resources and care for aged parents. This return obviously depends on work opportunities for girls and boys within and outside the household and also from marriage arrangements. Dyson and Moore (1984) highlight that if after marriage girls settle with the husband's family and care only for the in laws (patrilocal marriage), the investment value of girls will be low. This low valuation is exacerbated if marriage customs involve dowries; whereby the marriage of a daughter becomes much more expensive than that of a son. In Asian societies with predominantly patrilocal marriages, dowry payments, poor female earning opportunities and strong 
familial obligations for old age support, it seems predictable to find a larger excess of female mortality, as each family considers its own private benefit, comparing costs and returns. $^{44}$ In India this varies drastically from one state to another.

In our model we show that improved economic opportunities for women would increase their bargaining power and raise the investment values on daughters. This is particularly the case in some States in which women are more educated and have more economic opportunities (i.e. Kerala).

\subsection{Literature review}

To construct a model incorporating a large number of explanatory variables to potentially explain the tendency to neglect girls in India, we need to investigate the existing literature on gender bias in mortality. From this perspective, this section offers insights into the existing work on the topic, the theoretical framework for the analysis and a possible justification for incorporating some variables in our empirical model.

Most studies on gender bias in mortality show that unequal access to healthcare is the most important process driving excess female mortality and leading to a higher mortality for young girls (Basu 1999, Klasen 1999, Alderman and Gartler 1997). Differences in access to nutrition appear to be a smaller factor (Chen 1981, Sen 1992, Basu 1992). This comparative neglect of female children, generally worse in rural areas, appears to be particularly severe for later-born girls, especially for the girls with elder sisters (Das Gupta 1987, Dreze and Sen 1989, Klasen 1999).

The scarcity of economic resources is a necessary but not sufficient condition for experiencing gender bias in mortality. Poor households are forced to ration scarce resources allocated to nutrition and healthcare, which could disadvantage females, but many country studies notice that the poorest sections of the population experience less gender bias in mortality than slightly richer groups (Murthi, Guio and Dreze 1995, Klasen 1999).

Another point of interest for further investigation is provided by the dispute initiated by Das Gupta \& Mari Bhat and Murthi \& Dreze (1995, 1997, and 1999). The first two authors studied the relationship between fertility decline and gender bias in child

\footnotetext{
${ }^{44}$ For the society, however, the social benefits are different. There are relevant positive externalities involved in having a gender neutral society. The role of the policy maker should be to equalize the private and social benefits: in this case a good policy option would be to subsidize girls' schooling or to provide any help that justifies an investment in girls.
} 
mortality, showing evidence for the spread of sex-selective abortion, especially among women with lower fertility. Murthi and Dreze (1999) found that the association between fertility and gender bias is firmly positive rather than negative, casting doubt on the argument used by Das Gupta and Mari Bhat. Further research is needed to settle this dispute. If a decline in fertility leads to the intensification of gender bias in India, it will be necessary to intervene immediately (Klasen, 2009) so the already existing large bias is not exacerbated. $^{45}$

Last but not least, there is evidence that state policies can influence gender bias in mortality (Oster, 2009). State-supported free access to healthcare and nutrition would lessen the need to ration scarce resources (Asfaw, Lamanna and Klasen, 2010). Having state supporting policies that promote female education and employment would have a positive impact on the return on investment for girls and therefore improve circumstances for girls nationally (World Bank 2001).

\section{Gender bias in health expenditures}

While female mortality rates in excess of male rates in the reproductive years are likely to reflect the hazard of childbirth, the evidence for differential morbidity not directly or indirectly related to reproduction is not clear. In Bangladesh, Chen et al. (1981) conclude that while there is no gender difference in the incidence of disease, there may be gender difference in the duration and intensity of illness. Gender differences in clothing quality and expenditure may also influence health status (Das Gupta 1987). In cases from north India and Bangladesh, a marked gender imbalance in health expenditure on children is recorded (Das Gupta 1987) and the treatments given to females are often less orthodox. Mitra (1978) found that gender differences in child mortality rates from vitamin deficiency, respiratory and gastrointestinal diseases arise from relatively late stage of illness at which girls were brought for treatment.

Low availability of health facilities and low public expenditure on health per capita are other important aspects related to increased mortality rates. A conspicuous number of studies show that gender difference in mortality rates vary positively with the distance from home to treatment centre. Disadvantages in female access to treatment, especially at

\footnotetext{
${ }^{45}$ A number of cultural practices and customs appear to hurt females in some regions, including virilocal marriage patterns, ancestor worship undertaken by sons and high dowry for brides.
} 
young age, may have a remarkable influence on future female health. Gender differentials in access to state medical facilities may be further extended to access to other types of state institutions and to political life at village level and beyond. Asfaw, Klasen and Lamanna (2007) find that the strong preference for boys in India is reflected in the higher chances for girls to die at home than boys.

\section{Potential sources of discrimination}

In India and Bangladesh despite the enactment of legislation after Independence to guarantee equal inheritance rights to men and women, women's control over property is thought to have diminished throughout the subcontinent in the past fifty years. There remains notable differences between south and north, with southern women having greater access to property.

Similarly despite the Dowry Prohibition Act of 1961, the practice of transferring resources on marriage as dowry is said to be increasing in prevalence and size both in the south and north of India. The commercialization of females via resource transfer at marriage is punitive for households with a preponderance of daughters. This phenomenon could be linked directly to another unfortunate practice, seclusion, which may restrict the selected woman to the interior of the home.

Female discrimination also manifests in wage work. Although they play a roughly equal role in agriculture production, women receive less for it. Other better-paid sectors of female activity, such as trade, are restrictive in their dependence on male sanction for physical premises, credit and prices.

Female education plays a fundamental role advantageous to the welfare of women and may be a major source of change in domestic productive and reproductive behaviour (especially fertility decisions). The rise in female literacy rates and the increasing confinement of illiteracy to those over the age of 25 indicates the possibility of a rise in female status over the next decades. Yet female literacy lags behind that of males, especially in north and centre of India, areas with a high concentration of scheduled castes and tribes.

\section{Policy Debate}

An interesting paper that contributes to the policy debate on effective policies benefiting disadvantaged groups is the one recently published in the Journal of Devleopment Economics by Oster (2009). The paper investigates weather increases in 
access to social services decreases inequality in the level of these services between advantaged and disadvantaged groups. The paper, using a very large dataset of over 90,000 women (NFHS) ${ }^{46}$ shows that in India there is a strong non-monotonic relationship between access to services and gender inequality, where at low levels of access to investments, there is no gender bias in investment while an increase in access increases investments for boys in India, generating inequality. This result is collaborated also in our analysis (see section on empirical results).

\subsection{Methodology}

Using a Cox proportional hazard model, this paper investigates which household, mother, father and child characteristics are associated with higher child mortality rates in India. Specifically we investigate if there is any significant difference in the survival rates of girls and boys. Our dependent variable is child mortality under five years of age. After surveying the existing literature, we include as explanatory variables household composition and characteristics (location, income, number of people in the household, etc.), mother, father and child characteristics (mother and father education, mother nutritional and health status, exposure to media, birth spacing, sex of the child, having older sisters, etc.).

Further, in the context of India, there are significant variations in child mortality across the various geographical regions. To capture those differences, we added state dummies into the model. While on the one hand there are states like Kerala that have demographic features typical of middle-income countries, there is also a large part of India (in particular the northern states) that scores among those world's least developed in terms of demographic indicators.

In order to conduct our analysis we use a very rich and representative dataset (NFHS 1998-99 for India) that comprises more than 90,000 ever-married women across 26 Indian states. India makes an interesting laboratory for the study of demographic processes. It has one sixth of the world's population and almost a quarter of under-five child deaths in the world (Black et al. 2003). Infant mortality in India has been gradually declining, having halved between the early-1970s and 2000, but the rate of decline is less impressive than that observed in some other South and South-east Asian countries.

\footnotetext{
${ }^{46}$ Using the same dataset we are using in our analysis.
} 
The Millennium Development Goal to reduce the mortality rates among children under five by two thirds by 2015 (MDG 4) represents a huge challenge for India. In 1999, the under-five child mortality rate in India was 100 children per 1000; where the infant mortality was very high, 70 every 1000. Mortality rates overall decreased recently but the pace is not sufficient to ensure satisfying results in the next future and particularly the rates for girls’ mortality are much higher.

\subsection{The Data}

The paper uses India's NFHS for 1998-1999. ${ }^{47}$ Since the database was designed to strengthen and facilitate the implementation and monitoring of population and health programs, it provides state and national data on fertility, practice of family planning, infant and child mortality, maternal and child health, and utilization of health services provided to mothers and children.

The data analysis that follows is based on the interviews conducted with women who had at least one child younger than five during the survey period November 1998 to March 1999. The survey includes questions on mortality and morbidity on both the Household Questionnaire and the Woman's questionnaire. The Woman's questionnaire collects information on the survival status of all births and the age at death of children who died.

\section{The dependent variable}

Infant and child mortality rate in India is very high (Figure 2.1). One out of 15 children born in the five years preceding the survey (1994-98) died within the first year of life and one in every 11 died before reaching age 5 . Those results show that child survival programs in India need to be intensified to achieve further reductions in infant and child mortality $^{48}$.

\footnotetext{
${ }^{47}$ This survey was funded by the United State Agency for International Development (USAID) and UNICEF. The dataset can be downloaded from the following website: http://www.measuredhs.com/.

${ }^{48}$ The reliability of mortality estimates calculated from retrospective birth histories depends upon the completeness with which deaths of children are reported and the extent to which birth dates and ages at death are accurately reported and recorded. Estimated rates presented for infant and child mortality are subject to both sampling and non sampling errors. The method for calculating the probabilities presented in this papers follows the methodology of Rutstein (1984). The mortality estimates are not rates, but are true probabilities, calculated according to the conventional life-table approach.
} 
Rural mortality rates are considerably higher than urban mortality rates. Child mortality rates are almost twice as high in rural areas as in urban areas and infant mortality is 56 percent higher in rural area as in urban.

\section{Figure 2.1 Mortality estimates for rural and urban areas in India}

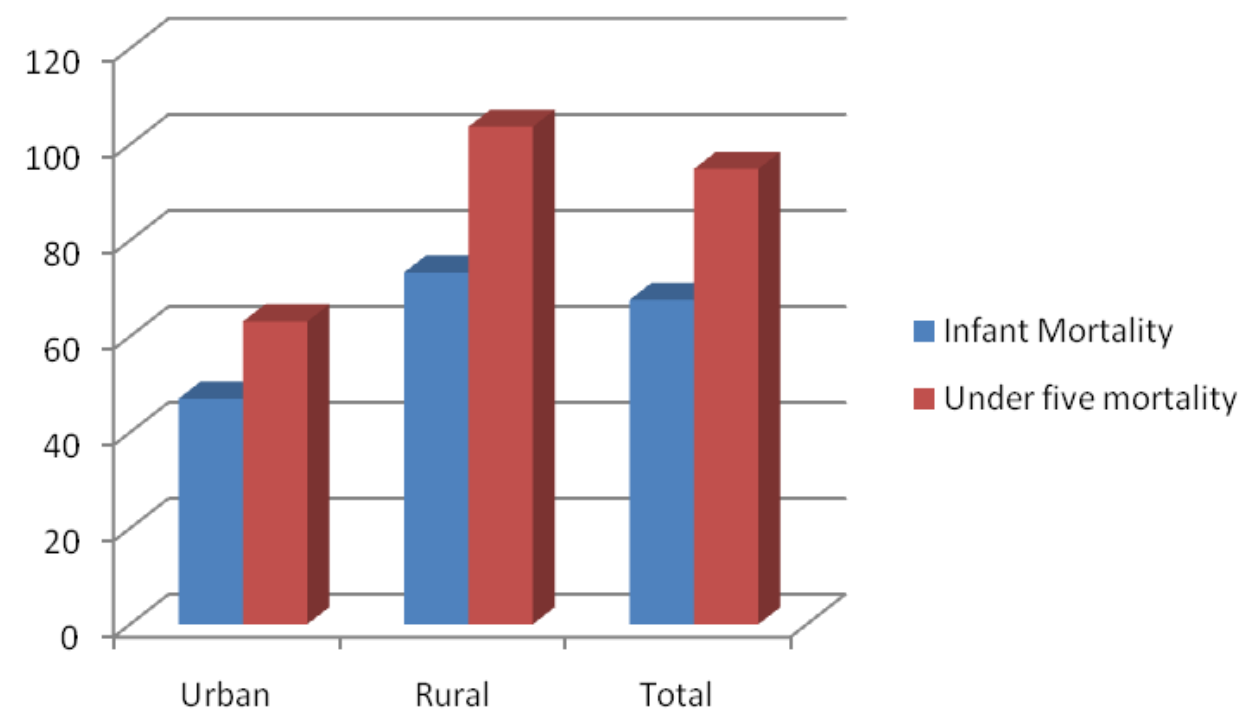

Source: NFHS-2, 1998-99.

Note: The first five-years period preceding the survey do not include the months in which the interview took place. Rates are specified on a per-thousand basis

Figure 2.1 shows that in the 4 years preceding the survey the infant mortality rate in rural setting was very high (73.3 every 1000 infants) and the same was for under five morality rates (103.7 every 1000 children).

The probability of dying in early childhood is higher in some population groups than in others (see Table 2.1). The overall infant mortality rate declines sharply with increasing education of mothers, as expected, ranging from a high of 87 deaths per 1000 live birth for illiterate mothers to a low of 33 deaths per 1000 live births for mother who have at least completed high school.

All the infant and child mortality rates are much higher for Hindus than for Muslims. The infant mortality rate is 31 percent higher and the child mortality rate is 28 percent higher for Hindu children than for Muslim children. This is also explained by the differential in mortality by region. 
Mortality rates vary drastically by gender. In most populations in the world, there are some more live births for boys than for girls. This numerical difference usually decreases in infancy, because of higher mortality of boys during the neonatal and subsequent period and is reflected in an average advantage is of $10-15 \%$ for females in infancy. In industrialized countries males often continue to be slightly more prone to die in their childhood. In areas where child mortality remains high, sex differences in post-infant death rates are infrequently reported.

\section{Table 2.1 Infant and child mortality by background and demographic characteristics}

\begin{tabular}{lcc}
\hline & $\begin{array}{c}\text { Infant } \\
\text { mortality }\end{array}$ & $\begin{array}{c}\text { Under-five } \\
\text { mortality }\end{array}$ \\
\hline \hline Mother's education & & \\
Illiterate & 86.5 & 122.8 \\
Literate (middle completed) & 58.5 & 75.8 \\
High school completed and above & 32.8 & 37.1 \\
Religion & & \\
Hindu & 77.1 & 107 \\
Muslim & 58.8 & 82.7 \\
Christian & 49.2 & 68 \\
Sex of the Child & & \\
Male & 74.8 & 97.9 \\
Female & 71.1 & 105.2 \\
\hline Source: NFHS-2, 1998-99 & &
\end{tabular}

Table 2.1 shows that differently from around the world in India female mortality rate below age five years is slightly higher that the male mortality rate (105 deaths per 1000 live births for females compared with 98 deaths per 1000 live births for males). This pattern is much more evident in rural areas (106.4 deaths for 1000 live births for males and 117 for females). Excess female mortality occurs mainly after the first year of life. The infant mortality rate during the 10 year before the survey is slightly higher for boys (75 deaths per 1000 live births) than for girls (71.1 deaths per 1000 live births).

Figure 2.2 shows the survival chances for boys and girls under five. In India girls at all ages have much lower survival rates than boys and the differential in survival rates increases drastically over childhood; this is reflected in a much steeper survival curve for girls.

The results is even more striking if we consider some states in which child mortality rates are very high (Figure 2.3). 
Figure 2.2 Proportion of boys and girls under age five surviving in India

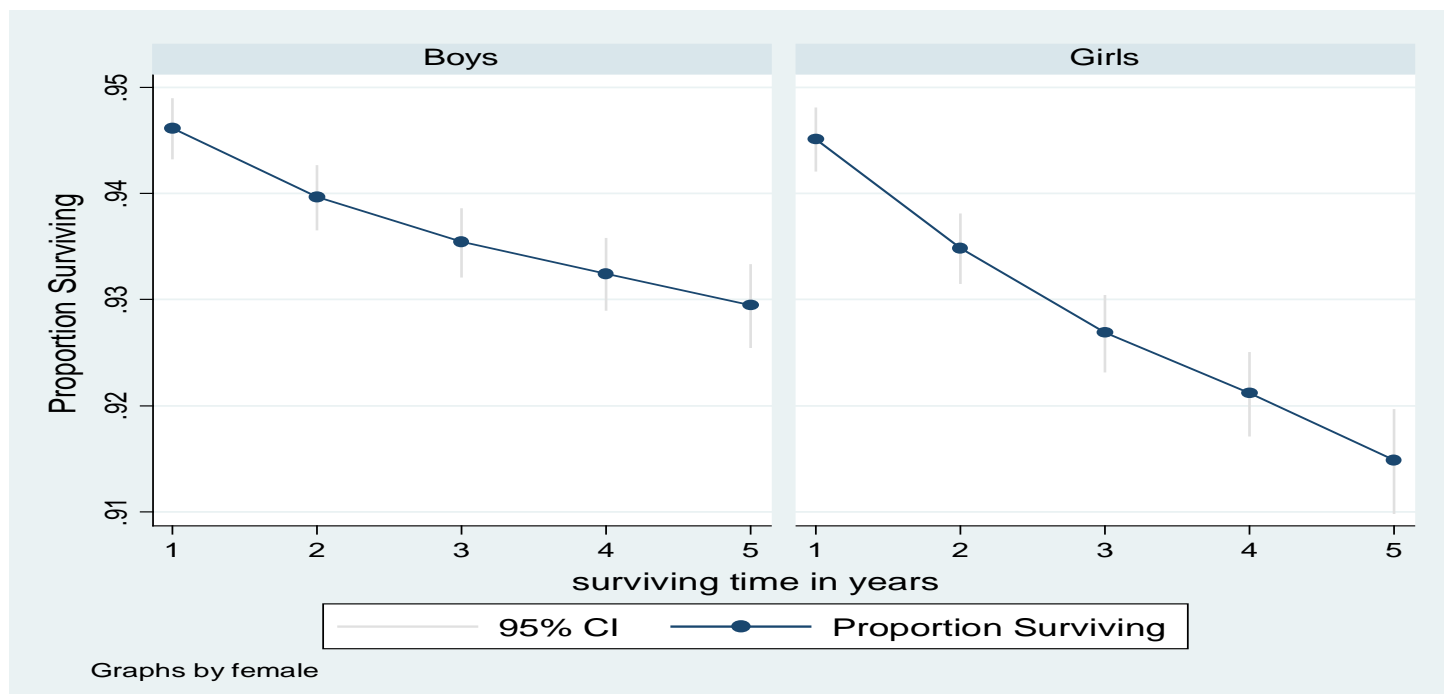

Source: NFHS-2, 1998-99 ${ }^{49}$

Figure 2.3 Proportion of boys and girls under age five surviving in Uttar Pradesh

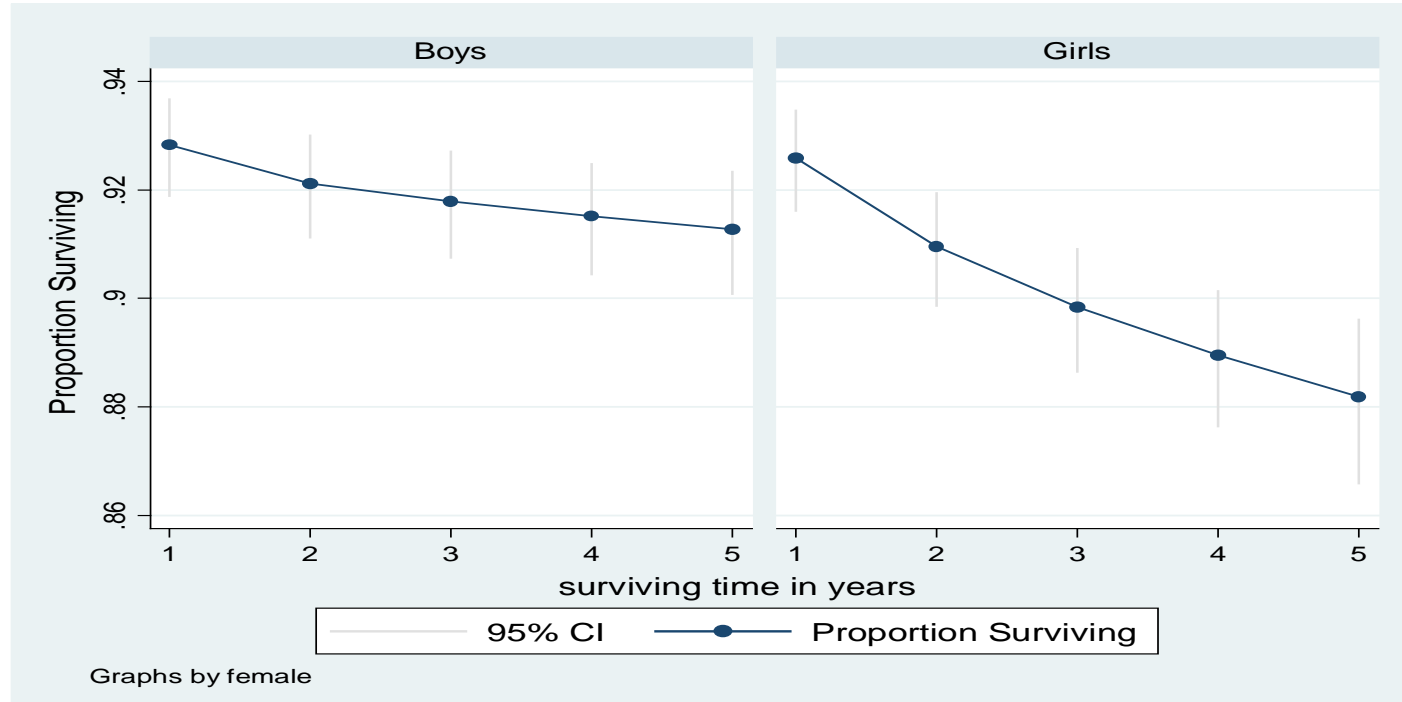

Source: NFHS-2, 1998-99

\section{The Explanatory Variables}

Sample characteristics of the major explanatory variables used in the model are presented with mean and standard deviations in Table 2.2. These explanatory variables can be divided into the following categories: household composition and characteristics, mother, father and child main characteristics.

\footnotetext{
${ }^{49}$ Figures reported in this session are sample means and standard deviations based on the sample of evermarried women that have at least one child under age five.
} 


\section{Household characteristics and composition}

In the household category we group variables that characterize the family. The large majority of households live in rural areas (75\%). For household standard of living concerns, we have built an index based on various elements ${ }^{50}$ that categorize the household levels as low, middle or high. Following this categorization, almost half of our sample belongs to the middle class, $34 \%$ to the low and the remaining to the high. Increased income typically leads to some decline of mortality chances; but the "income effect” can be slow and weak. Other personal characteristics, such as female literacy, often have a more powerful influence on demographic outcomes.

In our sample the household composition varies dramatically. On average size of a standard household is between seven and eight people. Most household heads are male.

\section{Maternal/Mother's characteristics}

As we mention in the literature review, a large number of mother characteristics can potentially influence child mortality in India. Dyson and Moore (1983) and other studies argue that mortality and women's status are linked. Women's status is thought to increase age at first marriage, to reduce the importance of son-preference and the patriarchal family structure.

Chronic energy deficiency in mothers can cause excessive in child mortality rates. In developing countries low energy intake of women is common, particularly during pregnancy and lactation, and the high incidence of low birth weight infants and growth faltering at an early age has been attributed to maternal undernutrition (Kramer, 1987). Maternal undernutrition in poor communities has been perpetuated for many generations, and recently the body mass index (BMI) has been introduced to define chronic energy deficiency (Ferro-Luzzi et al., 1992). The BMI measures the body fat based on height and weight that apply to both adult men and women. Three grades of BMI were suggested to categorize chronic energy deficiency as mild (17.0-18.4), moderate (16.0-16.9) and severe (<16.0), (grade I, grade II and grade III respectively).

The limitation of research on maternal nutrition is its almost exclusive preoccupation with infant outcomes: birth weight, breast milk production and infant

\footnotetext{
${ }^{50}$ The standard of living index is a composite index calculated by the International Institute of Population Sciences and ORC Macro and is based upon household ownership of possessions/consumer durables and land/livestock. An exhaustive explanation of the index is in Mohamed, Barriere and Otto (1997).
} 
growth (Kramer 1987). Little consideration is given to the repercussions of reproduction on maternal nutritional status and vice versa. In our sample, average mother body mass index is 19.9, but for younger mothers (under 20) this index indicates on average a mild undernutrition for mothers.

Characteristics indicating the independence of women are their capacity to set money aside and their degree of freedom to go to the market. Only $55.2 \%$ of the women interviewed are allowed to have their own savings. A quarter of the women interviewed can go to the market without the permission of their husband or the male head of the household, while $74 \%$ has either to ask permission or is not allowed to go at all. This degree of freedom could have an impact on the household decision processes in which the mothers are usually involved, resulting in positive outcomes for children (i.e., decisions on what to cook, etc.).

Other than private income, mother's education is considered in the literature to be the most important variable in influencing fertility decisions and child mortality. Lagerlof (2003) argues that higher education for girls increases the opportunity cost for women to have children especially if they have the opportunity to work, and that this eventually reduces fertility. This link between female education and fertility decline is now recognized worldwide. The relation between maternal education and child mortality, however, requires further investigation (Murthy et al., 1995). What seems obvious is that educated women are likely to be more knowledgeable about nutrition, hygiene and health care. This aspect of maternal education may be particularly significant given the uninformed and deficient nature of child care practices in large parts of rural India. In our sample more than $50 \%$ of the mothers interviewed had no education, $16.1 \%$ primary, $22.1 \%$ secondary and less than $8 \%$ higher education.

Women's participation in the labor force is another variable considered very important for child survival. Involvement in gainful employment often enhances effectiveness of women's agency roles in society and family, including those connected with child care. In our sample, one third of the women work. This is a very low percentage compared to other countries in the region.

The exposure to media is a variable that provides information on maternal seclusion. Programming on radio and TV includes government programs to inform people on important health and social issues, for example child vaccination. Over $40 \%$ of the sample did watch TV or listen to the radio at least once a week. 
In addition to these characteristics of mothers, we need to investigate variables of access to medical care during the pregnancy. Unfortunately most variables commonly used in the literature are recorded only for some mothers in our dataset. We limit the analysis using the number of antenatal visits and the number of tetanus vaccination during the pregnancy for mothers. We notice on average that mothers were visited less than three times during their pregnancy.

\section{Father characteristics}

There is a large literature showing that higher male education neither improves child nutrition nor reduces fertility. It actually seems that husband's occupation could have an impact on fertility decisions. For example, farmers may desire more child labour for faming or for work in domestic industry, cheap child labor is requested. In developing societies where children are valuable means of insurance in old age and there is no widespread or national system of social security, this may result in easy and near universal marriage (Das Gupta 1999). ${ }^{51}$ There is little evidence in the literature on the impact of father characteristics on on mortality.

Concerning father education level and labor participation we find the following: $29 \%$ had no education, $18 \%$ primary education, $37 \%$ secondary and $16 \%$ higher. The percentage of fathers working is very high at $98.3 \%$.

Investigating the characteristics of children, we notice that on average in our sample each family has fewer less than three children. The percentage of twins is extremely low at less than $1.5 \%$.

Many authors find empirical evidence for birth spacing influencing child survival (Das Gupta, 1990). The claim is that an increase in succeeding birth intervals improves children survivals. This might indicate that birth of a new child shifts a significant proportion of the household resources away from the older children to the younger (Makepeace and Pal, 2001). In our sample we find that the average birth interval is little less than 3 years in India.

\footnotetext{
${ }^{51}$ It is interesting to investigate the reasons given by population to have children. There is a study conducted in Karnataka (southern Indian state) showing that $32 \%$ of the family want to have a child for insurance purposes, $24 \%$ want to have a child of opposite sex to existing children, $10 \%$ to provide help to their mothers. Iyer (2002) shows that in Ramanagaran, in the southern Indian state of Karnataka, the 201 rural women interviewed recognized the need for children especially to contribute to the household's activities or insurance in old age, but they realize that the additional child would be expensive to rear and this cost would be especially high if they have a daughter.
} 
Table 2.2 Descriptive Statistics (mean and standard deviation, based on the sample of ever married women that have at least one child under age 5)

\begin{tabular}{|c|c|c|}
\hline Variables & mean & Sd \\
\hline \multicolumn{3}{|l|}{ Household Characteristics } \\
\hline Rural & 0.746 & 0.436 \\
\hline Urban & 0.254 & 0.436 \\
\hline Hindu & 0.741 & 0.438 \\
\hline Muslim & 0.148 & 0.356 \\
\hline Christian & 0.066 & 0.248 \\
\hline Sikh & 0.020 & 0.141 \\
\hline Household low index of living standard & 0.339 & 0.473 \\
\hline Household middle index of living standard & 0.483 & 0.5 \\
\hline Total number in the household & 7.575 & 3.87 \\
\hline Number of women eligible in the household & 1.425 & 0.784 \\
\hline Woman head of the household & 0.064 & 0.244 \\
\hline Age of the head of the household & 43.029 & 14.832 \\
\hline Total number of Children & 2.974 & 1.668 \\
\hline \multicolumn{3}{|l|}{ Mother Characteristics } \\
\hline Body mass index & 19.891 & 3.096 \\
\hline Age at first marriage & 17.277 & 3.268 \\
\hline Age at first birth & 24.443 & 5.423 \\
\hline Allowed to set money aside & 0.552 & 0.497 \\
\hline Allowed to go to the market & 0.256 & 0.436 \\
\hline No education & 0.544 & 0.498 \\
\hline Primary education & 0.161 & 0.368 \\
\hline Secondary education & 0.221 & 0.415 \\
\hline Work & 0.342 & 0.474 \\
\hline Watch TV weekly & 0.411 & 0.492 \\
\hline Listen to radio weekly & 0.335 & 0.472 \\
\hline \multicolumn{3}{|l|}{ Maternal Child care } \\
\hline Antenatal visit (number) & 2.826 & 3.229 \\
\hline Tetanus vaccination while pregnant (number) & 1.636 & 1.141 \\
\hline \multicolumn{3}{|l|}{ Father characteristics } \\
\hline No education & 0.289 & 0.453 \\
\hline Primary education & 0.183 & 0.387 \\
\hline Secondary education & 0.365 & 0.481 \\
\hline Work & 0.983 & 0.13 \\
\hline \multicolumn{3}{|l|}{ Child and Childbirth characteristics } \\
\hline Female & 0.480 & 0.5 \\
\hline Twin & 0.015 & 0.12 \\
\hline Previous birth interval & 34.158 & 19.232 \\
\hline
\end{tabular}

Source: Authors computation based on NFHS 1998-99

Child characteristics 
Becker (1991) argues that if households are subject to credit constraints, competition among siblings for limited resources may give rise to parental preferences for certain children over others. The existence of bias in the allocation of critical lifesustaining resources has micro-foundations in the household-level evaluations of the relative worth of female versus male children. To the extent that the value of a male child is perceived to be greater than that of a female, scarce life-sustaining resources are likely to be disproportionately allocated to male rather than female children (Kishor 1995). The question arises whether the availability of resources to the household will influence their allocation. Making life-sustaining resources less scarce will diminish the economic need to discriminate in their allocation. Nonetheless, if the economic and cultural worth of female children is found to be inversely related to the number of siblings, and more particularly to having older sisters, this is going to have an effect on their survival rates. In our model, we investigate whether girls with older sisters are discriminated against in particular in the allocation of limited life-sustaining resources.

\section{Variations across states in India}

The regional variation in our sample is very large. In the south of India consanguineous unions are quite common even today, while in the north they are not, and religion may be a factor influencing consanguineous relationships (Iyer 2002). The economic theory behind this practice is to minimize risk by retaining income strictly within the family, as well as facilitating better opportunities to monitor the behavior of family members. It also reduces the need for paying dowry. In general it appears that women are perceived in better terms in south India than in the northern states. This has been attributed not only to marriage practices but also to the nature of social organization in south India where female education rate is higher, women have more autonomy and mobility, and largely proactive regional governments have taken a deep interest in promoting literacy and a small family ideal. In fact, those governments have recognized those two subjects as key potentials for growth.

Our sample reveals clear regional patterning of gender differences in girls' mortality: excess female mortality is greatest in the north and central states. There is not only a large variation in gender differences in mortality across states but also in the actual levels of female and male mortality. To capture the state variation in child mortality, we use states dummies in our model. 


\subsection{The Empirical Model}

The econometric method used is a hazard regression model. The main objective of this econometric hazard analysis is to understand the relative impact of a set of explanatory variables in determining child survival in India. Moreover, we are interested in investigating whether or not the sibling composition has an impact on girls' mortality.

A very popular hazard method widely used in demographic studies, as well as in biomedical and econometric duration applications, is the Cox proportional hazards model (Cox, 1972). The Cox proportional hazard model is a semi-parametric model that postulates that the logarithm of the hazard function is a linear function of the covariates:

$$
h(t / z)=h_{0}(t) * \exp \left(\beta^{\prime} z\right)
$$

Where $h(t / z)$ is the hazard function at time t, given a vector of covariates $\mathrm{z}, h_{0}(t)$ the baseline hazard and the $\beta$ coefficients are estimated from the data.

Cox's method does not assume particular distribution for the survival times, it could be constant, increasing, decreasing or anything else we can imagine, but it is assumed that whatever the shape, it is the same for everyone. The effects of the different variables on survival are constant over time and are additive in a particular scale.

The advantage of the semi-parametric Cox model is that we do not need to make assumptions about the hazard baseline, $h_{0}(t)$, assumptions about which we may be wrong and which, if we are wrong, could produce misleading results. On the other hand, the cost is loss in efficiency; if we knew the functional form of $h_{0}(t)$, we could definitely do a better job of estimating $\beta$.

The $\beta$ regression coefficients for each explanatory variable in the model (i.e., mother and father education, sibling composition, sex of the child etc.) give the proportional change that can be expected in the hazard related to changes in the explanatory variables (estimated using maximum likelihood). There is the obvious need to test the assumption of a constant relationship between the dependent variable and the explanatory variables, the so-called proportional hazards assumption.

Interpreting a Cox model involves examining the coefficients of each explanatory variable, where a regression coefficient with a positive sign for an explanatory variable means that the hazard is higher for higher values of the explanatory variable and vice versa 
for a negative sign. ${ }^{52}$ For simplicity in the estimation, in Table 2.3 we present the results directly after computing the exponential factor: in other words, we present the hazard ratio directly.

Table 2.3 Proportional Hazard model

\begin{tabular}{|c|c|c|c|c|c|c|}
\hline & $\begin{array}{c}\text { Hazard } \\
\text { Ratio }\end{array}$ & $\begin{array}{l}\text { Std. } \\
\text { Err. }\end{array}$ & $\mathrm{P}>|\mathrm{z}|$ & $\begin{array}{c}\text { Hazard } \\
\text { Ratio }\end{array}$ & $\begin{array}{l}\text { Std. } \\
\text { Err. }\end{array}$ & $\mathrm{P}>|\mathrm{z}|$ \\
\hline \multicolumn{7}{|l|}{ Household Characteristics } \\
\hline Rural & 1.094 & 0.116 & 0.398 & 1.097 & 0.116 & 0.384 \\
\hline $\begin{array}{l}\text { Household low index of living } \\
\text { standard }\end{array}$ & 1.369 & 0.226 & 0.057 & 1.371 & 0.226 & 0.056 \\
\hline $\begin{array}{l}\text { Household middle index of living } \\
\text { standard }\end{array}$ & 1.288 & 0.188 & 0.083 & 1.286 & 0.188 & 0.085 \\
\hline Total number in the household & 0.827 & 0.018 & 0 & 0.827 & 0.018 & 0 \\
\hline $\begin{array}{l}\text { Number of women eligible in the } \\
\text { household (over 18) }\end{array}$ & 1.985 & 0.133 & 0 & 1.986 & 0.133 & 0 \\
\hline Woman head of the household & 0.818 & 0.127 & 0.194 & 0.815 & 0.126 & 0.186 \\
\hline Age of the head of the household & 1.009 & 0.003 & 0.001 & 1.009 & 0.003 & 0.001 \\
\hline \multicolumn{7}{|l|}{ Mother Characteristics } \\
\hline Allowed to set money aside & 1.094 & 0.077 & 0.2 & 1.092 & 0.077 & 0.213 \\
\hline Body mass index & 1.033 & 0.012 & 0.007 & 1.033 & 0.012 & 0.007 \\
\hline Allowed to go to the market & 0.835 & 0.075 & 0.045 & 0.835 & 0.075 & 0.045 \\
\hline No education & 1.437 & 0.393 & 0.185 & 1.441 & 0.394 & 0.182 \\
\hline Primary education & 1.312 & 0.356 & 0.317 & 1.313 & 0.356 & 0.316 \\
\hline Secondary education & 1.253 & 0.328 & 0.389 & 1.253 & 0.328 & 0.389 \\
\hline Work & 1.082 & 0.082 & 0.298 & 1.081 & 0.082 & 0.299 \\
\hline Watch TV weekly & 0.911 & 0.084 & 0.312 & 0.912 & 0.084 & 0.318 \\
\hline Listen to radio weekly & 0.97 & 0.083 & 0.725 & 0.968 & 0.083 & 0.706 \\
\hline \multicolumn{7}{|l|}{ Health status of the mother } \\
\hline Antenatal visit & 0.974 & 0.035 & 0.462 & 0.975 & 0.035 & 0.48 \\
\hline $\begin{array}{l}\text { Tetanus vaccination while } \\
\text { pregnant }\end{array}$ & 0.895 & 0.039 & 0.011 & 0.895 & 0.039 & 0.012 \\
\hline \multicolumn{7}{|l|}{ Father characteristics } \\
\hline No education & 1.341 & 0.199 & 0.048 & 1.34 & 0.199 & 0.049 \\
\hline Primary education & 1.259 & 0.193 & 0.134 & 1.26 & 0.194 & 0.132 \\
\hline Secondary education & 1.322 & 0.183 & 0.043 & 1.325 & 0.183 & 0.042 \\
\hline Work & 1.051 & 0.272 & 0.849 & 1.041 & 0.27 & 0.878 \\
\hline \multicolumn{7}{|l|}{ Child characteristics } \\
\hline Female & 1.138 & 0.074 & 0.048 & 0.913 & 0.115 & 0.467 \\
\hline Twin & 5.351 & 0.861 & 0 & 5.332 & 0.857 & 0 \\
\hline Has older brother & 1.12 & 0.093 & 0.17 & 1.12 & 0.093 & 0.172 \\
\hline Has older sister & 1.133 & 0.095 & 0.138 & 0.973 & 0.107 & 0.804 \\
\hline Previous birth interval & 0.982 & 0.003 & 0 & 0.982 & 0.003 & 0 \\
\hline \multicolumn{7}{|l|}{ Interaction term } \\
\hline Girl having an older sister & & & & 1.352 & 0.199 & 0.04 \\
\hline Regional Dummies & YES & & & YES & & \\
\hline
\end{tabular}

${ }^{52}$ Exponential individual coefficients have the interpretation of the ratio of the hazards for a one-unit change in the corresponding covariate for continuous explanatory variables. 
$\underline{\text { Test }}$

Prior to estimating the hazard model of child survival, there is the need to test the validity of the proportionality assumption for covariates that are likely to have a significant effect on child mortality and for which the proportionality assumption seems to be a restriction. We tested, in particular, for equality and proportionality of hazards with respect to several dichotomous covariates (our variables of particular interest, sex of the child, state of residence, asset classes and education level) and continuous covariates (total household members, number of women in the household). What we found is that the hypothesis of proportionality assumptions for covariates cannot be rejected.

In addition we tested that we adequately parameterized the model, and we ensure that we chose a good specification for the estimation. In general for specification tests, one searches for variables to add to the model. Under the assumption that the model is correctly specified, adding new explanatory variables will add little or no explanatory power to the model and, therefore, one tests that these variables are "insignificant." Tests of the proportional hazards assumption also follow that scheme.

Grambsch and Therneau (1994) use a specific method for checking the proportional hazards assumption. This method is based on analysis of residuals where the idea is to retrieve the residuals, fit a smooth function of time to them and then test whether there is a relationship and that the log hazard function is constant over time. Thus rejection of the null hypothesis indicates a deviation from the proportional hazards assumption. ${ }^{53}$ The validity of the proportional hazards assumptions for the overall goodness-of-fit of the estimated models can be judged using the test by Grambsch and Therneau (1994) based on adjusted Shoenfeld residuals (1982). ${ }^{54}$ The test shows that we chose a good specification for the estimation.

\subsection{Results}

Our analysis investigates whether a specific explanatory variable increases or decreases the hazard of mortality of children and to what extent. The estimated models include a large number of explanatory variables that can be categorized as follows:

Dousehold characteristics (rural or urban residence and household wealth)

\footnotetext{
${ }^{53}$ Stata stphtest command is based on the generalization by Grambsch and Therneau (1994). This test assumes homogeneity of variance across risk sets.

${ }^{54}$ See Global Test in STATA for results please contact the author.
} 
Household composition (number of eligible ${ }^{55}$ women in the household, sex and age of head of the household)

> Mother characteristics (index of nutritional status, education level, exposure to media, access to labor force, freedom of movement)

$>$ Maternal child care (number of antenatal visits and tetanus vaccination during pregnancy)

$>$ Husband characteristics (education level and labor force participation)

$>$ Children and childbirth characteristics (existence of twin, older brother or sister, birth interval with the previous sibling and sex of the child) ${ }^{56}$

All models were tested and passed the proportional hazards and omitted variables tests. Table 2.3 shows the results of the two Cox-proportional hazard models reporting the hazard ratio, standard error and p-value. This section reports the estimates of the econometric hazard model for child mortality, presenting the results by categories of explanatory variables.

In our estimation wealth and income effects on girls' and boys' mortality in India are big; not only for poor households but also for middle class households that still face a hazard rate $29 \%$ higher than the remaining population. Poor families with few resources cannot afford to provide proper food and clothes, health coverage and education to either their girls or to their boys ${ }^{57}$. On the other hand, households with more resources could make deliberate decisions on how to allocate those resources (Murthi, Guio and Dreze 1995).

The increasing number of household members and the existence of a female head of household decrease the hazard rate of dying. Nonetheless, an increasing number of eligible women in the household seems to increase the hazard rate drastically.

\section{Parental characteristics}

Mother's characteristics play a very significant role in explaining child mortality in India. A larger body mass index and the independence of the mother (expressed by the freedom of going to the market) appear to have an impact on the survival probability.

\footnotetext{
${ }^{55}$ Eligible women refer to female aged 15-49 who slept in the house the night previous the interview.

${ }^{56}$ In all regressions we control for state variation, adding to the model state dummies.

${ }^{57}$ Differently from Oster 2009, we find a monotonic relationship betwee health and gender bias in mortality.
} 
There is some evidence in the literature that higher status of women relative to men may contribute to an equitable allocation of resources. Maternal education is considered by the majority of the authors working on demographic transition to be the driving variable for changes. Literacy of women, marriage patterns, female labor force participation and fertility are all related to one another and to female autonomy. The more literate a woman, the higher the age at marriage and, in general, the lower the required dowry and associated marriage costs. Most of these variables have reciprocal relationships with female autonomy, and this female autonomy is likely to reflect the higher worth of females in society with consequent results for female survival (Kishor, 1995).

In our model we notice that mothers' education does not have a significant impact on child survival.

Murthi et al. (1995) interestingly find empirical evidence that female literacy, education and labor force participation not only increased women's empowerment but also reduced gender bias in mortality in India. They conclude their analysis by highlighting that education is the most powerful influence and the engine of immediate change in child mortality among social factors. This observation could be fundamental for Indian policy initiatives aimed at reducing gender differentials in child mortality. In our work, however, once we introduce an interaction variable between education and gender we find no significant evidence on girls' survival. ${ }^{58}$ Our model does indicate that having an illiterate father increases child hazard by 34\%.

Concerning maternal health care and children's characteristics, our model shows that mothers who took prenatal tetanus vaccinations have much lower child mortality rates. Other variables of mothers' health were excluded from the model because of data availability.

\section{Children's characteristics}

Birth interval is another variable that the literature has used extensively to explain higher rates of mortality within households. We find that longer intervals between births increases survival chances of children. In contrast, being a girl, having a twin brother or having sisters has a large negative impact on the survival chances of the child. ${ }^{59}$

Our model shows drastic discrimination against girls. Their hazard rate is over $13 \%$ higher than boys. Particularly we find that girls' survival chances are lower if they have an

\footnotetext{
${ }^{58}$ If interested in these results contact the author at flamanna@worldbank.org.

${ }^{59}$ Only less than $1.5 \%$ of our sample has a twin brother or sister.
} 
older sister (see interaction variable in column 4); in fact, girls with older sisters are $23 \%$ more likely to die before reaching age five. ${ }^{60}$

\section{$\underline{\text { Variations across states }}$}

In order to capture state differentials in child mortality, we introduced state dummies in our model. Results reflect the relative advantage of children living in one state over another, suggesting that in some states health access, hygienic habits and nutrition levels are negatively affecting child mortality. The extreme cases are Meghalaya, Haryana, Madhya Pradesh and Uttar Pradesh ${ }^{61}$ where mortality chances are seven to eight times higher than in Kerala. ${ }^{62}$

\subsection{Conclusion}

The childhood mortality data shows a declining trend in India. Previous demographic and economic research investigating child mortality and gender differentials in child mortality used small sample sets confined to some districts or regions of India. This paper is a first attempt to use a rich microdataset on mortality outcomes of children that covers the entire country.

In this paper using a Cox proportional hazard model, we investigate the determinants of under-five girls and boys' mortality rates in India. The results indicate that children born in households that are poorer, with a large number of eligible women, where the birth intervals are low, with little maternal autonomy and low access to prenatal services are at higher risk of death during their first five years of life than other children.

Above all, being born female bestows a major social disadvantage for childhood mortality. Having an older sister exacerbates this difference in mortality rates. To witness not only major reductions in under-five mortality rates but also an improvement in gender bias in mortality in India in the near future, the country requires major policy thrusts in the areas of female empowerment and female socio-economic independence.

\footnotetext{
${ }^{60}$ Those numbers refers to the linear combination of sex and having an older sister in the empirical estimations processed in STATA, where the combination is highly significant.

61 Those differences are significantly big and an interesting follow up paper could consider to further investigate state and regional variance in child and especially in girls mortality.

${ }^{62}$ Kerala is the omitted state in our model since it is considered to be the most developed state with respect to all socio-economic indicators. If interested in having the coefficients of the state dummies, contact the author.
} 
State variations appear to be a very important point of consideration when investigating child mortality in India. States like Uttar Pradesh experience much higher mortality rates than Kerala, specifically higher girls’ mortality rates.

Beside intervention programs focused on high-risk groups, other policies may be effective in increasing child survival and in reducing the gender gap in mortality in India. Gender differentials seem to respond favourably to changes in the status of women relative to men. Special attention should be given to specific states that appear to experience excessive child and, in particular, girls’ mortality rates.

\section{Issues for further investigation and policy options}

In South Asia, evidence of discrimination in feeding practices and nutrient allocation within the family certainly exists. Nutrient allocation is certainly problematic under conditions of scarcity, but no consistent allocative pattern emerges, even within the large class of the poor in times of scarcity. Instead, the gender impact of discrimination, its social incidence and severity all vary regionally through the subcontinent. Further investigation of the reasons for the apparent great diversity of allocative practices is necessary.

What seems to vary in India is the modus operandi of the patriarchy among classes, household composition, education level and different regions. The problem with gender bias in mortality is not only biological. It can be explained by gender differences in access or entitlement to health care, as well as by access or entitlement to nutrients. It is a social relationship affected by material carier the content of which is undergoing change. There is the need, therefore, to have gender specific plans to improve the chances for survival of girls. These plans should include nutritional education aimed at mothers with advocacy for gender neutral or positively discriminating nutritional therapy; an increase in the economic status of women; improvements in women's education and an increase in the aggregate household food supply through the public administration system.

State intervention should also play an important role in India to reduce child mortality and to close the existing gap between sons' and daughters' mortality. If for instance, the state had to provide free access to healthcare and nutrition, the need to ration scarce resources would lessen; in the framework of our model, this intervention should lead to an increase in child survival rate. On the other hand, if the aim of policy makers is to intervene in the existing gender gap in mortality, activist state policy should be designed 
and implemented in female education and employment. Further investigation is needed in this direction. 


\section{Chapter 3. Gender inequality in Health Care Utilization in India between 1986 and 1996: Is there any Progress? ${ }^{63}$}

\section{Abstract}

In the paper we show that the health care utilization of girls had shown significant improvements between 1986 and 1996 using the $42^{\text {nd }}$ and $52^{\text {nd }}$ Indian National Sample Surveys. The probability of girls getting medical help during illness and the amount of health care expenditure devoted to girls both in absolute terms and in relation to boys during the time under consideration improved drastically. These results indicate that the increase in return on investment for girls in the past decades lead to a different household behaviour with respect to health care utilization in India. The paper also shows that there is a large variance in the improvement in health care utilization for girls across the country, with some States showing little improvement and some other, particularly in the south drastic improvements. Those findings urge policy makers to focus on strategies that will increase homogeneously across India the return on investment for women.

\subsection{Introduction}

Studies from demographers, physicians, epidemiologists, and other disciplines have shown that women have inherent biological and behavioural advantages of living longer than men at all age levels in the same socio-economic environment (Hart, 1988; UNDP, 1995; Waldron, 1995; WHO, 1998; Gjonca et al., 1999; Kalben, 2002). This fact is known since 1750 when mortality rates were computed from the first Swedish national census (Kalben, 2002). It has also become clear that an improvement in social, cultural, and economic conditions enhances this biological advantage of women (WHO, 1998). Results from developed countries also show that women have lower mortality rates than men at all age levels. Gjonca et al (1999:1-2) show that 'infant and childhood mortality is

\footnotetext{
63 This chapter is co-authored with PhD Abay Asfaw, Ministry of Agriculture, United States and Professor Stephan Klasen, University of Goettingen, Germany.
} 
higher for boys than for girls, and these higher death rates for males continue throughout their entire life span'.

However, this biological advantage of women could not be realised in South Asian countries. Various researchers, using different demographic techniques, have shown that the sex ratio ((total male population/total female population) $\times 100$ ) in India is one of the highest in the world. For instance, the sex ratio at the beginning of the twentieth century was 103 and it increased to 107 in 1981, while the ratio was decreasing elsewhere (Sen, 1988). It is generally hypothesised that this higher than demographically normal sex ratio in South Asian countries including India reflects social, cultural, familial, behavioural, and other discriminatory behaviour of households, communities, and sometimes governments against girls and women. It also exposes the discriminatory practices of the society against women in these parts of the world (Sen, 1989). Das Gupta \& Mari Bhat (1997) studied the relationship between fertility decline and gender bias in child mortality, showing the increasing evidence for the spread of sex-selective abortion, especially among women with lower fertility.

Between 1986 and 1996, the sex ratio for children under 10 has shown a significant improvement in India ${ }^{64}$. It declined from 110 in 1986 to 108 in 1996. This pattern is observed almost in all different age categories of children (0-1, 2-4, and 5-9 years). The sex ratio has declined from 117 to 107 and from 109 to 105 in the age groups 0-1 and 1-4 years, respectively, during the time under consideration.

Various factors may explain the sex ratio decline in the country. Large progress was made in increasing education and employment opportunities for women in India in that decade. The return on investment for girls increased largely and this is automatically reflected in a different behavior of household towards girls and therefore in a decline in sex ratio.

In this study, we show that the increased return on investment for girls can lead to a significant reduction in health care utilization disparities between boys and girls and to a decline in sex ratio. To verify our argument, we examine if there was a reduction in health care utilization disparities between girls and boys during the time under consideration.

\footnotetext{
${ }^{64}$ Analysis based on the $42^{\text {nd }}$ and $52^{\text {nd }}$ Indian National Sample Survey (NSS). Using the census data results are different (Klasen and Wink, 2002 and 2003).
} 


\subsection{Methods}

Various methods can be used to examine the pattern of gender inequalities in health care demand behavior of households and consequently on the utilization of health care services between boys and girls. In this study, we use two different methods to examine such trends between 1986 and 1996. First, we use the need-standardized method developed by Wagstaff, et al. (1991), and Wagstaff \& Doorslaer (2000) to examine whether boys and girls are treated equally in getting medical care given illness. This method helps us to examine how children get equal treatment for equal medical 'need', regardless of their sex, location, income of their parents, etc., in 1986 compared to that of 1996. One major problem in such analysis is finding a good proxy to measure 'need'. In the literature demographic and morbidity variables are used as indicator of need (Wagstaff \& Doorslaer, 2000). In this study, we use age and severity of illness as a proxy for need. Since we are measuring gender inequity in health care utilization of children given illness, these variables are expected to be a good proxy for need.

We use indirect standardization method using linear and non-linear regression models to examine the distribution of health service utilization in the absence of differences in need factors between girls and boys (O’Donnel, et al. 2008). For linear specifications, the following model can be used.

$$
y_{i}=\alpha+\sum_{j} \beta_{j} x_{j i}+\sum_{k} \gamma_{k} z_{k i}+\varepsilon_{i}
$$

where $y_{i}$ is the health service utilization indicator of child $i, x_{j i}$ is need indicator $j$ of child $i$, and $z_{k i}$ is non-need indicator $k$ of child $i$ and $\varepsilon_{i}$ is a random error term with zero mean and constant variance.

Then, the predicted or 'x-expected' $\left(\hat{y}^{x}{ }_{i}\right)$ values of utilization of $y_{i}$ can be computed using the OLS coefficients of $\alpha, \beta$ and $\gamma$, the actual values of need variables, and the sample mean values of control (or non-need) variables as follows.

$$
\hat{y}_{i}^{x}=\hat{\alpha}+\sum_{j} \hat{\beta}_{j} x_{j i}+\sum_{k} \hat{\gamma}_{k} \bar{z}_{k}
$$

Then, the indirectly standardized utilization of health services can be computed as a difference between observed and expected utilization, plus the sample mean.

$$
\hat{y}_{i}^{I S}=\bar{y}+y_{i}-\hat{y}_{i}^{x}
$$

The difference between need-expected ('x-expected') and the actual health utilization variable $y$ between boys and girls measures the level of gender discrimination in the utilization of health care service $y$. 
The indirectly standardized health utilization variable can be used to compute concentration indices (CI) which measures horizontal inequality. In the case of non-linear models, marginal effects should be used to approximate need-expected values (see World Bank Technical Note \#13 for the details so as in O’Donnel, et al. 2008).

Second, we use bivariate and multivariate models to examine the effect of sex on probability of seeking medical care given illness between 1986 and 1996. It is hypothesized that the impact of sex on the various health care utilization indicators declines through time.

\subsection{Sources of Data and Measurement of Variables}

The data sources for this study are the Indian National Sample Surveys (NSS). The Indian NSS data are nationally representative data sets and collect information on socio-economic conditions of the population as well as on the economic and operational features of informal enterprises and establishments in the country (Saha, 2002). Since its inception in 1950, 56 country-wide NSSs focusing on different issues were collected. For this study we use the $42^{\text {nd }}$ (July 1986 to June 1987) and 52 ${ }^{\text {nd }}$ (July 1995 to June 1996) round surveys since they are exclusively devoted to health and related issues. The data sets contain extensive information on expenditure, pregnancies, mortality, ailments, immunization and other health care variables for children of age 0-4 years, maternity care and family planning services, utilisation of medical services, etc. for both rural and urban households. The $42^{\text {nd }}$ round covered 32,909 rural households in 48 sampled villages and 18,077 urban households in 104 sampled blocks in all states and union territories. In the $52^{\text {nd }}$ round, 71,269 rural and 49,654 urban households were surveyed. In this study, a total of 267493 (80745 from the $42^{\text {nd }}$ and 186750 from the $52^{\text {nd }}$ rounds) children younger than ten were considered.

Both the $42^{\text {nd }}$ and $52^{\text {nd }}$ rounds collected information on spells of ailments of household members during last 15 days, medial and non-medical expenses incurred for treatment, and sources of finance for treatment. The surveys also collected information on the incidence of hospitalization (inpatient care) during the last 365 days and on medical and non-medical expenses for each hospitalized patient. In this study, health care utilization is measured by visit to medical care given ailments during the last 15 days before the survey and by the amount of non-medical cost incurred for outpatient treatments given outpatient medical help and by non-medical inpatient expenditures given 
hospitalization. Since the physicians usually decide the type of medical tests to be carried out, the drugs to be used, the number of days to be hospitalized, etc., direct medical expenditures were not considered in the analysis. Appendix 1 presents the descriptive statistics of the variables used in the analysis.

\subsection{Patterns of Gender inequality in Health Care Utilization}

As it is the case in most developing countries, illness may not necessarily lead to demand for medical care in India owing to various reasons. First, some households who reported illness of children might not think that they need medical help. Second, even those households who perceived health problem of their children and the need for medical help might not be able to translate this need into effective demand. As a result, there can be variation between perceived illness and actual demand for health care. This discrepancy can have different effect on the probability of getting medical help between boys and girls if parents have special sex preference.

Both the $42^{\text {nd }}$ (conducted in 1986) and $52^{\text {nd }}$ (conducted in 1996) Indian NSSs collected information on whether each household member suffered from any ailment during last 15 days preceding the day of survey, and whether the ailment was treated or not. In 1986, out of 12,717 children who were sick, 85 percent got medical help. There was statistically significant difference in seeking medical help given illness between boys and girls. Only 83 percent of girls got medial attention given illness compared to 86 percent of boys and this difference was statistically significant (Chi2 $=23.64$ and significant at 0.00 level). This difference holds for all age categories as shown in Table 3.1.

After a decade, the proportion of children treated for sickness reported during the last 15 days before the survey increased by 1 percentage point to 86.21 percent. More interestingly, while the percentage of boys treated did not show significant change between 1986 and 1996, the percentage of girls treated increased by 2 percentage points from 83.24 to 85.25 percent. As Table 3.1 shows, this change was observed in almost all age categories, particularly in the infant age category. 
Table 3.1 Percentage of children treated for sickness reported during the last 15 days before the survey

\begin{tabular}{lllllll}
\hline \multirow{2}{*}{$\begin{array}{l}\text { Age } \\
\text { category }\end{array}$} & $\begin{array}{l}\text { Boys } \\
(\%)\end{array}$ & $\begin{array}{l}\text { Girls } \\
(\%)\end{array}$ & $\begin{array}{l}\text { Pearson } \\
\text { Chi }^{2}(\mathrm{pr} .)\end{array}$ & $\begin{array}{l}\text { Boys } \\
(\%)\end{array}$ & $\begin{array}{l}\text { Girls } \\
(\%)\end{array}$ & $\begin{array}{l}\text { Pearson } \\
\text { Chi }^{2}(\mathrm{pr} .)\end{array}$ \\
\hline 0-1 years & 89.8 & 86.7 & $7.27(0.01)$ & 90.67 & 88.28 & $4.90(0.03)$ \\
2-4 years & 86.01 & 82.75 & $9.1(0.00)$ & 86.65 & 84.22 & $3.39(0.07)$ \\
5-9 years & 84.37 & 81.64 & $6.59(0.01)$ & 83.45 & 83.22 & $0.02(0.86)$ \\
Total & 86.35 & 83.24 & $23.64(0.00)$ & 86.98 & 85.25 & $5.82(0.02)$ \\
\hline
\end{tabular}

Source: Computed form the $42^{\text {nd }}$ and $52^{\text {nd }}$ Indian National Sample Survey

Health expenses given illness

While expenses incurred for treatment of ailments such as purchase of medicines, diagnostic tests, consultation fees, etc., may not significantly vary by gender (since they usually depend on the decision of medical practitioners), expenses on other non-medical health expenses such as transport other than ambulance, lodging charges of escort(s), attendant charges, personal medical appliances, etc., can significantly vary by gender. In other words, the decision to buy non-medical services can be influenced by parental gender preferences.

\section{Out-patient non-medical health expenses}

Table 3.2 presents expenses related to non-medical health costs incurred for treatment of ailments (out-patient) by sex, age group, and year. In 1986, parents spent 28.7 percent more money for non-medical health expenditure of boys than for girls and this difference was statistically significant (F-test 11.77 and significant at 0.00 levels). As table 2 shows, this gender biased non-medical health expenditure was much higher in the infant age category (0-1) than in the other two age groups. Parents' non-medical spending for infant boys was 43.4 percent higher than for infant girls.

After ten years, this discrepancy has declined significantly and the amount of nonmedical out-patient health investment on boys was only 21 percent higher than that of on girls. This improvement was highly profound in the infant age group. Parents spent only 7 percent more for infant boys than for infant girls in 1996 and the difference was no longer statistically significant as shown in Table 3.2. 
Table 3.2 Non-medical out-patient health expenses (in Rupees.) for boys and girls

\begin{tabular}{lcccccc}
\hline Age category & \multicolumn{3}{c}{1986} & \multicolumn{2}{c}{1996} \\
\cline { 2 - 7 } & Boys & Girls & $\begin{array}{c}\text { ANOVA F-test } \\
\text { (pr.) }\end{array}$ & Boys & Girls & $\begin{array}{c}\text { ANOVA F-test } \\
(\mathrm{pr} .)\end{array}$ \\
\hline 0-1 years & 68.56 & 47.81 & $12.20(0.00)$ & 43.55 & 35.77 & $0.41(0.52$ \\
2-4 years & 70.32 & 56.3 & $2.38(0.12)$ & 36.86 & 34.18 & $6.86(0.00)$ \\
5-9 years & 71.51 & 57.47 & $3.61(0.05)$ & 43.34 & 30.16 & $1.10(0.29)$ \\
\hline Total & 70.29 & 54.63 & $11.77(0.00)$ & 52.33 & 42.58 & $0.63(0.42)$ \\
\hline \multicolumn{2}{l}{ Source $\cdot$ Computed form the $42^{\text {nd }}$ and $52^{\text {nd }}$ Indian National Sample Survey }
\end{tabular}

\section{In-patient non-medical health expenses}

Significant improvement was also observed in the amount of non-medical inpatient health expenses between 1986 and 1996 (see Table 3.3). Parents spent nearly 30 percent more on non-medial expenses for hospitalized boys than for hospitalized girls in 1986. This discrepancy, however, declined to 24.8 percent in 1996. Significant decline was observed again in the infant age groups as the table shows. While parents' nonmedical in-patient expenditure on infant boys was 102 percent higher than on infant girls in 1986, it declined to 22.8 percent in 1996.

Table 3.3 Non-medical in-patient health expenses (in Rs.) for boys and girls

\begin{tabular}{lllllll}
\hline Age category & 1986 & \multicolumn{5}{c}{1996} \\
\cline { 2 - 7 } & Boys & Girls & $\begin{array}{l}\text { ANOVA F- } \\
\text { test (pr.) }\end{array}$ & Boys & Girls & $\begin{array}{l}\text { ANOVA F- } \\
\text { test (pr.) }\end{array}$ \\
\hline 0-1 years & 155.61 & 77.75 & $5.76(0.00)$ & 210.03 & 171.00 & $1.07(0.30)$ \\
2-4 years & 145.79 & 91.43 & $3.38(0.00)$ & 307.35 & 206.24 & $3.30(0.06)$ \\
5-9 years & 256.22 & 241.27 & $0.01(0.90)$ & 293.04 & 252.63 & $0.92(0.33)$ \\
\hline Total & 191.80 & 147.83 & $0.72(0.30)$ & 273.89 & 219.52 & $4.12(0.04)$
\end{tabular}

Source: Computed form the $42^{\text {nd }}$ and $52^{\text {nd }}$ Indian National Sample Survey

\section{$\underline{\text { Patterns across states }}$}

Significant variation was observed in the proportion of girls who got medical help given illness compared to boys across states. The first two columns of Table 3.4 present the ratio of the percentage of boys (compared to girls) treated for sickness reported during the last 15 days before each survey by state. The third column gives the percentage change. Negative values indicate an improvement in the proportion of girls treated compared to boys during the time under consideration. States such as Orissa, Assam, Madhya Pradesh, Uttar Pradesh, Jammu Kashmir, Tamil Nadu, and Maharashtra have 
shown significant improvement in the proportion of girls treated compared to boys between 1986 and 1996.

Table 3.4 Patterns of access to health care and sex ratio in 1986 \& 1996 by state

\begin{tabular}{|c|c|c|c|c|c|c|}
\hline \multirow[t]{2}{*}{ State } & \multicolumn{3}{|c|}{$\begin{array}{l}\text { Ratio of percentage of boys } \\
\text { treated compared to girls }\end{array}$} & \multicolumn{3}{|c|}{$\begin{array}{c}\text { Child sex ratio } \\
\text { (number of boys/number of } \\
\text { girls) } * 100\end{array}$} \\
\hline & 1986 & 1996 & $\begin{array}{l}\text { \% change: } \\
\text { (1996- } \\
1986) / 1986\end{array}$ & 1986 & 1996 & $\begin{array}{l}\text { \% change: } \\
(1996- \\
1986) / 1986\end{array}$ \\
\hline Rajasthan & 1.00 & 1.03 & 2.30 & 125 & 112 & -10.40 \\
\hline Orissa & 1.00 & 0.86 & -14.00 & 111 & 100 & -9.91 \\
\hline Kerala & 1.00 & 1.00 & 0.00 & 111 & 102 & -8.11 \\
\hline Gujarat & 0.99 & 1.06 & 7.07 & 116 & 107 & -7.76 \\
\hline Assam & 1.07 & 0.97 & -9.35 & 127 & 119 & -6.30 \\
\hline Maharashtra & 1.05 & 1.02 & -2.86 & 108 & 103 & -4.63 \\
\hline $\begin{array}{l}\text { Madhya } \\
\text { Pradesh }\end{array}$ & 1.11 & 1.03 & -7.21 & 109 & 106 & -2.75 \\
\hline Tamil Nadu & 1.03 & 1 & -2.91 & 107 & 105 & -1.87 \\
\hline Karnataka & 0.97 & 0.98 & 1.03 & 103 & 102 & -0.97 \\
\hline $\begin{array}{l}\text { Jammu } \\
\text { Kashmir }\end{array}$ & 1.01 & 0.97 & -3.96 & 108 & 107 & -0.93 \\
\hline Uttar Pradesh & 1.06 & 1.01 & -4.72 & 112 & 111 & -0.89 \\
\hline West Bengal & 1.01 & 1.01 & 0.00 & 105 & 105 & 0.00 \\
\hline $\begin{array}{l}\text { Himachal } \\
\text { Pradesh }\end{array}$ & 0.97 & 1.03 & 6.19 & 106 & 106 & 0.00 \\
\hline Haryana & 0.99 & 0.99 & 0.00 & 109 & 110 & 0.92 \\
\hline Tripura & 0.99 & 1.22 & 23.23 & 106 & 112 & 5.66 \\
\hline Punjab & 1.03 & 1.04 & 0.97 & 112 & 124 & 10.71 \\
\hline
\end{tabular}

Source: Computed form the $42^{\text {nd }}$ and $52^{\text {nd }}$ Indian National Sample Survey

As shown in the last three columns of the table, these states have also achieved significant reduction in their child sex ratio during the time under consideration. States such as Kerala, Rajasthan, etc., who have achieved equal access of health care to both boys and girls have significant improvement in child sex ratio. Interestingly, states with high gender discrimination in getting medical help or states who did not achieve significant improvements in the proportion of girls treated compared to boys such as Punjab, Himachal Pradesh, Haryana, and Tripura did not show a reduction in the child sex ratio during the time under consideration. 


\subsection{Econometric Analysis}

We use equations (1) and (2) to estimate need-based health care utilization by boys and girls including probability of getting medical help given illness, the amount of nonmedical money spent for outpatient care given visit, and the amount of non-medical money spent for inpatient care given hospitalization in both rounds (for the need-based methodology see O’Donnel, et al. 2008). Age categories (0-1, 2-4, and 5-9) and severity of illness measured by the number of days ill before getting medical treatment (in outpatient case) and number of days hospitalized (in in-patient case) were used as need indicator variables. We use three indicators: the probability of getting medical help given illness, the amount of non-medical health expenditure for out-patient visit, and the amount of nonmedial expenditure for in-patient visit. The whole results are presented in Appendix 2.

First, let us start with the probability of getting medical help given illness. For the sake of clarity, results relating to actual and need based probability of getting medical help given illness are presented in Figure 3.1 separately for boys and girls and for 1986 and 1996. As the first panel of Figure 3.1 shows, on the average, the probability of girls to get medical care given illness was 1.5 percent less than would be expected based on their need in 1986 (the square point). On the other hand, the probability of boys to get medical help given illness was 1.1 percent higher than their expected need in the same year. Interestingly, significant improvements were observed in the probability of girls to get medical help in 1996 both in absolute and in relative terms.

After a decade, the difference between actual visit and need-predicted probability of getting medial care declined (in absolute terms) from 1.5 percent to 0.9 percent (the triangle point). At the same time, the probability of boys to visit medial service providers more than their expected need shrank from 1.1 percent to 0.7 percent. This implies that the difference between the actual visit and need-predicted probability declined by $40 \%$ for girls. During the same period, the excess (in comparison to their need) probability of boys to get medical care shrunk by 36 percent. This shows that during the time under consideration, the probability of girls to get medical care had improved both in absolute terms and in comparison to that of boys. 
Figure 3.1 Difference between actual and need based probability of getting medical help for girls and boys

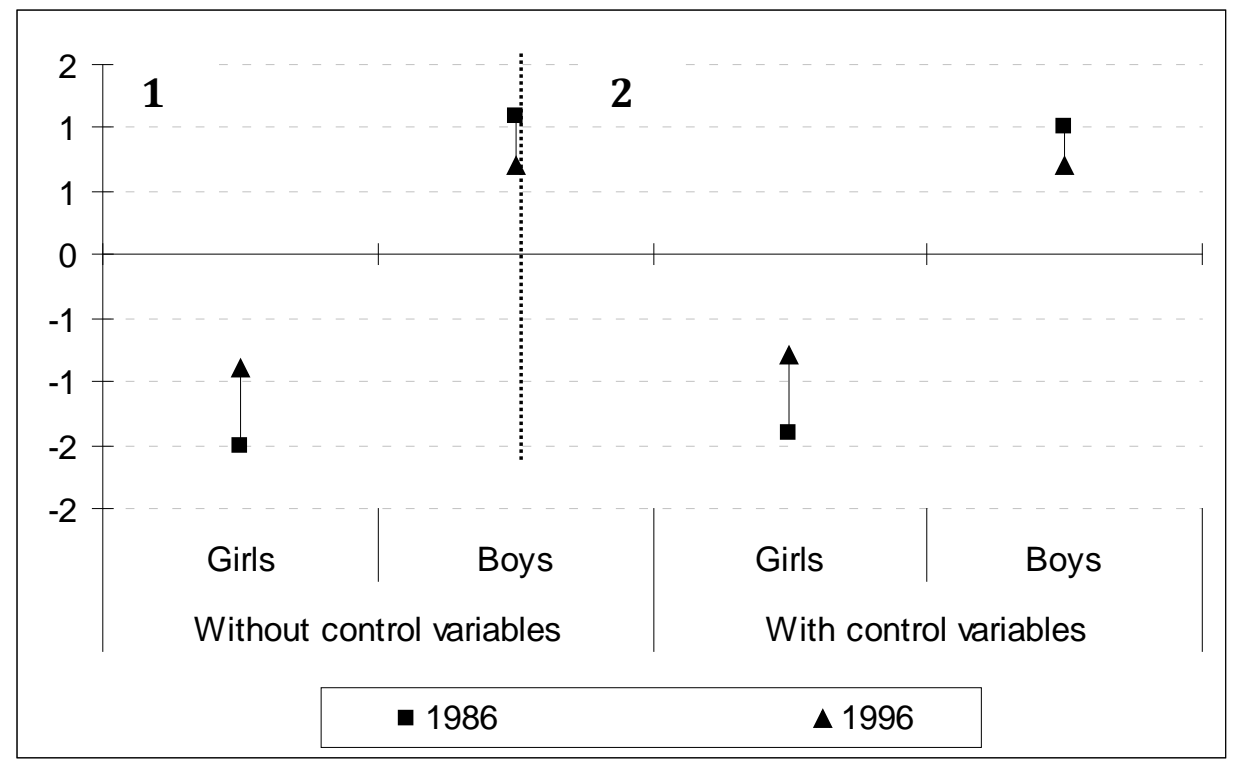

Notes:

1. \& $\quad \boldsymbol{\Delta}$ measure the difference between actual and need based probability of getting medical help (given illness) in 1986 and 1996, respectively. If children get medical attention based on their need, the difference should be zero. A movement towards the origin for both girls and boys shows a decline in the gender gap.

Source: Computed form the $42^{\text {nd }}$ and $52^{\text {nd }}$ Indian National Sample Survey

For robustness check, the need-predicted values were recomputed using control variables. Per capita expenditure, location (urban/rural), social class, and family size were used as control variables. The detailed results are presented in Appendix 2 and the summary is shown in the second panel of Figure 3.1. The results show that even after controlling various factors, the difference between actual visit and need predicted visits of girls declined significantly both in absolute and in relative terms (compared to boys).

Second, we examine the amount of money spent on non-medical health expenditure for out-patient and in-patient visits (Figure 3.2). In 1986, the amount of outpatient expenditure for girls was INR 4.37 less than would be expected on average given their need and INR 3.25 higher for boys (panel 1a of Figure 3.2). The difference is very striking in the case of non-medical expenses for hospitalization (panel 2a). While there was no statistically significant difference in the number of days hospitalized between boys and girls, parents spent INR 31.43 more on boys than their expected need and INR 50.32 less for girls than would be expected based on their need. 
Figure 3.2 The difference between actual and need based out-and in-patient health expenditure for girls and boys

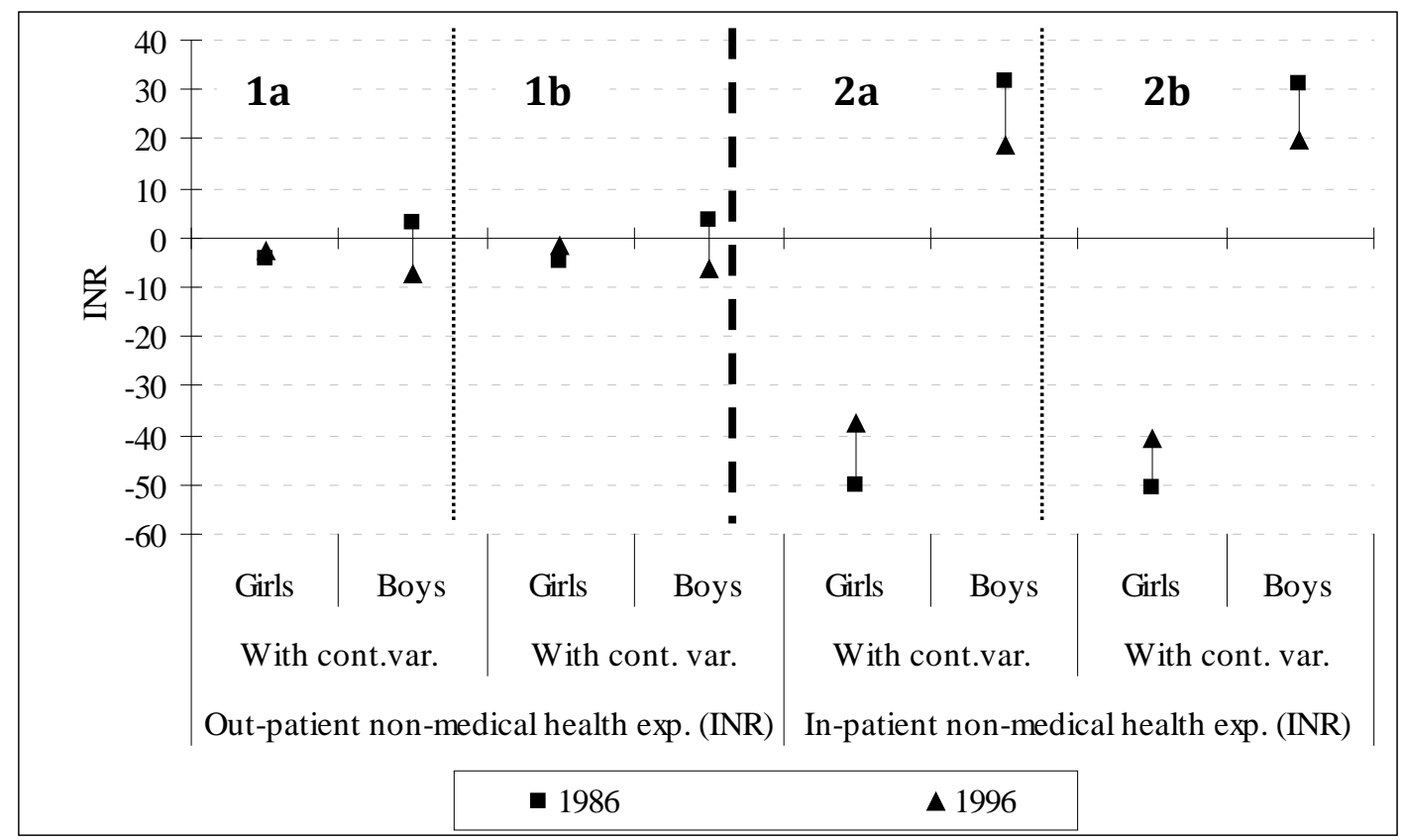

Note: The value of out-patient expenditure is divided by 10 for scaling purpose.

Again significant improvements were observed in these indicators in 1996. After a decade, the difference between actual and need predicted out-patient health expenditure for girls declined (in absolute terms) by almost half from IRN 4.37 to IRN 2.81. At the same time the same figure for boys declined from IRN 3.25 to IRN-7.6. Similar pattern is observed in the case of non-medical in-patient health expenditure (panel 2a). The difference between actual and need predicted non-medical in-patient health expenditure for girls declined (in absolute terms) from IRN -50.32 in 1986 to IRN 37.74 in 1996. This is a 26 percent improvement. In the case of boys, the amount of excess (based on their need) non-medical in-patent health expenditure declined from IRN 31.43 to IRN 18.43. Again for robustness check, the figures were estimated using control variables. The results presented in panels $1 \mathrm{~b}$ and $2 \mathrm{~b}$ of Figure 2 show similar patterns. These results clearly indicate that the health care demand behavior of households towards girls has improved significantly between 1986 and 1996.

A probit model was also estimated to examine the impact of sex variable on the probability of getting treatment given illness in 1986 and 1996. The results are presented in Table 3.5. The first column shows the bivariate relationship between getting medical care given illness and gender. The results indicate that boys were 3.1 percent more likely to get medical help given illness than girls in 1986. After a decade, though boys were still 
more likely to get medical care given illness, the marginal effect declined by 1.4 percentage point. In 1996, the probability of boys to get medical care given illness was only 1.7 percent higher than girls.

Table 3.5 Getting medical care given illness (Marginal coefficients of a probit model)

\begin{tabular}{|c|c|c|c|c|}
\hline Variable & 1986 & 1996 & 1986 & 1996 \\
\hline Sex ( 1 of boy \& 0 otherwise) & $\begin{array}{l}0.031 * * * \\
(0.006)\end{array}$ & $\begin{array}{l}0.017 * * \\
(0.007)\end{array}$ & $\begin{array}{l}0.021 * * * \\
(0.005)\end{array}$ & $\begin{array}{l}0.015 * * \\
(0.007)\end{array}$ \\
\hline Age $0-1$ years & & & $\begin{array}{l}\text { Reference } \\
-0.037 * * *\end{array}$ & $\begin{array}{l}\text { Reference } \\
-0.041^{* * *}\end{array}$ \\
\hline Age 2-4 years & & & $\begin{array}{l}(0.008) \\
-0.049 * * *\end{array}$ & $\begin{array}{l}(0.009) \\
-0.062 * * *\end{array}$ \\
\hline Age 5-9 years & & & $\begin{array}{l}(0.007) \\
0.169 * * *\end{array}$ & $\begin{array}{l}(0.009) \\
0.041^{* * *}\end{array}$ \\
\hline Severity of illness & & & $\begin{array}{l}(0.004) \\
0.004 * * *\end{array}$ & $\begin{array}{l}(0.008) \\
0.009 * * *\end{array}$ \\
\hline Family size & & & $\begin{array}{l}(0.001) \\
0.050^{* * *}\end{array}$ & $\begin{array}{l}(0.001) \\
0.092 * * *\end{array}$ \\
\hline Ln per capita exp & & & $\begin{array}{l}(0.006) \\
0.052 * * *\end{array}$ & $\begin{array}{l}(0.009) \\
0.065^{* * *}\end{array}$ \\
\hline Urban & & & $\begin{array}{l}(0.005) \\
-0.062 * * *\end{array}$ & $\begin{array}{l}(0.007) \\
-0.020 * * *\end{array}$ \\
\hline Scheduled tribe or caste & & & $(0.007)$ & $(0.008)$ \\
\hline No of observation & 12716 & 9346 & 12682 & 9319 \\
\hline Wald chi2(1) and (8) & 23.53 & 5.81 & 704.57 & 404.62 \\
\hline Prob > chi2 & 0.000 & 0.016 & 0.000 & 0.000 \\
\hline Log pseudo likelihood & -5366.19 & -3746.43 & -4726.846 & -3518.089 \\
\hline Pseudo R2 & 0.002 & 0.001 & 0.118 & 0.060 \\
\hline
\end{tabular}

Note: Figures in brackets are robust standard errors.

Source: Computed form the $42^{\text {nd }}$ and $52^{\text {nd }}$ Indian National Sample Survey

To take into account the impact of other factors on the probability of getting medical care, a multivariate model was run and the results are presented in the last two columns of Table 3.5. Almost all the need (age group and severity) and control factors took the expected signs and were statistically significant. Ceteris paribus, the marginal impact of sex on the probability of getting medical care given illness has declined by 0.6 percentage point. Keeping all other factors at their mean value, the probability of boys to get medical help given illness has declined from 2.1 percent in 1986 to 1.5 percent in 1996. The significance level of the sex variables has also declined from 0.1 in 1986 to 0.5 in 1996. 


\subsection{Conclusion}

In this study, we show that the increased return on investment on women in India in the past decades is reflected in the decline in health care utilization disparities between girls and boys.

In the decade from 1986 to 1996, there has been a drastic increase in the percentage of children treated for various sicknesses in India. Though the percentage of boys treated when ill remained higher than that of girls in 1996 (86.98 \% versus $85.25 \%$ ), we show that for all age-groups there was an increase in the percentage of girls treated when sick. Significant improvements were also observed in the amount of money invested on the non-medical out- and in- patient medical services.

Interesting patterns were also observed across states. Significant improvement was also seen in the percentage of girls who got medical help compared to boys particularly in Orissa, Assam, Madhya Pradesh, Uttar Pradesh, and the like. These states are considered the states in which women made larger advances in terms of economic and employment opportunities.

The econometric results also revealed significant improvements in the health care demand behavior of households towards girls. The difference between actual visit and the need-predicted probability of getting medical help for girls has declined from 1.5 percent in 1986 to 0.9 percent 1996 . At the same time, the probability of boys to visit medial service providers more than their expected need declined from 1.1 percent to 0.7 percent during the time under consideration. Similar improvements were also observed in all indicators especially in the amount of money parents spent on non-medical expenses for hospitalized girls. The bivariate and multivariate regression results also showed that the marginal impact of sex on the probability of getting medical help given illness declined from 3.1 to 1.7 percent and from 2.1 to 1.5 percent between 1986 and 1996, respectively.

These promising results have important policy implications and needs to be addressed in a timely manner. Evidence of gender inequality in heath care utilization is still wide spread in India and only a sharp and homogenous increase in the return on investment for girls across the country will produce the expected results in the next decades. 


\section{Appendix Chapter 3}

Table 3.6 Descriptive Statistics of the Variables Used in the Analysis

Variable (for children under ten years old) Mean

Total children under ten

\begin{tabular}{rr}
\hline 1986 & \multicolumn{1}{c}{1996} \\
\hline 80,759 & 163,585 \\
17.38 & 22.85 \\
31.35 & 27.52 \\
51.27 & 49.63 \\
84.99 & 86.21 \\
0.20 & 0.22 \\
9.93 & 9.18 \\
28.21 & 40.20 \\
256.44 & 206.25 \\
8.27 & 6.53 \\
25.72 & 33.37 \\
11983.56 & 35892.61
\end{tabular}

Age group 0-1 (\%)

Age group 2-4 (\%)

(20)

Age group 5-9 (\%)

49.63

Percentage treated given ailments

Number of days sick in the last 15 days

Number of days hospitalized (given hospitalized)

28.21

40.20

Non-medical health expenses for outpatient care (INR)

Non-medical health expenses for inpatient care (INR)

8.27

6.53

Family size

f scheduled tribe/caste

25.72

35892.61

Per capita monthly expenditure (INR) 
Table 3.7 Distribution of children's actual and need-predicted utilization of health care services by sex and year

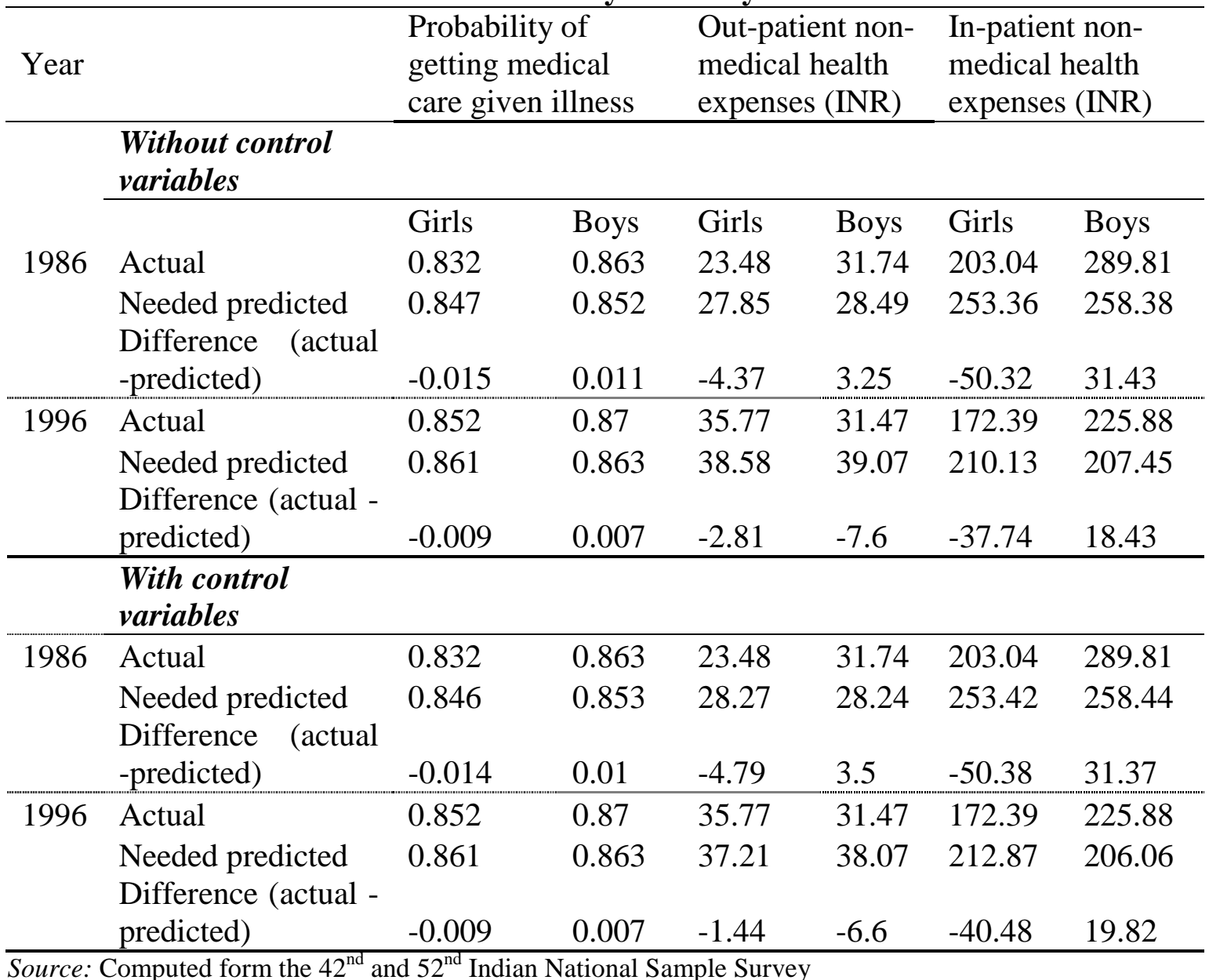





\section{Chapter 4. Intra-household Gender Disparities in Children's Medical Care before Death in India ${ }^{55}$}

\section{Abstract}

The existence of excess female mortality in India and other South Asian countries is no longer contentious. The less known issue is the reasons for such excess female mortality in the country. In this study, we argue that intra-household genderdiscrimination in receipt of medical attention can be one of the most important factors for the unbalanced sex ratio in the country. The $52^{\text {nd }}$ Indian National Sample Survey, which collected for the first time detailed verbal autopsies information was used. Place of death, which indicates whether a person got medical help immediately before her/his death, was used as a health indicator variable. The multinomial logit results showed that keeping all other factors constant, girls were 1.7 percent less likely to die in hospital than their brothers. The coefficients of different interaction variables also revealed that the probability of infant and very young girls with live female siblings to die in hospital was extremely low. The robustness of the regressions results was also checked using different indicators. The results confirmed that girls were highly discriminated against in being hospitalized and in the number of times being hospitalized before their death compared to boys. Therefore, in addition to the current effort of the government to control female feticide, effort should be put in reducing the current intra-household gender-disparities in getting medical care at least for life threatening illnesses.

\subsection{Introduction}

While the magnitude varies from one study to another (depending on the data and the standard sex ratio reference level used), the excess female mortality in India and other

\footnotetext{
65 This chapter is co-authored with PhD Abay Asfaw, Ministry of Agriculture, United States and PhD Professor Stephan Klasen, University of Goettingen, Germany.
} 
South Asian countries is no longer contentious (Sen, 1992; Coale, 1991; Klasen, 1994). It is also only in that part of the world that the life expectancy of women at birth is lower or equal to men, despite the biological advantage of women as a group to live longer than men (Hart, 1988; UNDP, 1995; Waldron, 1995; WHO, 1998; Gjonca et al., 1999; Kalben, 2002). Even for infants (aged less than one) the mortality of girls was 1.3 times higher than boys in India (Khanna et al., 2003). This fact seems paradoxical since these countries have relatively high economic performance, including high per capita income and growth, high medical personnel, and medical facilities population ratios, compared to countries in Sub-Sahara Africa. The non-responsiveness of this discrimination to the improvement in the economic status of households (Hill and Upchurch, 1995; Kurz and Johnson-Welch, 1997) also makes the issue of excess female mortality a serious concern in this region.

Factors related to social, cultural, familial, behavioural, and other discriminatory behaviour of households, communities, and sometimes governments against girls and women can be some of the reasons for the higher than expected female mortality in South Asian countries. Therefore, there is a crucial need to investigate factors and mechanisms that jeopardised the biological advantage of women to live longer than men and consequently produced millions of 'missing women' and an unbalanced sex ratio in this part of the world.

Several factors including sex-selected abortion, gender discrimination in nutrition especially among young children, discrimination in access to health care, labour markets, education, and other opportunities, and intra-household/ community discrimination against women/girls are hypothesized in the literature for this excess female mortality in the region. Gender discrimination in intra-household food distribution (nutrition) has long been identified as a major factor for excess female mortality in the region. However, several recent findings reveal that there is no significant evidence of gender discrimination in nutrition among children (Chaudhury, 1987; Das Gupta, 1987; Gopalan, 1987; Basu, 1989; 1993; Walker and Ryan, 1990; Kurz and Johnson-Welch, 1997; Hazarika, 2000 and Svedberg, 2006). Very recently, sex-selective abortion (Booth, et al., 1994; Khan et al., 1996; Sudha \& Arnold, 1999; Arnold 2002) has received greater attention as one of the major factors for the unbalanced sex ratio in the region. In this study, we argue that intrahousehold discrimination in health care behaviour of households against girls can be one of the most important factors for the unbalanced sex-ratio in the region.

Various authors examined gender discrimination in the provision of health care services. Despite some researchers could not find statistically significant gender 
differences in access to some types of health care services (Jatrana, 2003), there is evidence indicating gender discrimination in health care utilization in India, Bangladesh and Pakistan (Rajeshwari, 1991; Singh et al., 1962 ; Aziz, 1977 ; Chen et al., 1981; Miller 1981; Murthy, 1982 ; Das Gupta, 1987; Chaudhury, 1988; Wadley, 1993; Greenspan, 1994; Sood and Nagla, 1994; Rajeshwari, 1996; Kurz and Johnson-Welch, 1997; Gangadharan and Maitra, 2000).

This study provides fresh evidence on intra-household gender discrimination against girls (aged from 1 day to nine years) in getting medical attention before their death in India. Unlike most of the previous studies, which focused on small sample sizes and on illness symptoms, this study used a nationally representative data set and examined the existence and magnitude of gender discrimination in getting medical attention at the last critical time of life ${ }^{66}$. More specifically, the study examines whether girls were discriminated against in getting medical help before their death. We argue that although mortality differences between girls and boys can be the result of biological factors, disparity in getting medical attention between girls and boys before death reveals gender discrimination.

Out of several indicators that measure medical attention before death such as causes of death, whether medical attention was sought before death, number of times hospitalized, etc, we used place of death variable as a main indicator for various reasons. First, in contrast to developed countries where almost everybody gets medical attention before death and where to die is a matter of choice ${ }^{67}$, place of death (in hospital, at home, at nursery, etc.) is a crucial indicator of whether deceased individuals got proper medical attention before their death in developing countries like India (Gupta and Sankar, 2002). Second, the one-year recall period used in the national sample survey (see next section) is less likely to affect the reliability of the place of death information compared to other health indicators.

\footnotetext{
${ }^{66}$ The only exception in this area was the work of Gupta and Sankar (20002). However, the main focus of the study was on various factors that affect lack of medical attention before death. As a result gender did not get enough attention and the interaction of gender with other variables was not examined. Moreover, the study took only one indicator (medical attention before death) in the analysis.

${ }^{67}$ See for instance, Westerling, 1996; Axelsson and Christensen, 1996; Polissar et al., 1987;

Pritchard, et al., 1998; Costantini et al., 2000; Feudtner et al., 2002, Lock and Higginson, 2005.
} 
The study also focuses on infants and children (aged from one day to nine years) for two reasons; first because the excess of female mortality is much larger among children than adult and second because the chance of children to get medical care totally depends on the decision of parents. This helps us to clearly see the level intra-household gender discrimination in seeking medical help. Focusing on children will also avoid biological differences and gender differential in exposure to risks and deaths (occupation, pregnancy, gender violence, death due to old age, etc.) that may potentially affect the chance of getting medial care and consequently the place of death. The imbalance in the proportion of deaths between girls and boys is also high for this age group in India (BMJ, 2003; Khanna, et al., 2003).

Out of several South Asian countries the study focuses in India for various reasons. First, the country has the highest share of missing women in the world (Klasen and Wink, 2002) and currently the problem has reached a critical point where it affects the sex balance (UNICEF, 1990; WHO, 1992; Pande, 2000). Second, while female mortality is lower in infancy and early neonatal period (WHO, 2000), it is higher for females than for males in India (WHO, 2000, BMJ, 2003). Third, as we shall explain soon, India has a data set that can be used to address the issue of gender discrimination in getting health care before death.

The remaining part of the paper is organized as follows. Section two presents the data source and measurement of variables and section three explains the methodology used in the study. Finally, section four and five present the results and conclusion of the study.

\subsection{Source of data and Measurement of Variables}

The Indian National Sample Survey (NSS) data were used in this study. Since 1950, the National Sample Survey Organization of India has been collecting major information on socio-economic conditions of the population as well as economic and operational features of informal enterprises and establishments (Saha, 2002). In this study the $52^{\text {nd }}$ round NSS conducted between July 1995 and June 1996 were used. Two-stage stratified sampling procedure was adopted. At the first stage, 7,663 rural villages and 4,991 urban blocks were identified all over the country and at the second stage 71,284 rural and 49,658 urban households were surveyed.

The $52^{\text {nd }}$ round collected information on utilization of health care services, morbidity, problems of aged persons, and participation in education. For the first time in 
the long history of the NSS, the $52^{\text {nd }}$ round also collected detailed information about deceased family members. Detailed verbal autopsies including name and sex; age at death; time elapsed since death; cause of death; place of death; medical attention before death; whether hospitalized during last 365 days; and number of times hospitalized was collected. The recall period was one year before the survey.

From Schedule 25.0 of the $52^{\text {nd }}$ NSS, place of death (at home, in public hospital, in government hospital, during transport, at other places) was selected as a main indicator of getting medical attention before death. This variable is expected to measure the real concern of parents to save the lives of their children. Various factors that may influence the place of death of children such as age and sex of the child; location (urban/rural), income (approximated by monthly household expenditure), family size and composition, and social status (whether or not the household belongs to scheduled tribe or scheduled caste) of the household; and age, education, and sex of the household head, etc., were used as explanatory variables. The definition and descriptive statistics of the variables are presented in Table 4.1. Deceased children and infants aged from one day to nine years were considered.

Table 4.1 Descriptive statistics

\begin{tabular}{lrr}
\hline Variable & Mean & SD \\
\hline Age of the head & 41.359 & 13.408 \\
Male headed households (1 if the head is male \& 0 otherwise) & 0.943 & 0.232 \\
Per capita expenditure (Rupee) & 43041.95 & 28461.02 \\
Location (1 = urban \& 0 otherwise) & 0.258 & 0.438 \\
Social status (1 if scheduled caste/tribes \& 0 otherwise) & 0.335 & 0.472 \\
Head's education (1 if completed primary \& above \& 0 otherwise) & 0.359 & 0.480 \\
Family size & 5.869 & 3.128 \\
Gender of the deceased child (1 if girl \& 0 otherwise) & 0.476 & 0.500 \\
Age of the deceased child & 1.442 & 2.249 \\
No of female siblings younger than 15 & 0.949 & 1.138 \\
\hline
\end{tabular}

Source: Authors computation based on $52^{\text {nd }}$ NSS

\subsection{Methodology}

The probability of observing nominal outcomes such as places of death can be modelled using various nominal outcome models. In this study, a multinomial logit model 
was used to examine the determinants of dying at different places. The survey provided information for five different locations in which individuals die: at home, during transport, in government hospitals, in private hospitals, and at other places. Then, the likelihood of a child to die in any of the above places, say place $j$ can be presented as:

$$
\operatorname{Pr}\left(y_{i}=j\right)=f\left(X_{i}, Z_{i}\right), j=1, \ldots, m
$$

Where $X_{i}$ is a vector of individual characteristics of dead child $i$ such as sex, age at death, $Z_{i}$ is a vector of household level variables of child $i$ such as education, age, and sex of the household head, income, social status, location, and the like.

Based on a multinomial model, the probability of child $i$ will die at place $j$ is given by

$$
\operatorname{Pr}\left(y_{i}=j\right)=\frac{\exp \left(\beta_{j}^{\prime} X_{i}+\gamma_{j}{ }^{\prime} Z_{i}\right)}{\sum_{l=1}^{m} \exp \left(\beta_{l}^{\prime} X_{i}+\gamma_{l}^{\prime} Z_{i}\right)}
$$

Where $\beta$ and $\gamma$ are vector of parameters to be estimated. Note that since information on outcomes' characteristic is not available, all the explanatory variables represent the characteristics of child $i$ or her/his family and therefore vary over the outcomes. If there is any gender discrimination in the place of death, the coefficient of the sex variable should be statistically significant.

\subsection{Results}

\section{Descriptive Analysis}

Out of 3,506 individuals deceased during one year before the survey, 26 percent were children and infants aged from one day to nine years. From the total deceased children, infants (less than one year old) accounted for 68.35 percent followed by children aged between 1 and 4 (20.00 percent) and 5 and 9 (11.65 percent). Overall, 67.58 percent of children died at home, 26.15 died in hospital and 2.31 and 3.96 percent died during transport and other places, respectively. Various factors including accessibility of medical facilities, area of residence, income and education of parents might affect the place of death of children. Table 4.2 presents some descriptive statistics.

As expected, for all age groups rural children were more likely to die at home compared to urban children and the differences were statistically significant for young children (Person $\chi^{2}$ test). For instance, while 41 percent of infants had a chance of dying in hospitals in urban areas, only half of them had this chance in rural areas. 
Though not statistically significant $\left(\chi^{2}\right.$ test) at 5 percent level, 36.84 percent of children from the richest quintile died in hospital compared to 22.54 percent children from the poorest quintile. In general income did not have an important influence on the place of death of children. This was unexpected result since children from rich households were expected to die at hospitals more often than children from poor households.

The last column of the table to the left shows gender differences. Under normal circumstances, there should not be differences in the place of death for girls and boys. However, the table reveals that at all age groups girls were more likely to die at home than boys and the differences were statistically significant in the case of infants and 1-4 years old children. Boys were also more likely to die in hospital than girls at all age groups. Overall 33 percent of boys died in hospitals compared to only 19 percent of girls. The difference was much higher in the case of infants. While 35\% of boys died in hospital only 17 percent of girls had this chance.

This pattern remained the same even after controlling the place of residence and income of households as shown in Figures 4.1 and 4.2. In both rural and urban areas girls were less likely to die in hospital than boys and the differences were very striking in the case of infants.

In urban areas 31 percent of infant girls died in hospital compared to 48 percent boys. In rural areas the discrimination was even worse. Despite 30 percent of infant boys died in hospital, only less than half of infant girls got this chance. Similar pattern was observed across different income quintiles. Except for the age group 5-9, boys were more likely to die in hospital than girls for all income quintiles. The last two rows of Table 4.2 also indicate that girls with live female siblings (younger than 15 years old) were the most disadvantaged groups in getting medical help before their death. 
Table 4.2 Place of death for different age group children by location, income, and gender

\begin{tabular}{|c|c|c|c|c|c|c|}
\hline \multirow[b]{2}{*}{$\begin{array}{l}\text { Age } \\
\text { group }\end{array}$} & \multirow[b]{2}{*}{ Variable } & \multicolumn{5}{|c|}{ Place of death } \\
\hline & & $\begin{array}{l}\text { At } \\
\text { home }\end{array}$ & $\begin{array}{l}\text { Hospita } \\
1\end{array}$ & $\begin{array}{l}\text { During } \\
\text { transpo } \\
\text { rt }\end{array}$ & $\begin{array}{l}\text { Other } \\
\text { places }\end{array}$ & $\begin{array}{l}\text { Pearson } \\
\text { chi }^{2}\end{array}$ \\
\hline & 1. Location & & & & & \\
\hline \multirow[t]{2}{*}{$<1$ year } & Rural & 72.48 & 21.80 & 2.45 & 3.27 & \multirow{2}{*}{$\begin{array}{l}21.49 * * * \\
(0.000)\end{array}$} \\
\hline & Urban & 55.63 & 40.85 & 0.00 & 3.52 & \\
\hline \multirow[t]{2}{*}{ 1-4 years } & Rural & 74.78 & 18.70 & 1.74 & 4.78 & \multirow{2}{*}{$\begin{array}{l}6.78 * \\
(0.079)\end{array}$} \\
\hline & Urban & 67.69 & 21.54 & 7.69 & 3.08 & \\
\hline \multirow[t]{2}{*}{ 5-9 years } & Rural & 53.85 & 37.18 & 2.56 & 6.41 & \multirow{2}{*}{$\begin{array}{l}1.69 \\
(0.639)\end{array}$} \\
\hline & Urban & 42.86 & 50.00 & 3.57 & 3.57 & \\
\hline \multirow[t]{3}{*}{$0-9$ years } & Rural & 71.11 & 22.52 & 2.22 & 4.15 & \multirow{2}{*}{$\begin{array}{l}18.35^{* * *} \\
(0.000)\end{array}$} \\
\hline & Urban & 57.45 & 36.6 & 2.55 & 3.4 & \\
\hline & 2. Income & & & & & \\
\hline \multirow[t]{2}{*}{$<1$ year } & $1^{\text {st }}$ quintile. & 69.67 & 22.95 & 1.64 & 5.74 & \multirow{2}{*}{$\begin{array}{l}15.33 \\
(0.224)\end{array}$} \\
\hline & $5^{\text {th }}$ quintile. & 58.06 & 36.56 & 1.08 & 4.30 & \\
\hline \multirow[t]{2}{*}{$1-4$ years } & $1^{\text {st }}$ quintile. & 77.46 & 14.08 & 1.41 & 7.04 & \multirow{2}{*}{$\begin{array}{l}16.04 \\
(0.189)\end{array}$} \\
\hline & $5^{\text {th }}$ quintile. & 69.77 & 27.91 & 0.00 & 2.33 & \\
\hline \multirow[t]{2}{*}{ 5-9 years } & $1^{\text {st }}$ quintile. & 45.00 & 50.00 & 5.00 & 0.00 & \multirow{2}{*}{$\begin{array}{l}11.59 \\
(0.479)\end{array}$} \\
\hline & $5^{\text {th }}$ quintile. & 37.50 & 62.50 & 0.00 & 0.00 & \\
\hline \multirow[t]{2}{*}{$0-9$ years } & $1^{\text {st }}$ quintile. & 69.95 & 22.54 & 1.88 & 5.63 & \multirow{2}{*}{$\begin{array}{l}19.06 * \\
(0.087)\end{array}$} \\
\hline & $5^{\text {th }}$ quintile. & 59.21 & 36.84 & 0.66 & 3.29 & \\
\hline & 3. Gender & & & & & \\
\hline \multirow[t]{2}{*}{$<1$ year } & Girls & 77.33 & 17.33 & 2.22 & 3.11 & \multirow{2}{*}{$\begin{array}{l}20.18^{* * *} \\
(0.000)\end{array}$} \\
\hline & Boys & 60.21 & 34.86 & 1.41 & 3.52 & \\
\hline \multirow[t]{2}{*}{ 1-4 years } & Girls & 77.56 & 16.03 & 2.56 & 3.85 & \multirow{2}{*}{$\begin{array}{l}3.208 \\
(0.361)\end{array}$} \\
\hline & Boys & 68.35 & 23.02 & 3.60 & 5.04 & \\
\hline \multirow[t]{2}{*}{ 5-9 years } & Girls & 53.85 & 34.62 & 5.77 & 5.77 & \multirow[t]{2}{*}{$\begin{array}{l}4.18 \\
(0.243)\end{array}$} \\
\hline & Boys & 48.15 & 46.30 & 0.00 & 5.56 & \\
\hline \multirow[t]{2}{*}{$0-9$ years } & Girls & 74.60 & 18.94 & 2.77 & 3.70 & \multirow[t]{2}{*}{$\begin{array}{l}23.37 * * * \\
(0.000)\end{array}$} \\
\hline & Boys & 61.22 & 32.70 & 1.89 & 4.19 & \\
\hline \multicolumn{2}{|c|}{ Girls * <1 year* female siblings } & 83.17 & 11.88 & 0.99 & 3.96 & \multirow[t]{2}{*}{$\begin{array}{l}17.56 \\
(0.001)\end{array}$} \\
\hline \multicolumn{2}{|c|}{ Boys* $<1$ year* girl siblings } & 60.36 & 36.04 & 1.80 & 1.80 & \\
\hline
\end{tabular}

Standard errors in parentheses * Significant at 10\%; ** significant at 5\%; *** significant at 1\% Source: Authors computation based on $52^{\text {nd }}$ NSS 
Figure 4.1 Percentage of children died in hospital by sex, age, and location

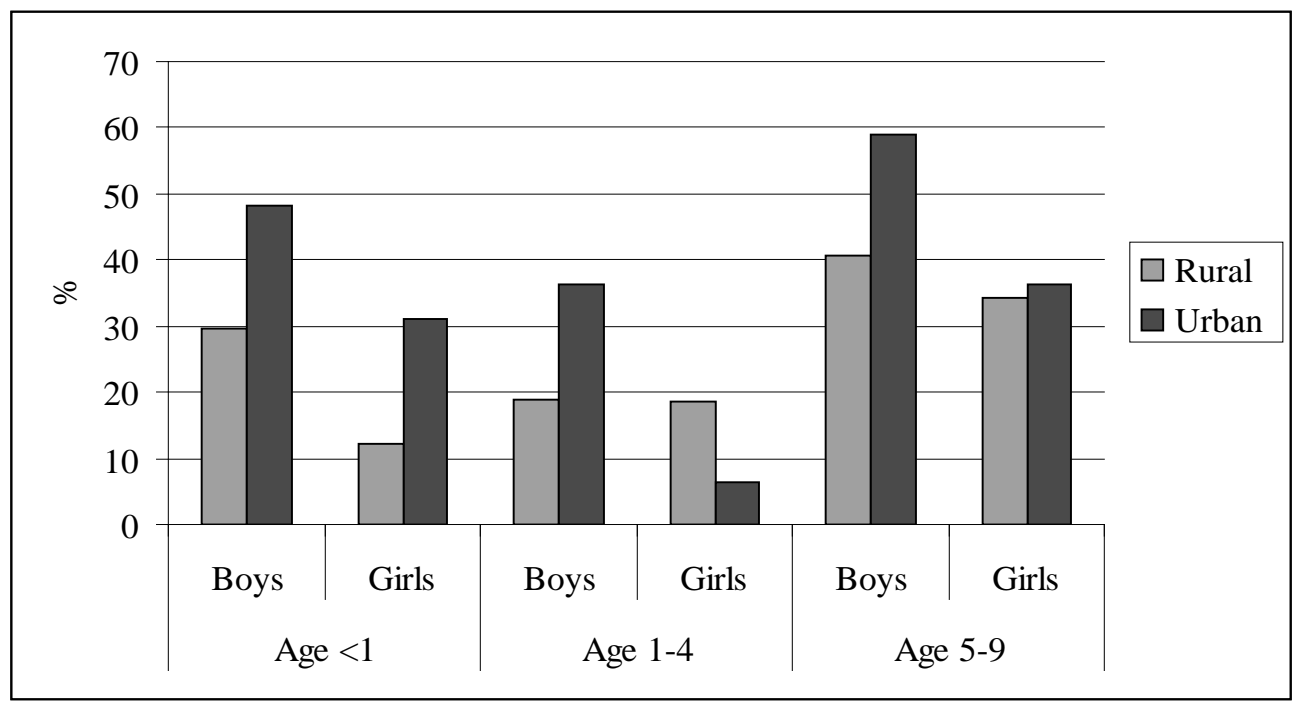

Source: Authors computation based on $52^{\text {nd }}$ NSS

Figure 4.2 Percentage of children died in hospital by sex, age, and income quintile

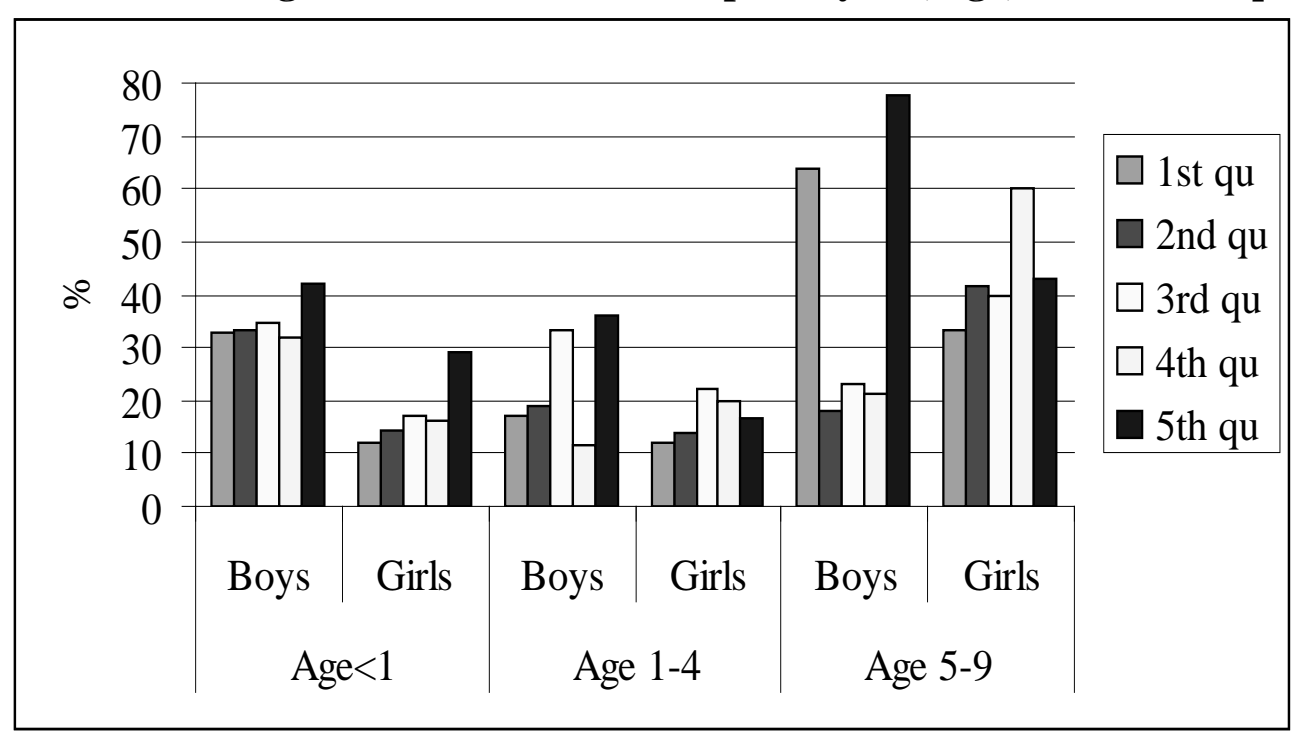

Source: Authors computation based on $52^{\text {nd }}$ NSS

All results indicate that girls, especially infant girls, were more likely to die at home without getting medical attention at the last critical time of their lives and this was true both in urban and rural areas, and across different income groups. Girls with sisters younger than 15 years of age were particularly vulnerable. Therefore, discrimination in seeking medical help against infant girls might be one possible explanation for the imbalance sex ratio in the country. 


\section{Multinomial logit results}

A multinomial logit model was estimated to determine whether gender affected the likelihood of place of death of children. Before presenting the final results of the model, we examined various specification and related issues. First, we test for combining any of the five outcomes (places of death). An outcome $j$ is said indistinguishable with outcome $k$, if none of the independent variables significantly affect the odds of outcome $j$ versus outcome $k$ (Long and Freese, 2003). In the light of the loglikelihood test results and common sense, government and private hospital and home and other outcomes were combined and three mutually exclusive places of death were created (at home, in hospital, and during transport). Second, we test for the independence of irrelevant alternative (IIA) assumption of the multinomial logit model using both Hausman-McFadden and SmallHsiao tests. Both tests showed that IIA assumption holds, i.e., odds (Outcome-j vs Outcome- $k$ ) are independent of other alternatives. Third we examine the variance inflation factors (VIF) to test for the existence of multicolinearity. The variance inflation factor is an index which mearures how much the variance of the coefficient is increased because of collinearity. VIF ranges from 1.0 to intifinity where VIFs greater than 10.0 are generally seen as indicative of severe multicolinearity. The computed VIF was 1.06 indicating absence of any significant multicolinearity.

Two individual variables, viz., sex and age of the deceased child, eight household level variables viz. sex, age, age square, and education level of the household head; number of live female siblings younger than 15 years of age, income, location, and social status of the household were included in the model (see Table 4.1 for definition and descriptive statistics of these variables). In addition to individual and household level variables, 77 district level dummy variables were included in the regression to take into account unobserved district level factors that might affect the place of death of children. The results of the multinomial model are presented in Table 4.3.

Death at home (versus death in hospital and during transport) was the reference (comparison or base) category. The coefficients of the district level dummy variables were omitted for brevity of presentation. The LR chi $^{2}$ test is significant rejecting the hypothesis that all of the regression coefficients across both models are simultaneously zero. The McFadden's pseudo $\mathrm{R}^{2}$ is 0.22 . Since direct interpretation of the coefficients is difficult, marginal coefficients were computed and presentment for statistically significant variables. 
Table 4.3 Determinants of place of death: Multinomial logistic regression results

\begin{tabular}{|c|c|c|c|c|c|}
\hline \multirow[t]{3}{*}{ Variable } & \multicolumn{5}{|c|}{ Place of death } \\
\hline & \multicolumn{2}{|c|}{ Hospital } & \multicolumn{2}{|c|}{ During transport } & \multirow{2}{*}{$\begin{array}{l}\text { At home } \\
\text { Marg eff. }\end{array}$} \\
\hline & Coeff. & $\begin{array}{l}\text { Marg } \\
\text { eff. }\end{array}$ & Coeff. & Marg eff. & \\
\hline Age of the head & $\begin{array}{l}0.074 \\
(0.057)\end{array}$ & & $\begin{array}{l}-0.001 \\
(0.069)\end{array}$ & & \\
\hline Age square of the head & $\begin{array}{l}-0.001 \\
(0.001)\end{array}$ & & $\begin{array}{l}-0.000 \\
(0.001)\end{array}$ & & \\
\hline Male headed household & $\begin{array}{l}0.284 \\
(0.462)\end{array}$ & & $\begin{array}{l}0.051 \\
(0.554)\end{array}$ & & \\
\hline Ln per capita expenditure & $\begin{array}{l}0.241 \\
(0.241)\end{array}$ & & $\begin{array}{l}-0.033 \\
(0.288)\end{array}$ & & \\
\hline Location (1 = urban) & $\begin{array}{l}0.369 \\
(0.244)\end{array}$ & & $\begin{array}{l}0.621^{* *} \\
(0.292)\end{array}$ & 0.00003 & -0.01211 \\
\hline Scheduled caste/tribes & $\begin{array}{l}-0.079 \\
(0.250)\end{array}$ & & $\begin{array}{l}0.158 \\
(0.293)\end{array}$ & & \\
\hline $\begin{array}{l}\text { Head's education( } 1 \text { if } \\
\text { completed primary and } \\
\text { above) }\end{array}$ & $\begin{array}{l}0.508 * * \\
(0.217)\end{array}$ & 0.0163 & $\begin{array}{l}0.939 * * * \\
(0.260)\end{array}$ & 0.00005 & -0.01644 \\
\hline Ln family size & $\begin{array}{l}0.031 \\
(0.219)\end{array}$ & & $\begin{array}{l}-0.123 \\
(0.261)\end{array}$ & & \\
\hline Age of the deceased child & $\begin{array}{l}0.227 * * * \\
(0.042)\end{array}$ & 0.0068 & $\begin{array}{l}0.077 \\
(0.061)\end{array}$ & & -0.00681 \\
\hline $\begin{array}{l}\text { Num. of female siblings } \\
\text { younger than } 15\end{array}$ & $\begin{array}{l}-0.082 \\
(0.101)\end{array}$ & & $\begin{array}{l}-0.123 \\
(0.122)\end{array}$ & & \\
\hline $\begin{array}{l}\text { Gender of the deceased } \\
\text { child ( } 1 \text { if girl) }\end{array}$ & $\begin{array}{l}-0.584 * * * \\
(0.208)\end{array}$ & 0.0174 & $\begin{array}{l}-1.071^{* *} \\
(0.268)\end{array}$ & -0.00005 & 0.01748 \\
\hline $\begin{array}{l}70 \text { district level dummy } \\
\text { variables }\end{array}$ & & & & & \\
\hline Constant & $\begin{array}{l}-5.433 * \\
(3.044) \\
\end{array}$ & & $\begin{array}{l}-0.465 \\
(3.658)\end{array}$ & & \\
\hline Observations & & & 907 & & \\
\hline Log likelihood & & & -563.35478 & & \\
\hline LR chi2(158) & & & 299.81 & & \\
\hline Prob > chi2 & & & 0.0000 & & \\
\hline Pseudo R2 & & & 0.2102 & & \\
\hline
\end{tabular}

Standard errors in parentheses * Significant at 10\%; ** significant at 5\%; *** significant at 1\% Source: Authors computation based on $52^{\text {nd }}$ NSS

Age and sex of the household head took the expected negative sign indicating that children in older and female headed households were less likely to die in hospital or during transport than children in young and male headed households. However, both variables were not statistically significant at the ten percent level. Income also took the expected positive sign but was not statistically significant in explaining place of death. 
Though consistent with the descriptive statistics, this result is counter intuitive. However, similar results were reported by other authors. For instance, Khanna et al. (2003) found that poverty did not explain sex discrimination in infants' death in urban India. Kurz and Johnson-Welch (1997) also concluded that increasing household income alone might not be sufficient to reduce gender discrimination in India.

As expected, children in urban areas were more likely to die in hospital or during transport than at home. Education level of the household head was the other most important variable that determined the place of death of children. Children with educated household heads (primary and above education) were 1.63 and 0.01 percent more likely to die in hospital and during transport, respectively than children with less than primary school household head, all other variables remaining constant. However, the interaction between education and gender variables was insignificant (not shown in the table) indicating that education did not affect gender differences in the place of death of children. Consistent with the descriptive analysis, the probability of dying outside home increased in child age, ceteris paribus. Keeping all other variables constant, a one year increase in the age of a child decreased the likely of dying at home by 0.68 percent. Other variables such as social status, family size, number of female siblings in the household did not have statistically significant impact on the place of death.

Our main interest variable, gender, took the expected positive sign in the case of dying at home and negative signs in the case of dying in hospital and during transport and was statistically significant in all cases. The marginal coefficient of the home outcome showed that all other variables remaining constant, girls were 1.8 percent more likely to day at home than boys. In other words, boys were 1.8 percent more likely to die in hospital and 0.01 percent during transport than girls keeping all other factors constant. This clearly indicates that controlling for all other factors, girls were less likely to get medical attention immediately before their death than boys.

The effect of various factors such as age of the deceased child and number of female siblings in the household on the place of death of children may vary by gender. We hypothesized that young girls and girls with female siblings were less likely to get medical attention before death than boys. We used two methods to examine these possibilities. First, we plot the probability of dying at different places as a function of age of the deceased child and number of female siblings in the household by gender keeping all other factors constant at their mean values. Second we created interaction variables between age 
and gender and number of female siblings and gender and add these interaction variables in the model.

Figure 4.3 presents the probability of dying at home, in hospital, and during transport as a function of age of the deceased child by gender keeping all other variables constant. As expected, at all age levels girls were more likely to die at home and less likely to die in hospital or during transport than boys. However, consistent with previous results, their probability of dying in hospital or during transport increases as their age increases.

Figure 4.3 Probability of dying at different places as a function of age of the deceased child
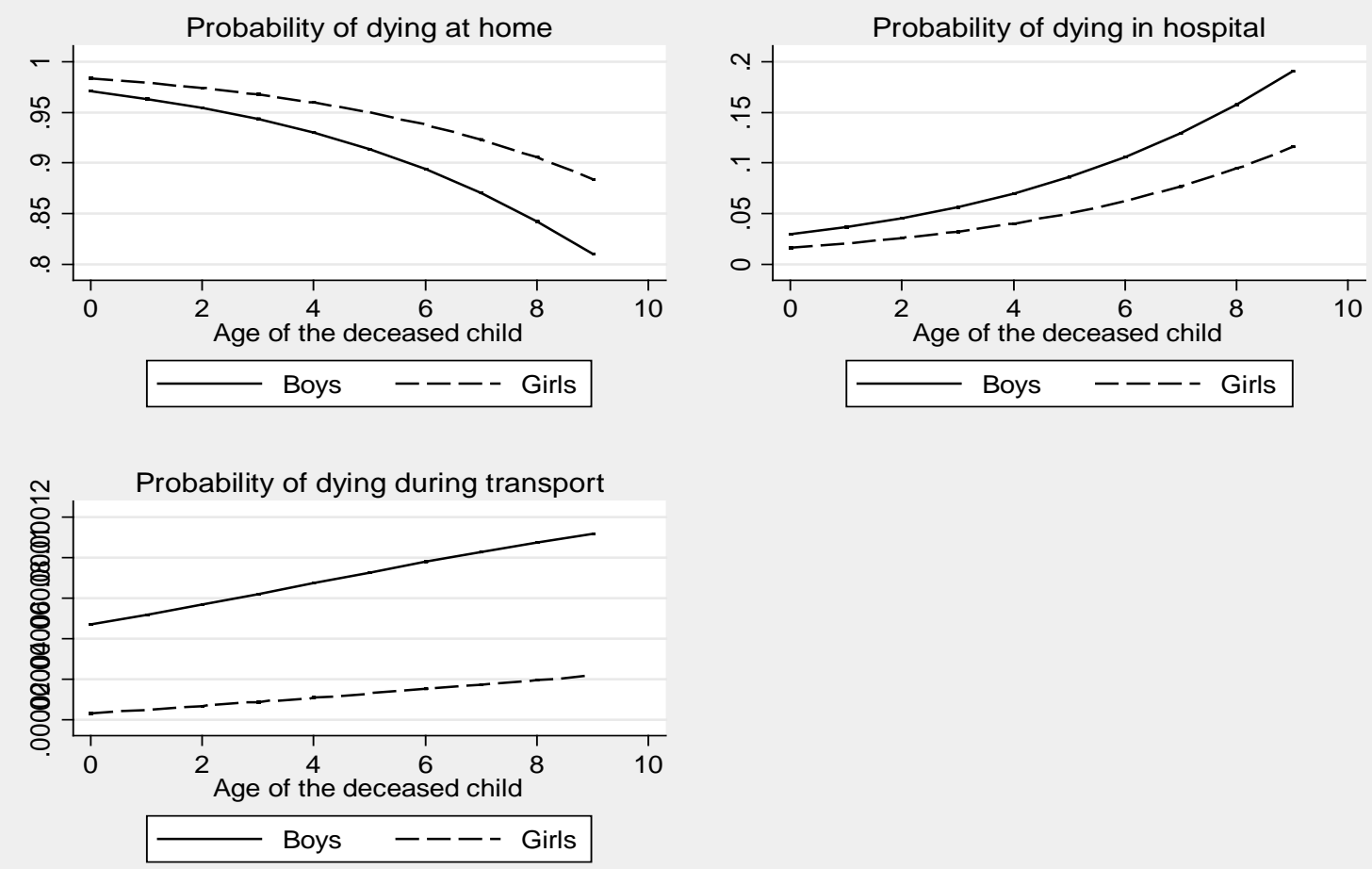

Source: Authors computation based on $52^{\text {nd }}$ NSS

Figure 4.4 portrays the probability of dying at different places as a function of number of female siblings in the household by the gender of the deceased child. The figure shows that, all other things remaining constant, as the number of female siblings in the household increased the chance of girls to die at home increased significantly compared to their brothers. Girls with female siblings had also small chance of dying in hospital or during transport compared to boys and this small chance significantly decreased as the number of female siblings in the household increased. 
Interaction variables between gender and age and gender and number of female siblings in the household were also included in the multinomial estimation and the results are presented in Table 4.4 .

\section{Figure 4.4 Probability of dying at different places as a function of number of female siblings}
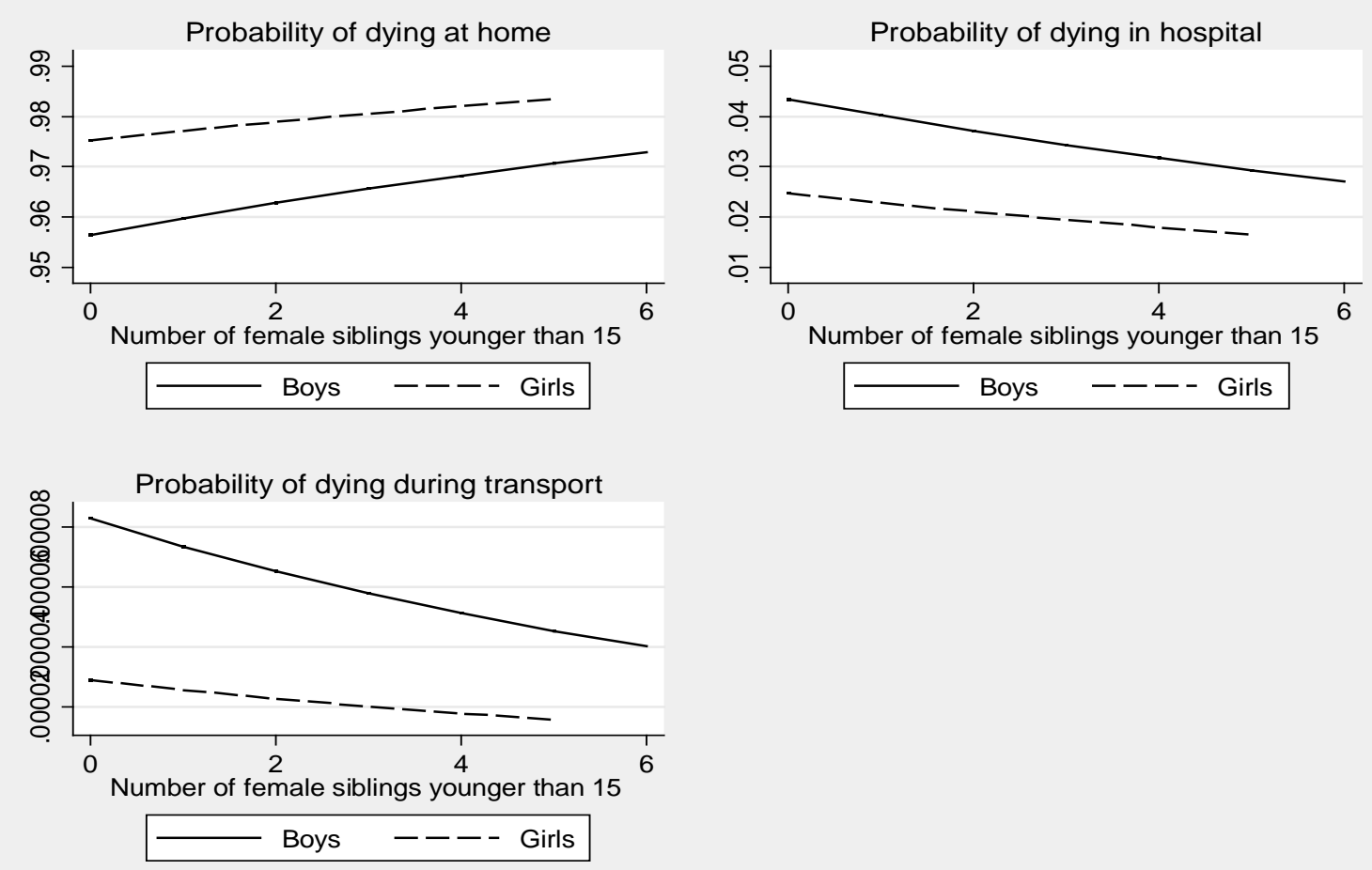

Source: Authors computation based on $52^{\text {nd }}$ NSS

The coefficients of all the interaction variables took the expected signs and were statistically significant in most of the cases. The interaction between age and gender variable showed that as age increased the likelihood of a girl to die during transport (compared to dying at home) increased, all other things remaining constant. More interestingly, after controlling gender and other variables in the model, girls with female siblings were less likely to die in hospital than girls with no or few female siblings and boys.

However, as pointed out by Ali and Norton (2003) and Norton (2004), the exact interpretation of interaction terms in nonlinear models such us ours is not straight forward. Therefore, we use graphs to examine the impact of the interaction terms and the results are 
presented in Figures 4.5 and $4.6^{68}$. These figures are expected to give more precise picture (than the one presented in Figures 3 and 4) since the interaction effects are included.

Table 4.4 Determinants of place of death with interaction variables: Multinomial logistic regression results

\begin{tabular}{|c|c|c|}
\hline \multirow[t]{2}{*}{ Variable } & \multicolumn{2}{|c|}{ Place of death } \\
\hline & Hospital & $\begin{array}{l}\text { During } \\
\text { transport }\end{array}$ \\
\hline Age of the head & $\begin{array}{l}0.073 \\
(0.057)\end{array}$ & $\begin{array}{l}0.009 \\
(0.069)\end{array}$ \\
\hline Age square of the head & $\begin{array}{l}-0.001 \\
(0.001)\end{array}$ & $\begin{array}{l}-0.000 \\
(0.001)\end{array}$ \\
\hline Male headed households & $\begin{array}{l}0.283 \\
(0.465)\end{array}$ & $\begin{array}{l}0.127 \\
(0.567)\end{array}$ \\
\hline Ln per capita expenditure & $\begin{array}{l}0.210 \\
(0.243)\end{array}$ & $\begin{array}{l}-0.022 \\
(0.292)\end{array}$ \\
\hline Location $(1=$ urban $)$ & $\begin{array}{l}0.365 \\
(0.246)\end{array}$ & $\begin{array}{l}0.647 * * \\
(0.294)\end{array}$ \\
\hline Scheduled caste/tribes & $\begin{array}{l}-0.092 \\
(0.250)\end{array}$ & $\begin{array}{l}0.135 \\
(0.295)\end{array}$ \\
\hline Head's education ( 1 if completed primary and above) & $\begin{array}{l}0.492 * * \\
(0.218)\end{array}$ & $\begin{array}{l}0.897 * * * \\
(0.261)\end{array}$ \\
\hline Family size (in Ln) & $\begin{array}{l}0.027 \\
(0.220)\end{array}$ & $\begin{array}{l}-0.120 \\
(0.263)\end{array}$ \\
\hline Gender of the deceased child ( 1 if girl) & $\begin{array}{l}-0.277 \\
(0.303)\end{array}$ & $\begin{array}{l}-1.355 * * * \\
(0.388)\end{array}$ \\
\hline Age of the deceased child & $\begin{array}{l}0.208 * * * \\
(0.057)\end{array}$ & $\begin{array}{l}-0.038 \\
(0.087)\end{array}$ \\
\hline Gender $\mathrm{X}$ age of the deceased child & $\begin{array}{l}0.031 \\
(0.082)\end{array}$ & $\begin{array}{l}0.261^{* *} \\
(0.121)\end{array}$ \\
\hline No of female siblings younger than 15 & $\begin{array}{l}0.063 \\
(0.123)\end{array}$ & $\begin{array}{l}-0.073 \\
(0.143)\end{array}$ \\
\hline Gender X Number of female siblings younger than 15 & $\begin{array}{l}-0.393 * \\
(0.200)\end{array}$ & $\begin{array}{l}-0.098 \\
(0.256)\end{array}$ \\
\hline 70 district level dummy variables & & \\
\hline Constant & $\begin{array}{l}-5.158^{*} \\
(3.067)\end{array}$ & $\begin{array}{l}-0.733 \\
(3.709)\end{array}$ \\
\hline Observations & & \\
\hline Log likelihood & & .01 \\
\hline $\operatorname{LR~chi}^{2}(162)$ & & \\
\hline Prob $>$ chi 2 & & \\
\hline Pseudo R2 & & \\
\hline
\end{tabular}

Standard errors in parentheses

* significant at $10 \%$; ** significant at $5 \%$; *** significant at $1 \%$

Source: Authors computation based on $52^{\text {nd }}$ NSS

\footnotetext{
${ }^{68}$ We use the xi3 command available in STATA.
} 
Figure 4.5 portrays the probability of dying at home, in hospital, and during transport as a function of age of the deceased child by including the interaction effect between age and gender of the deceased child.

Figure 4.5 Probability of dying at different places as a function of age of the deceased child (interaction between age and gender included)
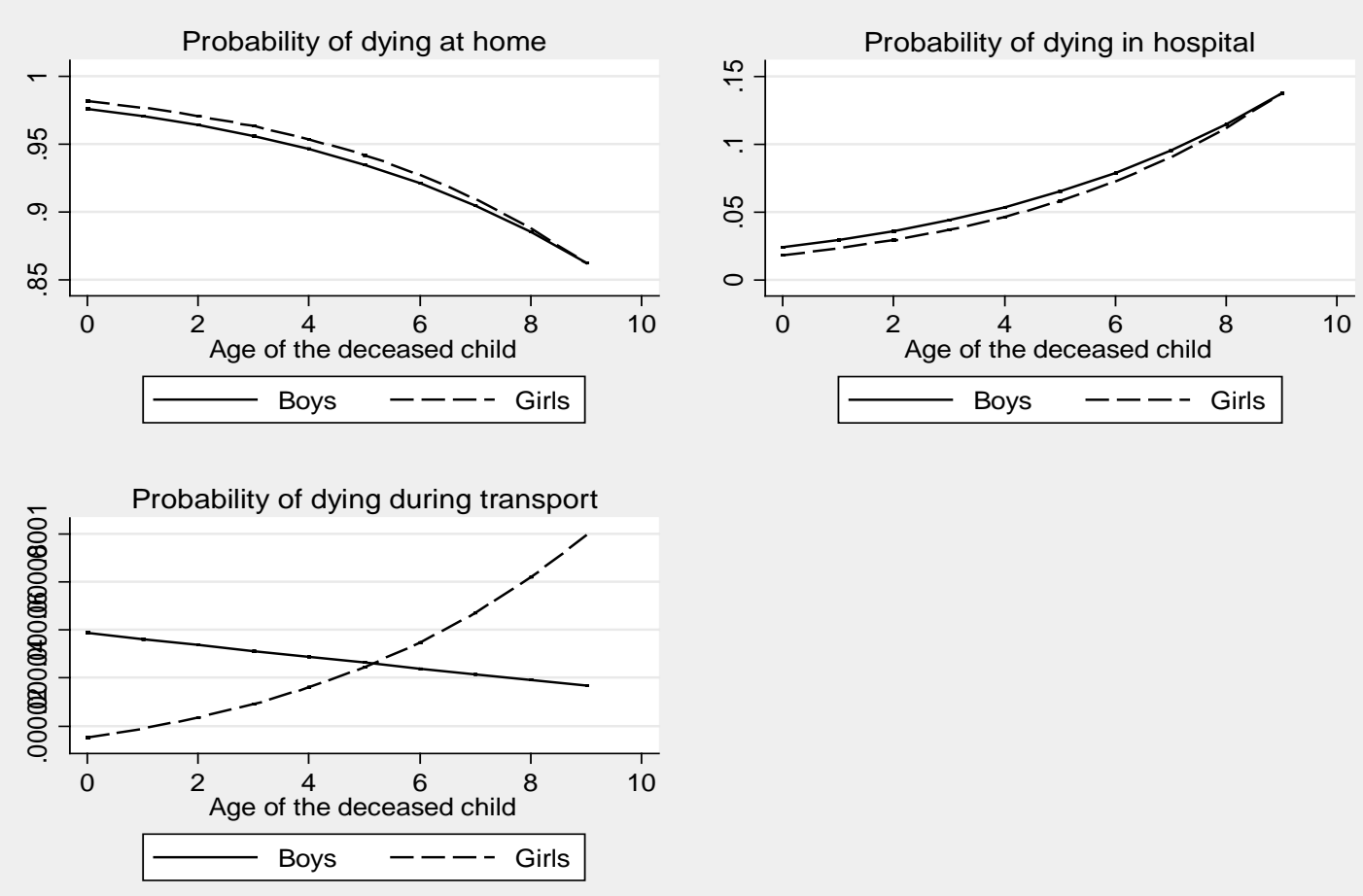

Source: Authors computation based on $52^{\text {nd }}$ NSS

Consistent with Figure 4.3, infants of both sexes were more likely to die at home than children. At the same time the probability of girls to die at home was higher and to die in hospital was lower than boys at all age levels. In contrast to Fig. 4.3, Fig. 4.4 clearly showed that these differences decreased as the age of the child increased.

Fig. 6 also showed very interesting results. The probability of boys to die at home decreased as the number of female siblings in the household increased while the probability of girls to die at home significantly increased as the number of female siblings increased.

The probability of girls to die in hospital also significantly decreased as the number of female siblings in the household increased. These results can be clearly seen by the funnel shape of the first two graphs of Fig. 6. However, the number of female siblings in 
the household was less likely to affect the difference in the probability of dying during transport between boys and girls.

All these results clearly indicate that there is significant gender discrimination in place of death in India. Boys were more likely to die in hospital and during transport to hospital than girls and girls were more likely to die at home. Particularly, infant girls with female siblings were unlikely to get medical help at the last critical time of their lives. This clearly shows that female infanticide can be one of the most important factors for the current imbalanced sex ratio in the country. Therefore, the focus of policy makers should not be limited to reduce medical termination of pregnancy based on fetal sex, but should also focus on the health care demand behaviour of households to ensure equality in medical access between boys and girls especially at their earlier life.

Figure 4.6 Probability of dying at different places as a function of number of female siblings (interaction between number of female siblings and gender included)
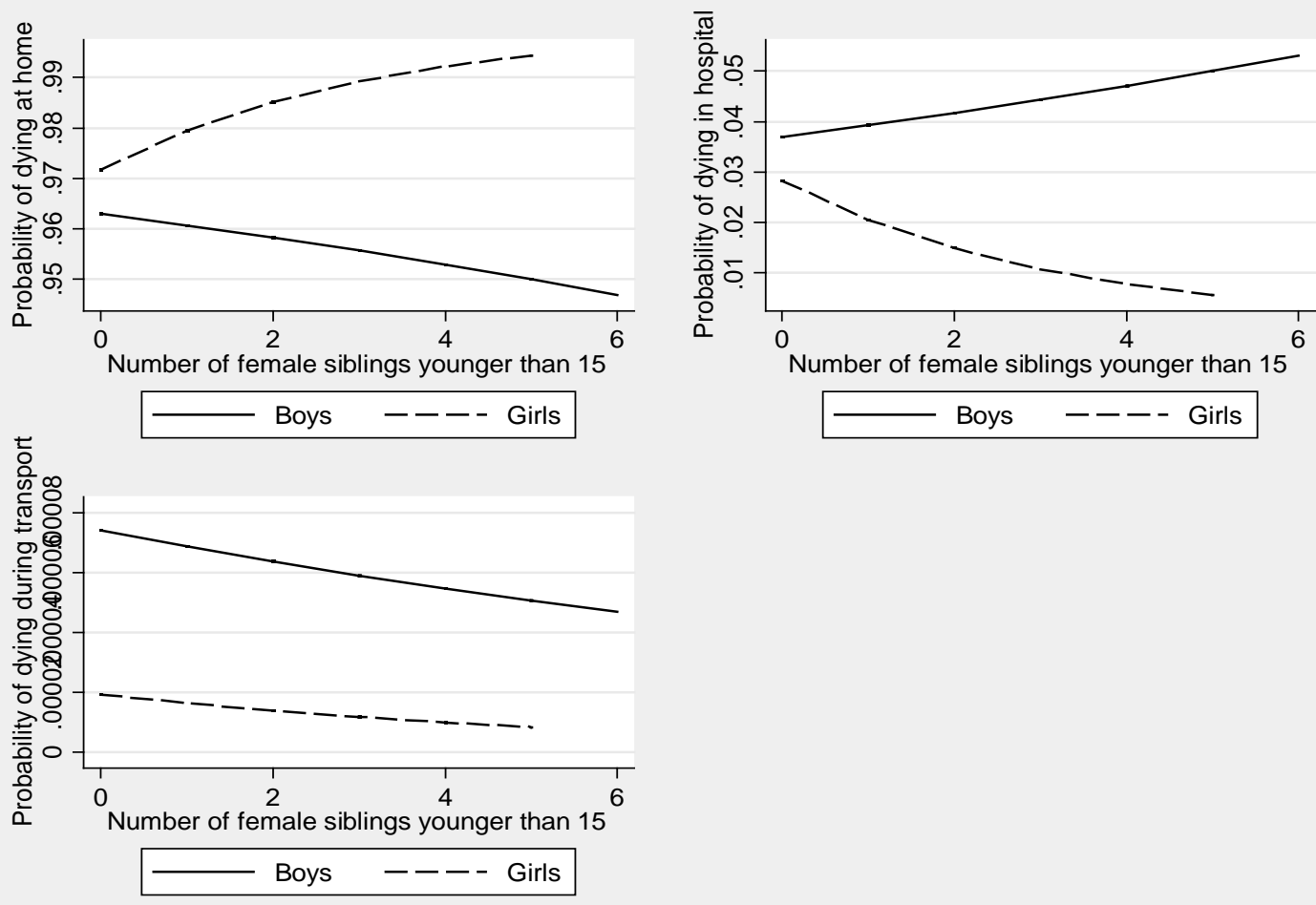

Source: Authors computation based on $52^{\text {nd }}$ NSS

\section{$\underline{\text { Robustness test }}$}

Place of death is a good indicator of gender discrimination in access to medial care in developing countries especially for children. However, dying at home may not necessarily imply deprivation of medical attention before death. Therefore, we used three 
additional indicators to examine gender discrimination in getting medial help before death in India. First, we examined whether the deceased child did not receive any medical attention before death. Overall 28 percent of deceased children did not get any type of medial help before death and there was no statistically significant difference between boys and girls. Second, we examined whether the child was hospitalized for treatment before death during last 365 days before the survey. The data showed that 38 percent of boys hospitalized before their death while only 26 percent of girls hospitalized before their death and the difference was statistically significant at less than one percent (Pearson $\chi^{2}$ test). Finally, we examined the number of times the deceased child was hospitalized during last 365 days preceding the day of the survey. On the average, boys were hospitalized 0.42 times while girls were hospitalized only 0.3 times.

We used the above three variables to examine gender discrimination in getting medical help before death. We used logit specification in the case of hospitalization and getting any medical help before death and OLS method in the case of number of times hospitalized before death. The results are presented in Table 4.5.

In all models the gender variable took the expected sign though not statistically significant in the case of no any medical help before death ${ }^{69}$. The marginal coefficient of the gender variable in the case of hospitalization before death indicated that, all other things remaining constant, the probability of girls to be hospitalized before their death was 12 percent less than boys. The OLS result also revealed that the average number of times girls were hospitalized before their death was 0.11 less than that of boys (the average was 0.36 times). All these results confirm that there was noticeable and statistically significant difference by sex of the child in getting medical help before death. Overall, girls were more likely to be denied medical attention before their death than boys.

${ }^{69}$ Gupta and Sankar (2002) also found insignificant coefficient for sex using the same data set and indicator. Their results showed that gender did not make a difference in getting medical attention before death. 
Table 4.5 Robustness test

\begin{tabular}{|c|c|c|c|}
\hline \multirow[t]{2}{*}{ Explanatory variable } & \multicolumn{3}{|c|}{ Dependent variable } \\
\hline & $\begin{array}{l}\text { Hospitalization } \\
\text { before death } \\
\text { (Logit results) }\end{array}$ & $\begin{array}{l}\text { No medical } \\
\text { attention } \\
\text { before death } \\
\text { (Logit } \\
\text { results) }\end{array}$ & $\begin{array}{l}\text { Number of } \\
\text { times } \\
\text { hospitalized } \\
\text { before death } \\
\text { (OLS results) }\end{array}$ \\
\hline Age of the household head & $\begin{array}{l}0.060 \\
(0.045)\end{array}$ & $\begin{array}{l}-0.029 \\
(0.041)\end{array}$ & $\begin{array}{l}0.012 \\
(0.009)\end{array}$ \\
\hline Age square of the household head & $\begin{array}{l}-0.001 \\
(0.000)\end{array}$ & $\begin{array}{l}0.000 \\
(0.000)\end{array}$ & $\begin{array}{l}-0.000 \\
(0.000)\end{array}$ \\
\hline Female headed household & $\begin{array}{l}0.458 \\
(0.380)\end{array}$ & $\begin{array}{l}-0.263 \\
(0.361)\end{array}$ & $\begin{array}{l}0.004 \\
(0.082)\end{array}$ \\
\hline Ln per capita expenditure & $\begin{array}{l}0.173 \\
(0.193)\end{array}$ & $\begin{array}{l}-0.641^{* * *} \\
(0.208)\end{array}$ & $\begin{array}{l}-0.023 \\
(0.044)\end{array}$ \\
\hline Location (1 = urban) & $\begin{array}{l}0.451^{* *} \\
(0.197)\end{array}$ & $\begin{array}{l}-0.456^{* *} \\
(0.225)\end{array}$ & $\begin{array}{l}0.118^{* *} \\
(0.047)\end{array}$ \\
\hline Scheduled caste/tribes & $\begin{array}{l}0.010 \\
(0.198)\end{array}$ & $\begin{array}{l}0.152 \\
(0.194)\end{array}$ & $\begin{array}{l}-0.038 \\
(0.045)\end{array}$ \\
\hline $\begin{array}{l}\text { Head's education( } 1 \text { if completed } \\
\text { primary and above) }\end{array}$ & $\begin{array}{l}0.247 \\
(0.177)\end{array}$ & $\begin{array}{l}0.048 \\
(0.186)\end{array}$ & $\begin{array}{l}0.114 * * * \\
(0.041)\end{array}$ \\
\hline Ln family size & $\begin{array}{l}0.054 \\
(0.177)\end{array}$ & $\begin{array}{l}-0.145 \\
(0.181)\end{array}$ & $\begin{array}{l}0.004 \\
(0.040)\end{array}$ \\
\hline Age of the deceased child & $\begin{array}{l}0.174 * * * \\
(0.037)\end{array}$ & $\begin{array}{l}-0.020 \\
(0.039)\end{array}$ & $\begin{array}{l}0.048^{* * *} \\
(0.009)\end{array}$ \\
\hline $\begin{array}{l}\text { Number of female siblings younger } \\
\text { than } 15\end{array}$ & $\begin{array}{l}-0.050 \\
(0.078)\end{array}$ & $\begin{array}{l}-0.059 \\
(0.082)\end{array}$ & $\begin{array}{l}-0.014 \\
(0.018)\end{array}$ \\
\hline Gender & $\begin{array}{l}-0.637 * * * \\
(0.167)\end{array}$ & $\begin{array}{l}-0.059 \\
(0.167)\end{array}$ & $\begin{array}{l}-0.114 * * * \\
(0.038)\end{array}$ \\
\hline Constant & $\begin{array}{l}-3.613 \\
(2.442)\end{array}$ & $\begin{array}{l}6.407 * * \\
(2.562)\end{array}$ & $\begin{array}{l}0.450 \\
(0.556)\end{array}$ \\
\hline Pseudo $\mathrm{R}^{2} / \mathrm{R}^{2}$ & 0.14 & 0.09 & 0.20 \\
\hline
\end{tabular}

Standard errors in parentheses

* Significant at $10 \%$; ** significant at $5 \%$; *** significant at $1 \%$

Source: Authors computation based on $52^{\text {nd }}$ NSS

\subsection{Conclusion}

The excess female mortality in India and other South Asian countries is no longer contentious. The ambiguous and controversial things are the reasons for such excess female mortality in the country. The non-responsiveness of this excess female mortality to the improvement in the economic status and educational level of households also makes the issue more complicated. Several factor including female feticide, gender discrimination in nutrition, health care, labour markets, education, and other opportunities 
are cited in the literature for this excess female mortality in the region. Using unique verbal autopsies information collected in the $52^{\text {nd }}$ Indian National Sample Survey and econometric models, this study provides new evidences on intra-household gender discrimination against girls in getting medical attention before death. We argue that compared to mortality differences between girls and boys which can be partly explained by biological factors, disparities in getting medical attention before death reveal gender discrimination potentially attributed to behavioural factors.

From several indicators that measure medical attention before death, we used place of death variable as a main indicator. Unlike developed countries where place of death is a matter of choice, in developed countries like India place of death is a crucial indicator of access to medical care at last critical time of life. Particularly in the case of non-adults it measures the real concern of parents for their children. The study also focused on infants and children (aged from one day to nine years) since their chance of getting medical help totally depends on the decision of their parents. This helps us to clearly see the level of intra-household gender discrimination in the health care decision of households.

The multinomial logit results showed that girls were highly discriminated against in getting medical help immediately before their death. The marginal coefficient of the gender variable showed that boys were 1.7 percent more likely to die in hospital and 0.01 percent during transport than their sisters, ceteris paribus. The coefficients of the interaction between age and gender and number of female siblings and gender also clearly pointed out part of the girls which were highly vulnerable to such discrimination. Controlling for all other factors, the probability of very young girls with live female siblings to die in hospital was extremely low and this probability decreased significantly as the number of live female siblings in the household increased. The robustness of the results was also tested using three different indicators that measures access to health care before death. Except in the case of 'any medical attention before death' indicator, the results of the two indicators confirmed the existence of statistically significant gender discriminations. Boys were more likely to be hospitalized before their death and the average number times boys were hospitalized before their death was 0.11 higher than their sisters.

Generally, the results of this study clearly indicated that girls, particularly infant girls were discriminated in receiving medical attention before their death compared to their brothers. This implies that reducing this discrimination can help to improve the current falling sex ratio in the country. Therefore, in addition to the current effort of the 
government to enforce the law which makes fetal sex determination and medical termination of pregnancy on the basis of fetal sex illegal, more should be done to improve the medical access of girls at least for life threatening sicknesses to the level of their brothers. This action coupled with reducing female foeticide may help to improve the declining sex ratio in the country. Looking at future research work on this topic, it would be useful to examine the type, spatial variation (across different regions and between rural and urban settings), and dynamic (through time) of intra-household gender disparities and their relationship with the current imbalance in sex ratios in the country. 


\section{References}

Abu-Ghaida, Dina and Stephan Klasen. 2004. "The costs of missing the Millennium Development Goal on Gender Equity.” World Development 32(7): 1075-1107.

Alderman, Harold, Jere Behrman, Shahrukh Khan, David Ross and Richard Sabot. 1995. Public Schooling in Rural Pakistan: Efficiently Targeting Girls and a Lagging Region., in. Van de Walle D. and K. Nead (eds.) Public Spending and the Poor. Baltimore: Johns Hopkins Press.

Alderman, Harold, Jere Behrman, David Ross, and Richard Sabot. 1996. "Decomposing the Gender Gap in Cognitive Skills in a Poor Rural Economy”. Journal of Human Resources 31: 229-254.

Alderman, H. and King, E., 1998. "Gender Differences in Parental Investment in Education.” Strucutal Change and Economic Dynamics 0: 453-68.

Alderman, H. and Gertler, P., 1997. “ Family Resources and Gender Differences in Human Capital Investments: The Demand for Children's Medical Care in Pakistan" in

Lawrence Haddad, John Hoddinott, and Harold Alderman (eds.) Intrahousehold Resource Allocation in Developing Countries: Models, Methods and Policy. Baltimore, MD: John Hopkins University Press.

Appadurai, A. 1981. “Gastropolitics in Hindu South Asia.”, American Ethnologist, 8

Appiah, Elizabeth and Walter McMahon. 2002. "The social outcomes of education and feedbacks on growth in Africa.” Journal of Development Studies 38: 27-68.

Arnold, A., Kishor, S., and Roy, T K. 2002. Sex-Selective Abortions in India. Population and Development Review 28(4): 759-

Arumpalam W., Bhalotra, S., 2004. "Inequality in Infant Survival Rates in India: Identification of State-Dependence Effects”, Discussion Paper No.04/558, University of Bristol (UK)

Asfaw, A., Klasen, S. and Lamanna, F., 2007. "Intra-Household Gender Disparities in Children's Medical Care Before Death in India”, Institute for the Study of Labor (IZA) discussion paper No.2586.

Asfaw, A., Klasen, S. and Lamanna, F., 2010. “Gender Gap in Parents’ Financing Strategy for Hospitalization of their Children: Evidence from India”, Health Economics Journal, 19: 265-279.

Axelsson, B. and Christensen SB. 1996. Place of Death Correlated to Sociodemographic Factors. A Study of 203 Patients Dying of Cancer in a Rural Swedish County in 1990. Palliat Med., 10(4): 329-335. 
Ayad, M., B. Barriere, and J. Otto. 1997. Demographic and socioeconomic Characteristics of Households. Demographic and Health Surveys comparative Studies. No. 26 Calverton, Maryland: Macro International, Inc.

Banister, J., Coale, J., 1994. "Five Decades of Missing Females in China.” Demography 31 (3): 459-79.

Barro, Robert.1991. "Economic Growth in a Cross- Section of Countries.” Quarterly Journal of Economics 106: 407-443.

Barro, Robert and Jong-Wha Lee. 1994. "Sources of Economic Growth.” CarnegieRochester Conference Series on Public Policy, 40, 1-46.

Barro, Robert and Jong-Wha Lee. 1996. "International Measures of Educational Achievement.” American Economic Review 86:218-223.

Barro, Robert and Jong-Wha Lee. 2000. "International data on educational attainment: updates and implications.” CID Working Paper No. 42 Cambridge, MA: Center for International Development.

Barro, Robert and Xavier Sala-i-Martin. 1995. Economic Growth. New York, NY: McGraw- Hill.

Basu, Alaka Malwade. 1992. Culture and the Status of Women, and Demographic Behaviour, Oxford, UK: Oxford University Press.

Basu, Alaka Malwade. 1999. "Fertility Decline and Increasing Gender Imbalance in India. Including a Possible South India Turnaround.” Development and Change 10: 237-63.

Becker, G.S. 1991. A Treatise on the Family: An Enlarged Edition, Harvard University Press, Cambridge, M.A.

Becker, G., Nigel, T. “Child Endowment and the Quantity and Quality of Children”, Journal of Political Economy, August 1976, 84, S143-162.

Bhalotra, S. 2001.“On selfish parents and child labour”, mimeograph, University of Cambridge and Bristol.

Bhuiya, A. and Streatfield K., 1991. Mother's education and survival of female children in a rural area of Bangladesh. Popul Stud, 45: 253-64.

BMJ, 2003. Girls are less likely to survive infancy in India. BMJ, Vol. 327, BMJ Publishing Group.

Black, R.E, Morris, S.S, and Bryce, J. 2003. When and why are 10 million children dying every year?, Lancet, 361, 2226-34. 
Blackden, Mark, Sudharshan Canagarajah, Stephan Klasen and David Lawson. 2007. "Gender and Growth in Africa: Evidence and Issues". In 'Advancing Development: Core Themes in Global Development', edited by George Mavrotas and Anthony Shorrocks, WIDER, Helsinki, Finland and UNU-WIDER Research Paper No. 2006/37.

Blecker, Robert and Stephanie Seguino. 2002. "Macroeconomic effect of reducing gender wage inequality in a export oriented, semi-industrialized economy”, Review of Development Economics, vol 6 n.1, pp.103-119.

Bloom, David and Jeffrey Williamson. 1998. "Demographic Transition and Economic Miracles in Emerging Asia.” The World Bank Economic Review, Vol.12, No3, 419-455.

Booth, BE., Verma, M., Beri, RS. 1994. Fetal Sex Determination in Infants in Punjab, India: Correlations and Implications. BMJ, 309(12): 1259-1261.

Bourne, KL. and Walker, GM., 1991. The differential effect of mother's education on mortality of boys and girls in India. Popul Stud, 45: 203-19.

Busse, Matthias and Christian Spielmann. 2006. Gender inequality and trade. Review of International Economics 14(3): 362-279.

Chaudhury, R. H, 1988. Adequacy of child dietary income relative to that of other family members. Food and Nutrition Bulletin, 10 (2): 26-34.

Chen, L., E. Huq, and S. D’Souza, 1981. Sex bias in the family allocation of food and health care in rural Bangladesh. Population and Development Review, 7 (91): 5570 .

Chen, L., Hug, E. and D’Souza, S., 1981. "Sex Bias in the Family Allocation of Food and Health Care in Rural Bangladesh.” Population and Development Review 7 (1): 55-70.

Claeson, M., E.R. Bos, T. Mawji, and I. Pathmanathan, 2000. Reducing Child Mortality in India in the New Millennium. Bulletin of the World Health Organization, 78(10):1192-99.

Cleves, M., Gould, W., Gutierrez, R., 2002. An introduction to survival analysis using STATA, STATA Press Publication

Coale, Ansley, (1991), "Excess Female Mortality and the Balance of the Sexes.", Population and Development Review 17 (3): 517-23.

Collier, Paul and Jan Willem Gunning. 1999. Why has Africa grown slowly? Journal of Economic Perspectives 13: 3-22.

Costantini, M., Balzi, D., Garronec E., Orlandini, C., Parodi, S., Vercelli, M., and Bruzzi, P. 2000. Geographical Variations of Place of Death among Italian Communities 
Suggest an Inappropriate Hospital Use in the Terminal Phase of Cancer Disease. Public Health, 114(1): 15-20.

Cox, D.R. 1972. "Regression Models and Life Tables (with Discussions)", Journal of Royal Statistical Society, Series B 34:187-220.

Croll, E., 2000. Endangered Daughters, London: Routledge.

Das Gupta, M., 1987. Selective discrimination against the female child in rural Punjab, India. Popul Dev Rev, Vol. 13(1): 77-100.

Das Gupta, M., 1990. "Death Clustering, Mothers' Education and the Determinants of Child Mortality in Rural Punjab, India.”, Population Studies 44:489-505.

Das Gupta, M., Mari Baht, P.N., 1997. "Fertility Decline and Increased Manifestation of Sex Bias in India.“ Population Studies 51(3): 307-15.

Deininger, Klaus and Lyn Squire. 1998. "New ways of looking at old issues: inequality and growth.” Journal of Development Economics, Vol.57, 259-287.

Desai, Jaikishan, 1995. Vietnam through the Lens of Gender. Unpublished report from the Poverty Alleviation Unit, Directorate of national Planning, Government of Vietnam.

Dollar, David and Roberta Gatti. 1999. "Gender Inequality, Income and Growth: Are Good Times good for Women?” Mimeographed. Washington CD: The World Bank.

Dreze and Murthi. 2001. Fertility, Education, and Development: Evidence from India. Population and Development Review 26.

Dreze, J. and Sen, A., 1989. Hunger an Public Action, Oxford, UK: Clarendon Press.

Dreze, J. and Sen, A., 1995. India Economic Development and Social Opportunity. Oxford, UK: Claredon Press.

Dreze, Sen Hussain, 1999. The Political Economy of Hunger, Selected Essays, Harriss Barbara, 1999, "The intrafamily distribution of hunger in South Asia"

Dyson, T., 2001. “The Preliminary Demography of the 2001 Census in India.”, Population and Development Review 27: 341-56.

Dyson, T., Moore, M, 1983. “On Kinship Structure, Female Authonomy and Demographic Balance”, Population and Development Review 9:35-60.

Egero, B, 2004. Understanding Reproductive Change: Kenya, Tamil Nadu, Punjab, Costa Rica, Sweden, Sweden University Press.

Esteve-Volart, Berta, 2004. 'Gender Discrimination and Growth: Theory and Evidence from India’, STICERD Discussion Papers DEDPS42, LSE: London. 
Ferro-Luzzi A, Sette S. Franklin M \& James WPT, 1992. As simplified approach of adult chronic energy deficiency. Eur J. Clin. Nutr 46, 173-186.

Feudtner, C., Silveria, MJ., Christakis, DA. 2002. Where Do Children with Complex Chronic Conditions Die? Patterns in Washington State, 1980-1998. Pediatrics, 109: 656-660.

Forbes, Kristin. 2000. "A Reassessment of the Relationship between Inequality and Growth.” American Economic Review 90:869-887.

Frankel, Jeffrey and David Roemer. 1999. “Does trade cause growth?” American Economic Review 89: 379-99.

Galor, Oded and David Weil. 1996. "The Gender Gap, Fertility, and Growth.” American Economic Review 86: 374-387.

Gangadharan, L. and Maitra, P. 2000. Does Child Mortality Reflect Gender Bias? Evidence from Pakistan. Indian Economic Review, 35(2): 113-131.

Gatti, Roberta. 1999. “A Cross-Country Analysis of Fertility Determinants.” Mimeographed. Washington DC: The World Bank.

Gellner, E., 1981. Muslim Societies, New York: Cambridge University Press

Gjonca, A., C. Tomassini, and J. W. Vaupel, 1999. Male-female Differences in Mortality in the Developed World. MPIDR Working Paper WP 1999-009. PMaxPlanck_Institute für demografische Forschung.

Grambsch, P.M., and Therneau, T.M., 1994. "Proportional Hazards tests and diagnostics based on weighted residuals”, Biometrica, 81, pp.515-526.

Greenspan, A. 1994. Cultural Influences Demographic Behavior: Evidence from India. Asia-Pacific Population and Policy, 28: 1-4.

Gupta, I. and Sankar, D. 2002. Medical Attention at Death: Evidence from India. Institute of Economic Growth, University of Enclave, Delhi 110007 India. Available at: http://iegindia.org/dis_ind_45.pdf

Harriss, B., 1989. Differential Child Mortality and Health Care in South Asia. Journal of Social Studies, Vol. 44: 2-123.

Hart, N., 1988. Sex, gender and survival: inequalities of life chances between European men and women in A.J. Fox (ed) Inequality in Health within Europe, Aldershot: Gower.

Hazarika, G., 2000. Gender Differences in Children's Nutrition and Access to Health Care in Pakistan. The Journal of Development Studies, Vol. 37, No. 1: 73-92. 
Hill, Anne and Elisabeth King. 1995. "Women’s Education and Economic Well-being.” Feminist Economics 1 (2): 1-26.

Hill, K., and D.M., Upchurch, 1995. Gender Differences in Child Health: Evidence from the Demographic and Health Surveys. Population and Development Review, Vol. 21(1): 127-151.

Iyer, S., Borooah, V., 2004, "Religion and Fertility in India: The Role of Son Preference and Daughter Aversion”, Cambridge Working Paper in Economics, 436.

Iyer, S., 2002. Demography and Religion in India, Oxford University Press.

Jatrana, S. 2003. Explaining Gender Disparity in Child Health in Haryana State of India. Asian Meta Centre Research Paper Series, no. 16.

Junhong, C., 2001. "Prenatal Sex Determination and Sex-Selective Abortion in Rural Central China.” Population and Development Review 27:259-82.

Kalben, B.B., 2002. Why Men Die Younger? Causes of Mortality Differentials by Sex. SOA Monograph M-LI01-1. Society of Actuaries.

Keller, John and Mustapha Nabli. 2002. "The macroeconomics of labor market outcomes in MENA over the 1990s: How growth has failed to keep pace with a burgeoning labor market.” World Bank Working paper.

Khan, ME., Barge, S., and Philip, G. 1996. Abortion in India: An Over-View. Social Change, 26: 208-225.

Khanna, R., Kumar, A., Vaghela, JF., Sreenivas, V., and Puliyel, JM. 2003. Community based retrospective study of sex in infant mortality in India. BMJ 327(19):126128.

King, Elizabeth and Anne Hill. 1993. Women's Education in Developing Countries: Barriers, Benefits, and Policies. Baltimore: Johns Hopkins Press.

King, Elizabeth, Stephan Klasen and Maria Porter. 2008. "Gender and Development Challenge Paper." Paper prepared for 2008 round of Copenhagen Consensus Project. Mimeographed, World Bank.

King, E. and Hill, A., 1993. Women ${ }^{1}$ s Education in Developing Countries, Baltimore, Maryland: Johns Hopkins University Press.

Kishor S., 1995. "Gender differentials in child mortality: a review of the evidence”, Das Gupta M. Chen L. C. Krishnan T. N. eds. Women’s Health in India: Risk and Vulnerability 1995:19-54 Oxford University Press Bombay, India.

Klasen, S., 1994. Missing Women Reconsidered. World Development, Vol. 22 (7): 106171. 
Klasen, S., 1996. Nutrition, Health and Mortality in Sub-Saharan Africa: Is There a Gender Bias? The Journal of Development Studies, Vol. 32 (6): 913-32.

Klasen, S., 1999. “Gender Inequality in Mortality in Comparative Perspective.”, Mimegraphed, University of Muenchen.

Klasen, S., 2001, “Warum fehlen 100 Million Frauen auf der Welt?”in O. Fabel and R. Nischik (eds.), Femina Oeconomia: Frauen in der Oekonomie. Muenchen: Rainer Hampp.

Klasen, Stephan 2002. "Low Schooling for Girls, slower Growth for All?” World Bank Economic Review 16: 345-373 (2002).

Klasen, S., and C. Wink, 2001. A Turning Point in Gender Bias Mortality? Discussion Papers in Economics 23, University of Munich, Department of Economics.

Klasen, S., Wink, C., 2002. “A Turning point in Gender Bias in Mortality? An update on the Number of Missing Women”. Population and Development Review 28 (2): 285-312.

Klasen, S., Wink, C., 2003. "Missing Women”: Revisiting the Debate”, Feminist Economics, p.263-299.

Klasen, S. and Lamanna, F., 2003. "The Impact of Gender Inequality in Education and Employment on Economic Growth in Middle East and North Africa", Background paper for World Bank Study: Women in the Public Sphere. World Bank, Washington DC.

Klasen, Stephan 2006. Gender and Pro-Poor Growth. In Menkoff, L. (ed.) Pro-Poor Growth: Evidence and Policies. Berlin: Dunker\&Humblot.

Klasen, Stephan 2007. Gender-Related Indicators of Well-Being, in McGillivray, M. (2007) Measuring Human Well-Being. London: Palgrave Macmillan

Klasen, S. and Lamanna F., 2007. “The Impact of Gender Inequality in Education and Employment on Economic Growth in Developing Countries: Updates and Extensions.”, Mimeo University of Goettingen.

Klasen, S. and Lamanna F., 2009. "The Impact of Gender Inequality in Education and Employment on Economic Growth: New Evidence for a Panel of Countries.”, Feminist Economics, 15(3), July 2009, 91-132.

Knowles, Stephen, Paula Lorgelly and Dorian Owen. 2002. “Are Educational Gender Gaps a Brake on Economic Development? Some Cross-Country Empirical Evidence.” Oxford Economic Papers 54: 118-149.

Kramer MS., 1987. Determinants of low birth weight: methodological assessment and meta-analysis. Bull WHO 65:663-737 
Kurz, K.M. and C. Johnson-Welch, 1997. Gender Bias in Health Care Among Children 05 Years: Opportunities for Child Survival Programs. A Review Paper Prepared for the BASICS Project.

Lagerlöf, Nils-Petter. 1999. Gender Inequality, Fertility, and Growth, Mimeographed, Department of Economics, University of Sydney.

Lagerlöf, N, 2003. “Gender Equality and Long-Run Growth”, Journal or Economic Growth 8 (4): 403-26.

Lock, A. and Higginson, I. 2005. Patterns and Predictors of Place of Cancer Death for the Oldest Old. BMC Palliative Care, 4(6): 1-8.

Long, J.S., 2001. Regression Model for Categorical Dependent Variables using STATA, College Station, Texas: Stata Press, USA.

Long, J.S. and Freese, J. 2003. Regression Models for Categorical Outcomes using Stata, Second Edition. College Station, TX: Stata Press. First edition, 2001.

Lorgelly, Paula and Dorian Owen. 1999. "The Effect of Female and Male Schooling on Economic Growth in the Barro-Lee Model.” Empirical Economics, Vol.24, August.

Makepeace, G., Pal, S., 2001. "Sibling rivalry? Evidence from an analysis of the duration survival in India”, preprint, Cardiff Business School.

Mayer, P., 1999. “India’s Falling Sex Ratio.” Population and Development Review 25(2): 323-43.

Miller, MD. 1981. The Endagered Sex: Neglect of female Children in Rural North India. Ithaca, New York and London, Cornell University Press.

Mitra, A, 1978. India’ Population: Aspects of Quality and Control (New Delhi: Abhinar Publications).

Mrhuri, P.K. and S.H. Preston, 1991. Effects of family composition on mortality differentials by sex among children in Matlab, Bangladesh. Population and Development Review, 17 (3): 415-434.

Murthy, N. 1982. Reluctant Patients-the Women of India. World Health Forum, 3(3):315316.

Murthi, M, A. Guio, and J. Drèze, 1995. Mortality, Fertility, and Gender Bias in India: A District-Level Analysis. Population and Development Review, 21(December): 745-82.

Obermeyer, C., 1992. "Islam, Women and Politics: The Demography of Arab Countries.” Population and Development Review 18 (1), pp. 33-60.

Obermeyer, C., Cardenas, R., 1997. "Son Preferences and Differential Treatment in Morocco and Tunisia.” Statistic in Family Planning 28 (3): 235-44. 
O’Donnel, O.m Van Doorslaer, E., Wagstaff, A. and Lindelow M., 2008, Analyzing Health Equity Using Household Survey Data, World Bank Publication, Washington DC.

Oster, E, 2009. "Does Increased Access Increase Equality? Gender and Child Health Investments in India” Journal of Development Economics, May 2009.

Pande, P.R., 2000. Family composition effects on gender differentials in nutrition and immunization in rural India. Hopkins Population Center Papers on population WP 00-01.

Park, C.B., Chao, N-H, 1995. "Consequences of Son Preference in a Low-Fertility Society: Imbalance of the Sex Ratio at Birth." Population and Development Review 21 (1): 59-84.

Polissar, L., Severson, RK, and Brown, NK. 1987. Factors affecting place of death in Washington State, 1968-1981. J Community Health, 12(1):40-55.

Pritchard, RS., Fisher, ES., Teno, JM., Sharp, SM., Reding, DJ., Knaus, WA., Wennberg, JE., Lynn, J, for the SUPPORT Investigators. Influence of Patient Preferences and Local Health System Characteristics on the Place of Death. Journal of the American Geriatrics Society, 46: 1242-1250.

Rajeshwari, 1996. Gender bias in utilisation of health care facilities in rural Haryana.):, Economic and Political Weekly, Vol 31(1): 489-494.

Ravallion, Martin 2001. Growth, Inequality and Poverty: Looking beyond Averages, Development Research Group, World Bank.

Ravallion, M., 2002. Growth, Inequality, and Poverty: Looking Beyond Averages, Washington DC, World Bank Group.

Registrar General, 2001. Provisional Population Totals. Census of India Series 1, Paper 1 of 2001. New Delhi: Ministry of Home Affairs.

Rodrik, Dani and Francisco Rodriguez. 2000. "Trade Policy and Economic Growth: A Skeptic's Guide to the Cross-National Evidence”. In B. Barnange and K. Rogoff (eds.) NBER Macroeconomics Annual. Cambridge: MIT Press.

Rosenzweig and Schultz, 1980. "Market Opportunities, Genetic Endowments and the Intrafamily Distribution of Resources: Child Survival in Rural India”, American Economic Review, 63.

Rutstein, Shea O. 1984. Infant and child mortality: Levels, trends, and demographic differentials. Revised edition. WFS Comparative Studies No. 43. Voorburg, Netherlands: International Statistical Institute. 
Saha, V., 2002. Salient Features of NSS Consumer Expenditure Surveys (51st - 54th Rounds). India: Workshop on Poverty Measurement, Monitoring and Evaluation. January 11-12.

Sachs, Jeffrey and Andrew Warner. 1995. "Natural Resources and Economic Growth.” Development Discussion Paper 517a. Harvard Institute for International Development.

Schultz, T. Paul. 1997. Demand for Children in Low-Income Countries. In M. Rosenzweig and O. Stark (eds.) Handbook of Population and Family Economics. Amsterdam: Elsevier.

Seguino, Stephanie. 2000a. "Gender Inequality and Economic Growth: A Cross-Country Analysis.” World Development 28: 1211-1230.

Seguino, Stephanie. 2000b. “Accounting for Gender in Asian Economic Growth", Feminist Economics, Taylow and Francis Journals,. Vol 6(3), pages 27-58.

Seguino, Stephanie and Maria Sagrario Floro. 2003. "Does gender have any effect on aggregate saving?” International Review of Applied Economics 17(2): 147-166.

Sen, A., 1988. Family and food: Sex bias in poverty. In T. Srinivasan and P. Bardham (eds.) Rural Poverty in South Asia. New York: Columbia University Press.

Sen, Amartya, 1989. “Women's Survival as a Development Problem.” Bulleting of the American Academy of Arts and Sciences 43 (2): 14-29.

Sen, Amartya, 1990a, "More than 100 Million Women are Missing." The New York Review of Books, December 20.

Sen, Amartya, 1990b, Gender and Cooperative Conflicts, in Tinker I. (ed.) Persistent Inequalities.

Sen, Amartya, 1992, “Missing Women.” British Medical Journal 304: 586-7.

Sood, A.K. and B.K. Nagla, 1994. The extent and pattern of utilisation of health services by rural women: A study in District Rohtak, Haryana. Indian Journal of Preventive Social Medicine Indian Journal of Preventive and Social Medicine, Vol. 25 (3\&4): 110-117.

Stosky, Janet. 2006. "Gender and its relevance to Macroeconomic Policy: A Survey, IMF Working Paper, WP/06/233.

Sudha, S., \& Arnold, SIR. 1999. Female Demographic Disadvantage in India 1981-1991: Sex Selective Abortions and Female Infanticide. Development and Change 30(3): 585

Svedberg, P., 2006, "Declining Child Malnutrition: A Reassessment", International Journal of Epidemiology, 35(5): 1336-46. 
Swamy, Anand, Omar Azfar, Stephen Knack and Young Lee. 2001. "Gender and Corruption“. Journal of Development Economics 64(1): 25-55; and The World Bank 2001, pp. 8, 12, and 95. See also: UN Millennium Project 2005

Thomas, Duncan. 1997. "Incomes, Expenditures and Health Outcomes: Evidence on Intrahousehold Resource Allocation.” in L. Haddad, J. Hoddinott, and Harold Alderman (eds) Intrahousehold Resource Allocation in Developing Countries, Johns Hopkins University Press: Baltimore.

United Nation Children's Fund, 1990. The State of the World's Children 1989. Oxford, Oxford University Press.

United Nations, 1991. The world's women 1970-1990:trends and statistics, Social Statistics and Indicators Series, K. no 8, New York, UN.

United Nations Development Program, 1995. Human Development Report 1995, UNDP New York, USA.

United Nations International Labour Organization, 2007. ILO Report: Key Indicator of the Labor Market, 5th Edition, Geneva.

Visaria, L., and P. Visaria, 1995. India’s Population in Transition. Population Bulletin 50(3).

Wadley, SS. 1993. Family Composition Strategies in Rural North India. Social Science and Medicine, 37(11): 1367-1376.

Wagstaff, A. \& van Doorslaer, E. 2000. Measuring and testing for inequity in the delivery of health care. Journal of Human Resources, 35(4): 716-733.

Wagstaff, A., van Doorslaer, E \& Paci, P. 1991. On the measurement of horizontal inequity in the delivery of health care. Journal of Health Economics, 10(2): 169205.

Waldron, I., 1993. Sex Difference in Human Mortality Among Children in Developing countries, The World Health Statistics Quarterly, 40(3), p.194-210.

Waldron, I. 1995. Contributions of changing gender differentials in behaviour to changing gender differences in mortality in D. Sabo and D. Gordon (eds), Men's Health and Illness: gender , power and the body. London: Sage

Westerling, R. 1996. Can Regional Variation in "avoidable” mortality be explained by Deaths outside Hospital? A Study from Sweden, 1987-90. Journal of Epidemiology and Community Health, 50(3): 326-33.

Wolfe, B.L., and J.R., Behrman, 1984. Determinants of Women's Health Status and Health-Care Utilization in a Developing Country: A Latent Variable Approach. Review of Economics and Statistics, Vol. 66 (4): 696-703.

World Bank. 2001. Engendering Development. Washington, DC: The World Bank. 
World Bank. 2004. Gender and Development in the Middle East and North Africa. Washington, DC: The World Bank.

World Bank. 2006. Economic Growth in the 1990s: Learning from a Decade of Reform, World Bank Publication.

World Bank. Quantitative Techniques for Health Equity Analysis- Technical Note \# 13. siteresources.worldbank.org/INTPAH/Resources/Publications/QuantitativeTechniques/health_eq_tn13.pdf

World Health Organization, 1946. Preamble to the Constitution of the World Health Organization as adopted by the International Health Conference, New York, 1922 June, 1946; signed on 22 July 1946 by the representatives of 61 States (Official Records of the World Health Organization, no. 2, p. 100) and entered into force on 7 April 1948.

World Health Organization, 1992. Missing Women. British Medical Journal, 304:586-587.

World Health Organization, 1998. Gender and Health a Technical paper. http://www.who.int/frh-whd/index.html

World Health Organization, 2000. Women's Health in South-East Asia. http://w3.whosea.org/women2/Default.htm

Yamarik, Steven and Sucharita Ghosh. 2003. "Is female education productive? A reassessment.” Mimeographed, Medford, MA: Tufts University. 